UNIVERSIDADE DE SÃO PAULO

ESCOLA DE ENFERMAGEM

MILEIDE MORAIS PENA

ANÁLISE DO GRAU DE SATISFAÇÃO DE USUÁRIOS DE UM HOSPITAL UNIVERSITÁRIO PRIVADO: uma abordagem multissetorial

SÃO PAULO

2010 


\section{ANÁLISE DO GRAU DE SATISFAÇÃO DE USUÁRIOS DE UM HOSPITAL UNIVERSITÁRIO PRIVADO: uma abordagem} multissetorial

Dissertação apresentada ao Programa de Pós-Graduação em Gerenciamento em Enfermagem da Escola de Enfermagem da Universidade de São Paulo para obtenção do título de Mestre em Ciências.

Área de concentração: Fundamentos e Práticas de Gerenciamento em Enfermagem e em Saúde.

Orientadora: $\operatorname{Prof}^{\mathrm{a}} \mathrm{Dr}^{\mathrm{a}}$ Marta Maria Melleiro 


\section{AUTORIZO A REPRODUÇÃO TOTAL OU PARCIAL DESTE TRABALHO, POR QUALQUER MEIO CONVENCIONAL OU ELETRÔNICO, PARA FINS DE ESTUDO E PESQUISA, DESDE QUE CITADA A FONTE.}

Assinatura:

Data

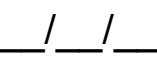

Catalogação na Publicação (CIP)

BIBLIOTECA "WANDA DE AGUIAR HORTA"

Escola de Enfermagem da Universidade de São Paulo

Pena, Mileide Morais

Análise do grau de satisfação de usuários de um hospital universitário privado: uma abordagem multissetorial. / Mileide Morais Pena. - São Paulo, 2010.

$108 \mathrm{p}$.

Dissertação (Mestrado) - Escola de Enfermagem da Universidade de São Paulo.

Orientadora: Prof $^{\mathrm{a}} \mathrm{Dr}^{\mathrm{a}}$ Marta Maria Melleiro

1. Assistência à saúde (qualidade) 2. Serviços de saúde (avaliação) 3. Satisfação dos consumidores de serviços de saúde I. Título 


\section{FOLHA DE APROVAÇÃO}

Nome: Mileide Morais Pena.

Título: Análise do grau de satisfação de usuários de um hospital universitário privado: uma abordagem multissetorial

Dissertação apresentada à Escola de Enfermagem da Universidade de São Paulo para obtenção do título de Mestre em Ciências.

Aprovado em:

Banca Examinadora

Prof $^{\mathrm{a}} \mathrm{Dr}^{\mathrm{a}}$ Marta Maria Melleiro Julgamento:

Julgamento:

Julgamento:
Universidade de São Paulo Assinatura:

Assinatura:

Assinatura: 
$\mathcal{A}$ Deus, que sinto tão presente em cada momento de minha vida.

Ao meu pai, Osvaldo (in memorian) e à minha mãe, Cirley, que me ensinaram, cada um ao seu modo, valiosas lições sobre a vida. 


\section{AGRADECIMENTOS}

Ao meu irmão Ronan,

mais que os laços de sangue, somos unidos por uma amizade infinita e a certeza de sempre poder contar um com o outro.

À professora Doutora Marta Maria Melleiro,

que me acolheu como orientanda e me conduziu com respeito, carinho e confiança, tornando esta jornada consistente e agradável.

Às professoras Doutoras Daisy Maria Rizatto Tronchin e Inaiáh Pinhel, pela valorosa contribuição no exame de qualificação.

À Roselene, prima, madrinha e sobretudo amiga, sempre me apoiando e incentivando em todos os momentos.

Aos amigos Andressa e Alexandre, que me acolheram num momento crucial de minha vida e contribuíram para um novo recomeço.

À Michelle, amiga e irmã que tanto me ajudou em várias etapas desta pesquisa.

À Aretuza, pela amizade fraterna, sincera e verdadeira.

Aos amigos de Campinas e de Elói Mendes, por acreditarem em mim e me apoiarem nos momentos de dificuldade.

À enfermeira Ana Luíza Ferreira Meres, por contribuir para que este sonho se tornasse realidade. 
"É direito dos cidadãos ter atendimento resolutivo com qualidade, em função da natureza do agravo, com garantia de continuidade da atenção, tendo garantidos o atendimento com presteza $e$ as informações sobre seu estado de saúde..."

(Carta dos Direitos dos Vsuários da Saúde, 2006) 
Pena MM. Análise do grau de satisfação de usuários de um hospital universitário privado: uma abordagem multissetorial [dissertação]. São Paulo: Escola de Enfermagem, Universidade de São Paulo; 2010.

\section{RESUMO}

O objetivo deste estudo foi conhecer o grau de satisfação dos usuários de convênios privados e particulares, de um hospital universitário privado e analisar os fatores intervenientes nesse processo, baseado no modelo avaliativo de Parasuraman, Zeithaml e Berry. Trata-se de um estudo exploratório-descritivo de abordagem quantitativa, com coleta prospectiva de dados. Foi realizado na unidade de internação de clínica médica e cirúrgica de um hospital de grande porte, nível terciário, localizado no interior do estado de São Paulo. A amostra foi composta por 288 usuários. Utilizou-se o instrumento baseado na Escala Service Quality do modelo de Parasuraman, Zeithaml e Berry (1985), considerando cinco dimensões: confiabilidade, responsividade, tangibilidade, garantia e empatia. Na caracterização dos usuários verificou-se que a amostra consituiu-se, em sua maioria, de jovens e adultos jovens, com nível de escolaridade superior à média nacional, sendo que $70,1 \%$ deles foram submetidos a procedimentos cirúrgicos. Em relação aos atributos, os maiores índices de satisfação foram: educação da equipe de enfermagem $(96,2 \%)$, cuidados prestados pela equipe de enfermagem $(96,2 \%)$, qualidade geral da enfermagem que atende durante a noite $(95,8 \%)$, educação da equipe médica $(95,8 \%)$, orientação para continuidade do tratamento $(95,8 \%)$ e resultado do tratamento ou cirurgia $(95,8 \%)$. Os atributos que apresentaram menores níveis de satisfação foram: atendimento da nutricionista $(76,2 \%)$ e tempo de espera para conseguir atendimento inicial $(75,3 \%)$. A dimensão tangibilidade foi a que apresentou maior variação nos níveis de satisfação: maior índice no item limpeza do quarto com $92,4 \%$ e menor índice no item nível de barulho à noite com $81,6 \%$. As dimensões confiabilidade e garantia representaram os atributos com maior grau de satisfação tais como cuidados da equipe de enfermagem e educação da equipe de enfermagem, respectivamente. Nas dimensões responsividade e empatia estão inseridos os atributos com menores níveis de satisfação: tempo de espera para atendimento inicial e atendimento da nutricionista. Observou-se diferença significativa entre os níveis de satisfação dos usuários clínicos e cirúrgicos somente nos itens: tempo de espera para atender a campainha e facilidade de localização do balcão, nos quais os usuários de internação cirúrgica demonstraram maiores níveis de satisfação do que os clínicos. Quanto à confiança na instituição, $90 \%$ dos entrevistados referiram intenção em indicar o hospital para parentes ou amigos, sendo que $45,8 \%$ relataram sentir total confiança e $46,2 \%$ bastante confiança na instituição. Por conseguinte, esta pesquisa possibilitou conhecer os atributos do atendimento que impactam na satisfação dos usuários, fornecendo subsídios para reformulação dos processos assistenciais e gerenciais.

Descritores: qualidade da assistência à saúde, avaliação de serviços de saúde, satisfação dos consumidores. 
Pena MM. Assessment degree of the users satisfaction of a private university hospital: a multisectoral approach [dissertation]. São Paulo: School of Nursing, Universidade de São Paulo; 2010.

\begin{abstract}
The aim of this study was to find out the degree of satisfaction of users and private health insurance users of a private university hospital and analyze the involved factors in this process, based on the Parasuraman, Zeithaml and Berry's evaluative model. It is a descriptive-exploratory study done through a quantitative approach, with prospective data collection. It was conducted at the inpatient unit and at the surgical unit of a large private university hospital, tertiary care, located within the state of Sao Paulo. The sample consisted of 288 users. It was used the instrument based on the Service Quality Scale model by Parasuraman, Zeithaml and Berry (1985), concerning the following five dimensions: reliability, responsiveness, tangibles, assurance and empathy. In the characterization of users found that the sample means whereby to youth and young adults with education level higher than the national average, with $70.1 \%$ underwent surgical procedures. The attributes with the highest levels of satisfaction were: nursing staff politeness $(96.2 \%)$, care provided by nursing staff $(96.2 \%)$, general quality of nursing staff working during the night $(95.8 \%)$, medical staff politeness $(95,8 \%)$, and guidance for continuing care $(95.8 \%)$, outcome of treatment or surgery (95.8\%). The attributes that had the lowest levels of satisfaction were: attendance of the nutritionist $(76.2 \%)$, and waiting time to get initial care (75.3\%). The tangibles dimension showed greatest variation in satisfaction levels: a higher rate of item cleanliness $(92.4 \%)$ and lowest in the item level of noise at night with $81.6 \%$. The dimensions reliability and security attributes represented the highest level of satisfaction with such care as the nursing staff and education of nursing staff, respectively. Responsiveness and empathy dimensions are embedded attributes with lower levels of satisfaction, waiting time for initial treatment and care of a nutritionist. It was not observed any significant difference between the levels of satisfaction of medical users and surgical procedures users, except in items: waiting time to answer the bell and ease location of the desk or person to whom to talk to as soon as entering at the hospital; in which users of surgical hospitalization demonstrated greater satisfaction than clinicians. $90 \%$ of respondents stated intention to suggest the hospital for relatives or friends. It was also noted high levels of reliability in the hospital expressed by the study participants, $45.8 \%$ reported felling full confidence and $46.2 \%$ reported a lot of confidence in the institution. Therefore, this research allowed knowing the attributes of care that impact on user satisfaction, providing support to process care and management redesigns.
\end{abstract}

Keywords: quality of health care, health services evaluation, consumer satisfaction. 
Pena MM. Análisis de satisfacción de los usuários de un hospital universitário privado: abordaje multisectorial [disertación]. São Paulo: Escuela de Enfermería, Universidade de São Paulo; 2010.

\section{RESUMEN}

El objetivo de este estudio fue conocer el grado de satisfacción de los usuarios con seguro médico de una institución privada universitaria y analizar los factores que intervienen en el proceso, basado en el modelo de evaluación de Parasuraman, Zeithaml y Berry. El presente trabajo de investigación de carácter exploratorio, descriptivo, de abordaje cuantitativo, con recolecta de datos prospectivos fue realizado en la unidad de hospitalización médica y quirúrgica de un hospital de tercer nivel localizado en el interior del estado de São Paulo. Fueron entrevistados 288 usuarios. Fue usado un instrumento basado en la Calidad de Servicio del modelo de Parasuraman, Zeithaml y Berry, considerando cinco atributos: confiabilidad, sensibilidad, tangibilidad, garantía y empatía. Los usuarios entrevistados fueron en su mayoría personas jovens y adultas con educación secundaria, de los cuales el $70,1 \%$ fueron sometidos a procedimientos quirúrgicos. Los mayores índices de satisfacción fueron: buenos modales del equipo de enfermería $(96,2 \%)$, atención prestada por el equipo de enfermería $(96,2 \%)$, capacidad del equipo de enfermería del turno nocturno $(95,8 \%)$, buenos modales del equipo médico $(95,8 \%)$, orientación médica sobre el tratamiento a seguir $(95,8 \%)$ y el resultado del tratamiento o de la cirugía $(95,8 \%)$. Los atributos con bajos niveles de satisfacción fueron: asistencia de la nutricionista $(76,2 \%)$ y el tiempo de espera para recibir atención inicial $(75,3 \%)$. La tangibilidad mostró alta variación en los niveles de satisfacción: limpieza del dormitorio $(92,4 \%)$ y ruido para dormir por la noche $(81,6 \%)$. La confiabilidad y la garantía tuvieron altos niveles de satisfacción: la atención y educación del equipo de enfermería. En lo referente a la sensibilidad y empatía, estos presentaron niveles de satisfacción más bajos: tiempo de espera para recibir atención inicial y la atención de la nutricionista. Fueron observadas diferencias significativas entre los niveles de satisfacción de los usuarios de hospitalización médica y quirúrgica en: tiempo de espera para responder la campanilla y la facilidad de localizar la recepción del hospital. En este punto los pacientes quirúrgicos mostraron altos niveles de satisfacción. Por otro lado, $90 \%$ de los usuarios entrevistados aprobaron el hospital y lo indicarían para sus familiares y amigos, de los cuales 45,8\% mostraron plena confianza y $46,2 \%$ bastante confianza en la institución. Por lo tanto, esta investigación permitió conocer los atributos de la calidad de servicio de la institución que repercuten en la satisfacción de los usuarios, el cual proporcionará soporte para el proceso de reformulación de la atención.

Palabras clave: calidad de la atención de salud, evaluación de servicios de salud, satsifacción de los consumidores. 


\section{LISTA DE SIGLAS}

$\begin{array}{ll}\text { ANVISA } & \text { Agência Nacional de Vigilância Sanitária } \\ \text { ANS } & \text { Agência Nacional de Saúde Suplementar } \\ \text { CEP } & \text { Comitê de Ética em Pesquisa } \\ \text { IBGE } & \text { Instituto Brasileiro de Geografia e Estatística } \\ \text { JCAHO } & \text { Joint Commission on Accreditation of Healthcare } \\ & \text { Organizations } \\ \text { MSI } & \text { Marketing Science Institute } \\ \text { ONA } & \text { Organização Nacional de Acreditação } \\ \text { SERVQUAL } & \text { Service Quality } \\ \text { SAC } & \text { Serviço de Atendimento ao Cliente } \\ \text { SUS } & \text { Sistema Único de Saúde } \\ \text { SPSS } & \text { Statistic Package for Social Sciences } \\ \text { UTI } & \text { Unidade de Terapia Intensiva }\end{array}$




\section{LISTA DE ILUSTRAÇÕES}

Quadro 1 - Modelo original comparado ao modelo refinado das cinco dimensões. 29

Quadro 2 - Atributos de atendimento segundo dimensão ..................... 50

Quadro 3 - Atributos de atendimento segundo tipo de internação e dimensão

Figura 1 - Modelo GAP da Qualidade dos Serviços.............................. 30

Figura 2 - Organograma de um Hospital Universitário Privado................. 37

Figura 3 - Distribuição dos usuários segundo a faixa etária ..................... 42

Figura 4 - Distribuição dos usuários segundo a escolaridade.................... 43

Figura 5 - Distribuição dos usuários segundo o tipo de internação............. 44

Figura 6 - Distribuição dos níveis de satisfação dos usuários por atributos 51

Figura 7 - Distribuição dos níveis de satisfação dos usuários por atributos segundo tipo de internação ............................................... 54

Figura 8 - Distribuição do grau de satisfação dos pacientes em relação aos itens da equipe médica segundo o tipo de internação.

Figura 9 - Distribuição do grau de satisfação dos pacientes em relação aos itens da equipe de enfermagem segundo o tipo de internação 57

Figura 10 - Distribuição do grau de satisfação dos pacientes em relação aos itens da equipe de nutrição segundo o tipo de internação 60

Figura 11 - Distribuição do grau de satisfação dos pacientes em relação aos atributos gerais segundo o tipo de internação

Figura 12 - Distribuição do grau de satisfação dos pacientes em relação ao atendimento inicial segundo o tipo de internação.

Figura 13 - Distribuição dos usuários em relação ao tempo de espera para internação. 66

Figura 14 - Distribuição dos atributos do atendimento segundo a dimensão de qualidade Tangibilidade.

Figura 15 - Distribuição dos atributos do atendimento segundo a dimensão de qualidade Confiabilidade 71

Figura 16 - Distribuição dos atributos do atendimento segundo a dimensão de qualidade Responsividade. 
Figura 17 - Distribuição dos atributos do atendimento segundo a dimensão de qualidade Garantia ................................................................ 74

Figura 18 - Distribuição dos atributos do atendimento segundo a dimensão de qualidade Empatia ......................................................... 75

Figura 19 - Distribuição dos usuários segundo a intenção de indicar o hospital para parentes e amigos................................................. 77

Figura 20 - Distribuição dos usuários segundo a confiança no hospital ...... 79 


\section{LISTA DE TABELAS}

Tabela 1 - Distribuição dos usuários segundo a especialidade 45

Tabela 2 - Distribuição dos usuários segundo convênio utilizado 47

Tabela 3 - Valores de média, desvio-padrão, mediana, mínimo e máximo do tempo de internação segundo a unidade de internação. 48 


\section{SUMÁRIO}

1 INTRODUÇÃO......................................................................... 15

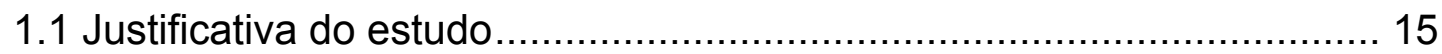

1.2 Qualidade e avaliação dos serviços de saúde .................................... 16

1.3 Satisfação de usuários de serviços de saúde ....................................... 23

1.4 Referencial teórico: $O$ modelo de Qualidade em Serviços de Parasuraman, Zeithaml e Berry .................................................... 26

2 OBJETIVOS

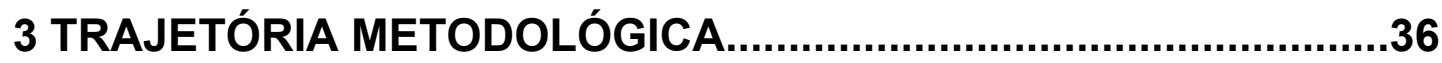

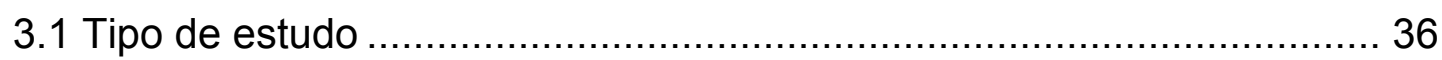

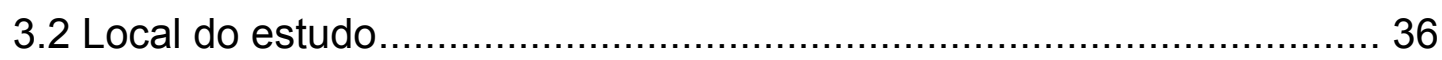

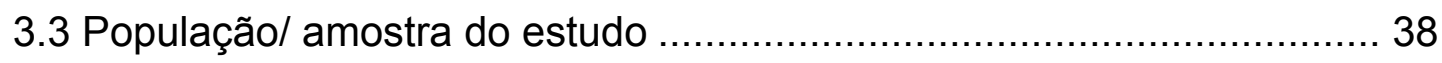

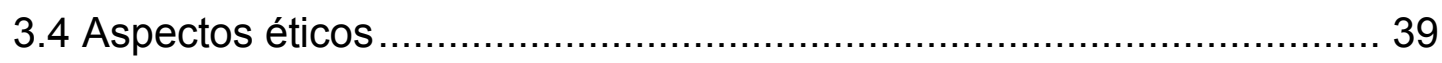

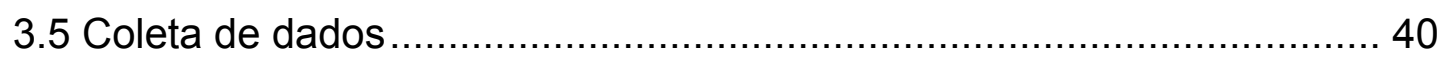

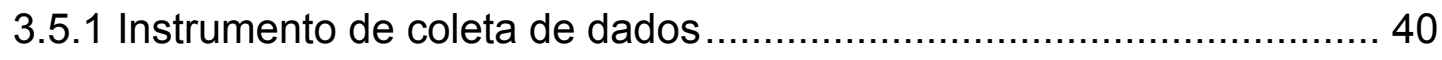

3.5.2 Operacionalização da coleta de dados ............................................ 40

3.6 Organização e análise dos dados ....................................................... 41

4 RESULTADOS E DISCUSSÃO …..................................................42

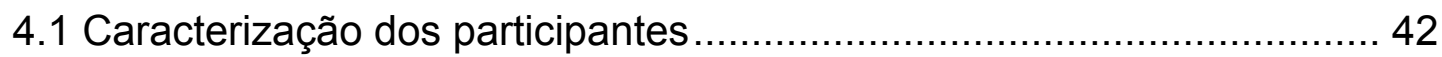

4.2 Classificação dos atributos do atendimento de acordo com o modelo avaliativo de Parasuraman, Zeithaml e Berry ....................................... 49

4.2.1 Análise da satisfação dos usuários relacionados aos atributos dos

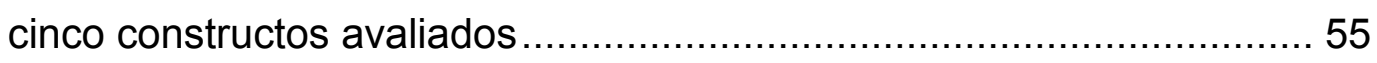

4.2.2 Análise das dimensões de qualidade segundo os atributos do

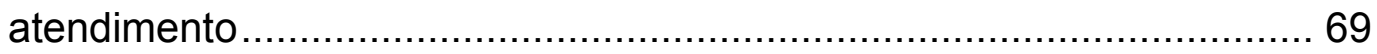

4.3 Análise do quesito confiança em relação à instituição ............................ 77

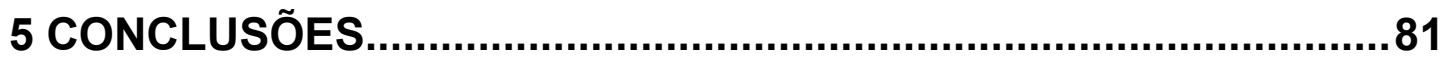

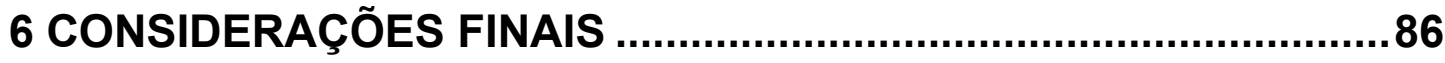

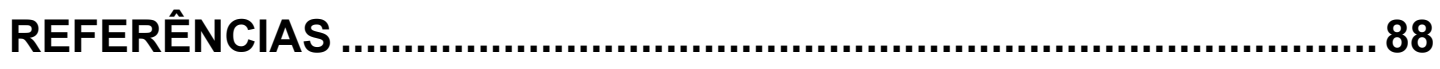

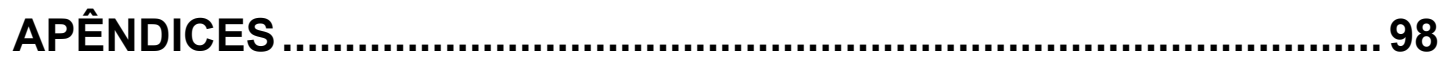


1 INTRODUÇÃO 


\subsection{JUSTIFICATIVA DO ESTUDO}

A busca pela qualidade nos estabelecimentos de saúde tem se mostrado uma tendência mundial, chegando a ser considerada indispensável para a sobrevivência dessas instituições. Assim, nas últimas décadas, a sociedade passou a exigir e a optar por serviços de saúde que apresentem padrões de excelência em seus processos e resultados.

Nessa direção, a avaliação dos serviços de saúde, na percepção do usuário, tornou-se uma importante ferramenta para os tomadores de decisão ao gerenciarem esses serviços. No entanto, trata-se de uma tarefa árdua, uma vez que atender as expectativas de um indivíduo é um processo complexo, cercado de subjetividades, que envolvem crenças, valores, experiências, nível cultural, dentre outros aspectos; inferindo-se, nesse contexto, que o usuário, ao avaliar um serviço de saúde, percebe a qualidade sob a dimensão interpessoal e interdisciplinar.

Quando os usuários avaliam a qualidade de um serviço de saúde comparam o que desejam com o que recebem. Quando os serviços recebidos atendem as suas expectativas, os resultados obtidos são bons. Logo, pode-se afirmar que quanto mais se conhece o usuário, suas necessidades e expectativas, maior é a possibilidade de satisfazê-lo, e com isso, proporcionar a tão almejada qualidade assistencial.

Corroborando com esses pressupostos, primeiramente como enfermeira assistencial atuando em Unidades de Internação e Pronto Atendimento e depois na Chefia de Enfermagem das Unidades de Internação de Convênios e Particulares de um Hospital Universitário, tenho ratificado o quanto a percepção do usuário é de vital importância para nortear a tomada de decisão, a mudança de processos e a integração entre os diferentes setores. Além disso, constitui-se em um meio de conferir credibilidade e visibilidade à instituição.

Todavia, apesar de constatada a relevância da avaliação dos serviços oferecidos, na instituição onde atuo, a avaliação através da percepção dos usuários, ainda, mostra-se incipiente. 
$\mathrm{Na}$ referida organização, em 2004, foi criado o Serviço de Atendimento ao Cliente (SAC) instituindo-se a primeira tentativa de aferir o grau de satisfação dos usuários, por meio do formulário de pesquisa de satisfação. A tabulação dos dados era de responsabilidade do Serviço de Assessoria de Imprensa e a pesquisa era realizada apenas nas Unidades de Internação de Convênios e Particulares. No entanto, a adesão dos usuários foi considerada baixa, não oferecendo subsídios para análises criteriosas.

Uma nova tentativa foi estabelecida no ano de 2005 com a implantação do Serviço de Ouvidoria, no intuito de estreitar a comunicação entre os usuários e a instituição e fornecer mais uma alternativa para o usuário expressar sua opinião. Em 2008, os formulários de pesquisa de satisfação foram revisados e disponibilizados para todos os setores do hospital, ficando o Serviço de Ouvidoria responsável por tabular e identificar os motivos de satisfação ou insatisfação e cabendo à chefia de cada serviço propor ações de melhoria.

Com os dados levantados no citado serviço, as unidades passaram a adequar seus processos de trabalho, partindo das sugestões e críticas recebidas. No entanto, intensifica-se a inquietação em conhecer o perfil dos usuários portadores de planos de saúde ou particulares e sua real percepção sobre a qualidade dos serviços prestados.

Diante dessas considerações e verificando as lacunas ainda existentes na literatura, em relação à avaliação dos serviços de saúde na percepção dos usuários, fui motivada a realizar este estudo com o intuito de conhecer o grau de satisfação dos usuários do serviço que gerencio em um hospital privado.

\subsection{QUALIDADE E AVALIAÇÃO DOS SERVIÇOS DE SAÚDE}

Nas últimas décadas, a qualidade nos serviços de saúde tem ganhado magnitude e o seu significado tem passado por constante construção conceitual e metodológica. Definir níveis de qualidade em saúde é de uma complexidade ímpar, dada a natureza e a peculiaridade das instituições de saúde. Além disso, padrões de qualidade, cada vez mais 
elevados, vêm sendo exigidos de tais instituições, levando-as a buscar efetivos meios para mensurar e avaliar os serviços prestados.

Os primeiros esforços despendidos, acerca da qualidade em saúde, são atribuídos consensualmente à Florence Nigthingale, a partir de sua atuação na Guerra da Criméia. A referida enfermeira foi pioneira no processo de avaliação da assistência pela iniciativa de classificar os enfermos por complexidade, instituindo princípios básicos de saneamento e higiene. Assim, foi criado o primeiro modelo de melhoria contínua que demonstrava através de estudos estatísticos a queda das taxas de mortalidade após reformas implantadas nos hospitais (Bolton, Goodenough, 2003).

Deming (1990) relata que a qualidade pode ser entendida como tudo aquilo que representa as necessidades futuras do usuário, em características mensuráveis, podendo somente ser decidida em termos de quem avalia.

Para Donabedian (1988, 1992), qualidade é a obtenção de maiores benefícios em detrimento de menores riscos para o usuário. Os benefícios, por sua vez, definem-se em função do alcançável de acordo com os recursos disponíveis e os valores. Para esse autor, a qualidade pode ser definida também como a satisfação das necessidades dos usuários, que devem ser ouvidos tanto sobre a avaliação sistemática das atitudes dos profissionais de saúde como a respeito do impacto dos processos de tratamento a eles oferecidos.

Segundo Zeithaml, Parasuraman e Berry (1990), a qualidade é o julgamento do usuário sobre a excelência global ou superioridade de um serviço. Cabe salientar, a relevância da percepção do usuário na avaliação dos serviços de saúde, uma vez que, decorrente do seu ponto de vista, é possível obter-se um conjunto de percepções relacionado à atenção recebida, com os quais se adquirem informações que beneficiam a organização desses serviços.

Conforme Zaicaner (2001), o conceito de qualidade em saúde significa um julgamento a respeito do quanto são bons o cuidado técnico, as relações interpessoais, as condições sob as quais este cuidado foi prestado 
e a que custo. Consiste também nas características do produto por inferência dos serviços, que vão ao encontro das necessidades dos usuários sendo a satisfação destes a principal meta do desenvolvimento de um plano de qualidade. Tal autor ainda afirma que o prestador de serviço precisa ser capaz de oferecer benefícios aos usuários, utilizando os meios possíveis para que fiquem efetivamente satisfeitos.

Miguel (2001) destaca que a implementação da qualidade nos serviços prestados está relacionada ao conceito de qualidade assumido pela organização, que ao construir e praticar uma política de qualidade tem suas atividades atreladas a um contínuo monitoramento, viabilizando a redução de não conformidades, de menores custos, da ausência do desperdício e do retrabalho.

O termo qualidade também tem sido empregado em um sentido amplo para refletir não só a qualidade da atenção, definida como atendimentos das necessidades de saúde existentes ou potenciais, mas também a satisfação com os serviços, os custos da atenção, a qualificação do pessoal dos serviços de saúde, a segurança e a aparência das instituições nas quais os serviços são fornecidos e a adequação dos equipamentos que contribuem para a prestação dos serviços (Starfield, 2002).

De acordo com Vasconcellos (2002), a diferença fundamental, ao se definir qualidade na prestação de serviços, encontra-se na subjetividade e na dificuldade de se estabelecer o que é qualidade, uma vez que os usuários reagem diferentemente ao que parece ser o mesmo serviço. Cada usuário percebe a qualidade de forma diferente, pois seus padrões sobre a mesma irão variar ao longo de suas vidas.

Morais et al (2008) constatam que a qualidade pode ser mensurada por meio da avaliação em saúde e que sua definição perpassa por uma complexa relação entre a cultura organizacional da instituição prestadora de serviços, as necessidades e expectativas dos usuários aos quais se pretende satisfazer.

Analisando os conceitos de qualidade citados anteriormente, percebese que os mesmos vêm evoluindo ao longo dos anos, porém apresentando dois aspectos em comum: o primeiro refere-se à busca de padrões elevados 
nos serviços e o segundo explicita a importância dos usuários na avaliação dos mesmos.

Corroborando com tal análise, Castellanos (2002) afirma que, na gestão contemporânea, a qualidade é definida pelos usuários, por isso é bastante relevante conhecer suas necessidades e expectativas para que se ofereçam produtos e serviços de padrão elevado, sendo esse desempenho de responsabilidade de todos na organização.

Dessa forma, ao se constatar a importância da qualidade na prestação de serviços, principalmente nos de saúde, torna-se necessário instituir meios de avaliá-la.

Nesse contexto, Donabedian (1985), um dos principais estudiosos sobre a avaliação da qualidade em saúde, introduz parâmetros não estatísticos de avaliação e cria um quadro conceitual a partir de três dimensões: a estrutura, que envolve os recursos físicos, humanos, materiais e financeiros e os equipamentos necessários para assistência; o processo, que se refere às atividades envolvendo os profissionais de saúde e os usuários; e o resultado, que corresponde à etapa final da assistência prestada, considerando a saúde, satisfação de padrões e expectativa dos usuários.

Segundo o mesmo autor, cada uma dessas dimensões deve ser especificada para dados contextos, pela identificação dos critérios mais adequados para cada instituição, dando conta das suas particularidades e ao mesmo tempo, mantendo uma coerência entre si. As dimensões consideradas mais técnicas condicionam as dimensões interpessoais, mas ao mesmo tempo dependem das outras para realizarem seu potencial. Além disso, os critérios e padrões podem estabelecer níveis mínimos ou máximos de qualidade e se orientar segundo as prioridades dos prestadores de serviço, através da visão dos usuários ou sob as prioridades definidas pela sociedade.

Donabedian (1990) amplia esses princípios quando desenvolve os chamados "Sete Pilares da Qualidade", a saber: eficácia, capacidade de melhorias na saúde e no bem-estar, ou seja, o melhor que se pode fazer nas condições mais favoráveis devido ao estado do usuário, mantidas as demais 
circunstâncias; efetividade, alcance do grau atingível na busca da melhoria da saúde, nas condições da prática cotidiana; eficiência, habilidade de obter o melhor resultado ao menor custo; otimização, emprego da relação custobenefício na assistência à saúde; aceitabilidade, adaptação do cuidado aos desejos, expectativas e valores dos usuários e de seus familiares; legitimidade, aceitação do cuidado da forma como é visto pela sociedade, em geral; equidade, igualdade na distribuição dos cuidados, sendo parte daquilo que torna o cuidado aceitável aos indivíduos e legítimo à sociedade.

$\mathrm{Na}$ década de 80, Zeithaml, Parasuraman e Berry (1990), desenvolvem um trabalho pioneiro para avaliação da qualidade em serviços no qual propõem três características fundamentais. A primeira delas diz que os serviços são basicamente intangíveis, julgados pelo desempenho e experiências vivenciadas pelos usuários. A segunda considera os serviços como heterogêneos, com possibilidade de desempenho e julgamentos diferentes conforme fornecedor e o usuário. A última característica define a produção e o consumo dos serviços como inseparáveis, dificultando assim seu controle e sua avaliação.

No final da década de 80 e início da seguinte, o aumento do interesse dos usuários pela qualidade e a participação mais ativa dos mesmos fizeram com que melhorias se tornassem essenciais e, consequentemente, a opinião dos que utilizavam tais serviços se tornasse fundamental.

Nesse sentido, órgãos governamentais nacionais, baseando-se na experiência de outros países, começaram a se empenhar na criação de programas e projetos e a buscar a melhoria dos serviços prestados, prevenindo possíveis agravos. Iniciativas relacionadas ao processo de acreditação hospitalar começaram a ser incorporadas nos serviços de saúde. Em 1988, o Ministério da Saúde cria o Programa de Acreditação Hospitalar, visando implantar um processo de melhoria da assistência (Malik, Schiesari, 1998; Adami, 2000).

Em 2001 a Organização Nacional de Acreditação (ONA) foi reconhecida pelo Ministério de Saúde, dando início a um novo modelo de trabalho e desempenhando um importante papel na melhoria dos padrões 
de qualidade das instituições hospitalares por meio da certificação (Brasil, 2003).

Desde então, a avaliação dos serviços de saúde vem ocupando um lugar de destaque entre as ações de planejamento e gestão nos órgãos públicos e privados.

Tronchin, Melleiro e Takahashi (2005) afirmam que a avaliação dos serviços vem sendo considerada como um processo de determinação da extensão com a qual as metas e os objetivos estão sendo alcançados. Reportam também como esse processo técnico-administrativo fornece subsídios para a tomada de decisão.

Para Bosi e Uchimura (2007), há uma tendência de se considerar as especificidades de cada contexto, incluindo as relações que se processam e produzem reflexos diretos na operacionalização de práticas de saúde. Diante disso, observa-se a geração de estratégias metodológicas variadas e multidimensionais, incluindo uma superação dos contornos positivistas.

Segundo Novaes (2000), existem três grandes tipos de avaliação:

$\checkmark \quad$ Investigação avaliativa, visa à produção do conhecimento enfocando os impactos obtidos pelas ações a serem avaliadas e identificando relações de causalidade;

$\checkmark$ Avaliação para decisão, seu objetivo dominante é participar de processos de tomada de decisão, enfocando no reconhecimento do objeto e na profundidade necessária para a sua adequada compreensão. Há uma busca pela identificação dos problemas e, em seguida, alternativas de equacionamento possíveis;

$\checkmark \quad$ Avaliação para gestão, a produção da informação deve contribuir para o aprimoramento do objeto avaliado. Não se trata da busca de fundamentos ou justificativas e nem redirecionamentos, mas o melhoramento de uma condição dada, focando na caracterização de uma condição e a sua tradução em medidas que possam ser quantificadas e replicadas.

Tomando por base o referencial de Novaes (2000), pode-se considerar que o presente estudo trata-se de uma avaliação para decisão, pois seu intuito é produzir respostas para perguntas colocadas por aqueles que vivenciam o objeto avaliado, sendo os resultados transformados em 
recomendações positivas, capazes de contribuir para a solução dos problemas identificados.

O sentido fundamental, ao se teorizar no campo da avaliação dos serviços de saúde é, sobretudo, a tentativa de converter os conceitos em estratégias, critérios e padrões de medição, a fim de contribuir para a produção de medidas úteis que auxiliem na tomada de decisão e subsidiem aperfeiçoamento no âmbito dos serviços. A utilização dos conceitos torna-se importante à medida que permitem representar aspectos da realidade através de construções lógicas estabelecidas de acordo com um quadro teórico de referência (Espiridião, Trad, 2006).

Em revisão de literatura, verifica-se, embora por estudos preliminares, que a mensuração de resultados necessita ainda de aprimoramento e de controles mais precisos envolvendo outros dados e causas da prestação do cuidado para que se obtenham avaliações mais equânimes e eficazes. Ainda assim, tornar claras as razões pelas quais uma organização alcança resultados extraordinários, superando a eficácia de outras, é uma difícil tarefa, podendo estar associada à intangibilidade dos recursos que lhe conferem vantagem competitiva (Adami, Yoshitome, 2003; Feldman, 2004).

Diante disso, pode-se caracterizar a satisfação do usuário como uma avaliação de resultados associada à efetividade do cuidado ou a um ganho específico de um determinado tipo de intervenção (Donabedian, 1984; Oliveira, 1992). Todavia, alguns autores fazem crítica ao emprego da satisfação para avaliação da qualidade, ao considerar que ela está fortemente baseada nas expectativas dos usuários. Ainda assim, é importante lembrar que o usuário é o consumidor final do produto dos serviços de saúde.

Por conseguinte, acredita-se que quando se pensa em avaliação de serviços de saúde, a satisfação do usuário está, intrinsecamente, vinculada ao tema, daí a opção em utilizar tal método para avaliar a qualidade do serviço em questão. 


\subsection{SATISFAÇÃO DE USUÁRIOS DE SERVIÇOS DE SAÚDE}

A gestão das instituições hospitalares tem preconizado, sobretudo, um olhar atento à satisfação plena dos usuários, como uma ferramenta para mensurar a qualidade do serviço prestado, partindo do pressuposto de que a eficácia nos processos da assistência hospitalar, somente, terá êxito se estiver a serviço dessa população.

A satisfação pode ser definida como a reação do usuário à experiência de utilizar um serviço ou adquirir um produto de acordo com a sua expectativa. É o sentimento de prazer ou desapontamento resultante da comparação do desempenho esperado em relação às expectativas do indivíduo. É entendida como uma função de desempenho e expectativa percebidos (Zanon, 2001).

Espiridião e Trad (2006) acrescentam que a polissemia no campo da avaliação em saúde é fenômeno retratado por diversos autores da área. No caso das avaliações de satisfação de usuários de serviços de saúde, refletese que embora o termo satisfação esteja em alta, sendo referido em larga escala na literatura internacional, é um conceito cujos contornos mostram-se vagos e dotados de realidades múltiplas e diversas. Os enfoques teóricos encontrados para a compreensão da satisfação de usuários de serviços de saúde são predominantemente abordagens da escola de psicologia social, de vertente nitidamente norte-americana e do marketing:

$\checkmark$ Teoria da atitude, a satisfação é entendida como uma atitude, ou seja, uma avaliação positiva ou negativa feita pelo indivíduo sobre um determinado aspecto do serviço (Linder-Pelz, 1982);

$\checkmark \quad$ Teoria da equidade, considera que os usuários avaliam os serviços em termos de ganhos e perdas individuais e na comparação com outros usuários (Linder-Pelz, 1982).

$\checkmark \quad$ Teoria da discrepância, os níveis de satisfação são preditos a partir da diferença entre as expectativas e a percepção da experiência. É a mais utilizada nas pesquisas de satisfação (Carr-Hill, 1992; Williams, 1994; Sitzia, Wood, 1997); 
$\checkmark \quad$ Teoria da realização (de expectativas e de necessidades), a satisfação é dada simplesmente pela diferença entre o que é desejado, ou esperado e o que é obtido. Essa teoria tem sido bastante criticada por não considerar a experiência do serviço. Dois tipos de teoria da realização podem ser encontrados: a realização da expectativa e a realização da necessidade, onde aspectos da efetividade, do serviço e o nível de saúde do usuário são levados em conta nas respostas sobre a satisfação (Aspinal et al, 2003).

Como podem ser observadas, essas teorias centram-se nos usuários, destacadamente em aspectos psicológicos como crenças, expectativas e percepções.

Órgãos reguladores e instituições de saúde reconhecem a satisfação do usuário como indicador significativo da qualidade em saúde. Desenvolver uma medida exata da satisfação do usuário revela muitos aspectos do cuidado recebido por ele. Hospitais dos Estados Unidos mensuram a satisfação como medida de desempenho e acrescentam que satisfação e fidelidade estão intimamente interligadas (Marley, Collieri, Goldstein, 2004).

A satisfação relaciona-se à qualidade do serviço ou do produto oferecido. Contudo, não basta oferecer produtos ou serviços de qualidade do ponto de vista técnico se o usuário não a percebe concretamente.

Além disso, a relação entre um produto ou serviço de qualidade e a percepção do usuário tem sido repetidamente abordada. O usuário satisfeito pode representar cerca de mais de $25 \%$ do total em uma avaliação. No sistema atual de atenção à saúde, os usuários não querem mais ser tratados como meros dependentes, exigindo envolvimento no processo de tomada de decisão em relação ao tratamento (Allen, 2004).

Cabe, também, considerar os estudos que demonstraram como os usuários satisfeitos tendem a aderir melhor ao tratamento prescrito, a fornecer informações importantes para o provedor e a continuar utilizando os serviços de saúde. Outro ponto importante é que usuários satisfeitos são mais propensos a ter melhor qualidade de vida (Baron-Epel, Dushenat, Friedman, 2001). 
Segundo Donabedian (1990), a avaliação do ponto de vista dos usuários é realizada, sobretudo, por meio da categoria aceitabilidade, que se refere à conformidade dos serviços oferecidos em relação às expectativas e aspirações dos usuários e seus familiares, as quais nem sempre são as preferidas pelo gestor

Donabedian (1992) aponta, ainda, o elevado valor da participação dos usuários na concepção, na produção e na avaliação dos serviços de saúde, enfatizando que um modelo de avaliação deve responder as seguintes questões: a infra-estrutura existente atende às necessidades do cliente? Os processos estão ocorrendo de maneira adequada? Os resultados obtidos são bons? Os usuários estão satisfeitos com os serviços oferecidos?

Por outro lado, Carr-Hill (1992) atenta para o aspecto otimista da avaliação feita pelos usuários de serviços de saúde e o impacto que isto causa aos gestores, pois os usuários tendem a enfatizar os aspectos positivos do serviço, ou seja, aqueles que Ihes causam maior satisfação, enquanto que aos gestores interessam os aspectos que devem ser melhorados, pois é por meio deles que se darão as intervenções necessárias. Porém, acrescenta que mesmo nas respostas com grande número de avaliações positivas podem ser notadas algumas diferenças que devem ser levadas em consideração. Outro aspecto levantado por esse autor é a importância da análise criteriosa das observações e sugestões feitas pelos usuários, visando o fornecimento de dados que podem contribuir para a melhoria da qualidade.

Kotaka, Pacheco, Higaki (1997) alegam que muitas estratégias para melhoria de serviços de saúde estão baseadas na satisfação do usuário. Ouvir e observar o comportamento dos usuários dentro das instituições de saúde é fundamental para a compreensão e melhoria da organização desses serviços. Portanto, um administrador atento encontrará dados valiosos para o gerenciamento de seu serviço na avaliação feita por tais usuários.

Acredita-se que, a partir da realização de trabalhos e discussões entre os profissionais da saúde, acerca da participação dos usuários, é que se 
embasará a importância do papel dos mesmos na avaliação dos serviços de saúde.

Nessa perspectiva, pesquisar a respeito da satisfação dos usuários é uma tarefa fundamental para a gestão dos serviços, uma vez que seu entendimento pode proporcionar, sob a ótica dos usuários, uma avaliação de desempenho que indicará decisões tanto estratégicas como operacionais influenciáveis na qualidade dos serviços prestados pelas organizações e, até mesmo, na adesão dos usuários ao tratamento (Williams, 1994; Gerschman et al, 2007).

Tendo em vista esses aspectos e frente à necessidade da escolha de um referencial teórico que fundamentasse o presente estudo é que se optou pelo modelo avaliativo de Parasuraman, Zeithaml e Berry (1985), que utiliza critérios tangíveis para medir o grau de satisfação dos usuários.

\subsection{REFERENCIAL TEÓRICO: O MODELO DE QUALIDADE EM SERVIÇOS DE PARASURAMAN, ZEITHAML E BERRY}

Parasuraman, Zeithaml e Berry $(1985,1991)$ desenvolveram um modelo de avaliação de qualidade funcional, aplicável a inúmeros setores de serviços. Inicialmente, tal modelo foi utilizado no contexto de marketing empresarial e depois validado no contexto da saúde.

No intuito de entender como os usuários percebiam e avaliavam a qualidade dos serviços, os mesmos autores desenvolveram em 1985 um estudo com doze grupos focais, sendo três em cada um dos quatro diferentes serviços investigados (banco de varejo, cartão de crédito, corretagem de ações e reparos e manutenção). Baseados nas percepções comuns entre os grupos, esses autores definiram formalmente a qualidade em serviço como o grau e o tipo de discrepância entre as percepções e expectativas dos usuários, sugerindo que todos eles utilizam os mesmos aspectos gerais do serviço para avaliação da qualidade.

Os resultados obtidos com os referidos grupos focais confirmaram que os usuários são influenciados pelas dimensões do processo e não só pelos resultados na avaliação da qualidade do serviço. 
Em continuidade ao citado estudo, Parasuraman, Zeithaml e Berry (1991), relatam que o padrão das respostas revelou dez critérios avaliativos gerais que o usuário pode empregar, independente do serviço investigado, a saber: tangibilidade, aparência física das instalações, equipamentos, quadro de funcionários, materiais normativos; confiabilidade, capacidade de realizar o serviço prometido de forma confiável e precisa; responsividade, capacidade para ajudar os clientes com prontidão; competência, posse das habilidades requeridas e conhecimento para realizar serviços; cordialidade, polidez, respeito, consideração e amistosidade dos colaboradores; credibilidade, confiança, verdade e honestidade; segurança, ausência de perigo, risco ou dúvidas; acessibilidade, proximidade e contato fácil; comunicação, manter os clientes informados numa linguagem inteligível; compreensão do cliente, que seria esforçar-se para entender o cliente e suas necessidades.

Após análise estatística para determinar as inter-relações entre essas dimensões, três delas permaneceram intactas: tangibilidade, confiabilidade e responsividade. As sete dimensões remanescentes foram inseridas em outras duas dimensões: garantia e empatia.

O estudo dessas cinco dimensões demonstrou que os usuários as utilizam como critérios de julgamento da qualidade do serviço. As dimensões não são mutuamente exclusivas, ainda assim, fornecem uma importante estrutura para a compreensão das expectativas dos usuários, servindo de aspectos que delineiam o serviço sob o ponto de vista do usuário que irá julgá-lo. Com o refinamento dessas cinco dimensões, os referidos autores definiram que:

Tangibilidade, inclui a aparência das instalações físicas, equipamentos, pessoal e materiais de comunicação, representando os aspectos materiais do fornecimento que podem ser percebidos pelos cinco sentidos humanos;

$\checkmark \quad$ Confiabilidade, traduzida na habilidade do fornecedor executar de forma segura e eficiente o serviço. É a capacidade de prestar o serviço prometido de forma confiável. Retrata um desempenho consistente, sem falhas, no qual o usuário possa confiar. O fornecedor deve cumprir com o 
que foi prometido sem a possibilidade de trabalhos refeitos. Esta dimensão pode ser considerada um resultado, enquanto tangibilidade, responsividade, garantia e empatia são dimensões do processo, pois ocorrem durante a prestação do serviço. As expectativas dos usuários são maiores e as zonas de tolerância mais estreitas para a confiabilidade do que para as outras dimensões;

$\checkmark \quad$ Responsividade (ou receptividade), refere-se à disponibilidade do prestador, voluntariamente, ajudar os usuários; prestando um serviço de forma atenciosa, com precisão e rapidez de resposta. Diz respeito à disposição dos colaboradores da instituição em auxiliar os usuários e fornecer o serviço prontamente;

$\checkmark$ Garantia, identificada como a cortesia, o conhecimento dos colaboradores e suas habilidades de transmitir confiança;

$\checkmark \quad$ Empatia, relata que a organização importa-se com o usuário e o atende de forma individualizada, referindo-se a capacidade de demonstrar interesse e atenção personalizada. A empatia inclui acessibilidade, sensibilidade e esforço em entender as necessidades dos usuários.

A seguir, o Quadro 1 demonstra os critérios do modelo original e as alterações que configuraram no modelo refinado das dimensões: 
Quadro 1- Modelo original comparado ao modelo refinado das cinco dimensões de Parasuraman, Zeithaml e Berry

\begin{tabular}{|l|l|l|}
\hline \multicolumn{1}{|c|}{ Modelo original } & \multicolumn{1}{|c|}{ Modelo refinado } & \multicolumn{1}{|c|}{ Descrição } \\
\hline Tangibilidade & Tangibilidade & Aspectos físicos daquilo que é fornecido aos. \\
\hline Confiabilidade & Confiabilidade & $\begin{array}{l}\text { Habilidade de cumprir o que foi prometido com } \\
\text { exatidão. }\end{array}$ \\
\hline Responsividade & Responsividade & $\begin{array}{l}\text { Capacidade para ajudar os usuários e fornecer o } \\
\text { serviço prontamente, capturando a noção de } \\
\text { flexibilidade e habilidade para adaptar o serviço às } \\
\text { necessidades do usuário. }\end{array}$ \\
\hline $\begin{array}{l}\text { Competência } \\
\text { Cortesia }\end{array}$ & Garantia & Competência e cortesia estendida aos usuários e a \\
Segurança & segurança fornecida através das operações. \\
\hline Comprilidade & Atenção individualizada aos usuários. \\
\hline
\end{tabular}

Fonte: Marshall, Murdoch. Service quality in consulting marketing engineers, 2001.

Para realizar a mensuração da satisfação do usuário, Parasuraman, Zeithaml e Berry (1991) concluíram que é preciso focar as expectativas e percepções que os usuários têm do serviço fornecido. $O$ conceito de qualidade percebida, utilizada tanto para os serviços como para os produtos, tem sido entendido como superioridade ou excelência, enquanto a conceituação de qualidade do serviço é mais abstrata e intangível. $\mathrm{Na}$ ausência de medidas objetivas, pode-se considerar apropriado que a avaliação seja realizada pela mensuração da percepção do serviço pelo usuário.

O intervalo que separa o nível desejado e o mínimo aceitável estabelece uma zona de tolerância que aponta para o âmbito de desempenho do serviço que o usuário considera satisfatório. O desempenho inferior causa frustração, ao passo que o superior surpreende positivamente.

Nessa visão, a zona de tolerância pode variar segundo o usuário, a ocasião em que o serviço é prestado e as circunstâncias nas quais os 
processos ocorrem, atribuindo-se essa variação a fatores pessoais ou externos. Os usuários avaliam a qualidade do serviço comparando o que desejam com o que esperam e com aquilo que obtêm.

No estudo desenvolvido por Parasuraman, Zeithaml e Berry (1985), os critérios de avaliação aplicados consideram as lacunas (gaps) que são as diferenças entre as expectativas dos usuários e o que é realmente oferecido (Cronin, Taylor, 1994; Marshall, Murdoch, 2001).

A Figura 1, apresentada a seguir, ilustra o referido modelo avaliativo, explicando as lacunas ou gaps de qualidade dos serviços.

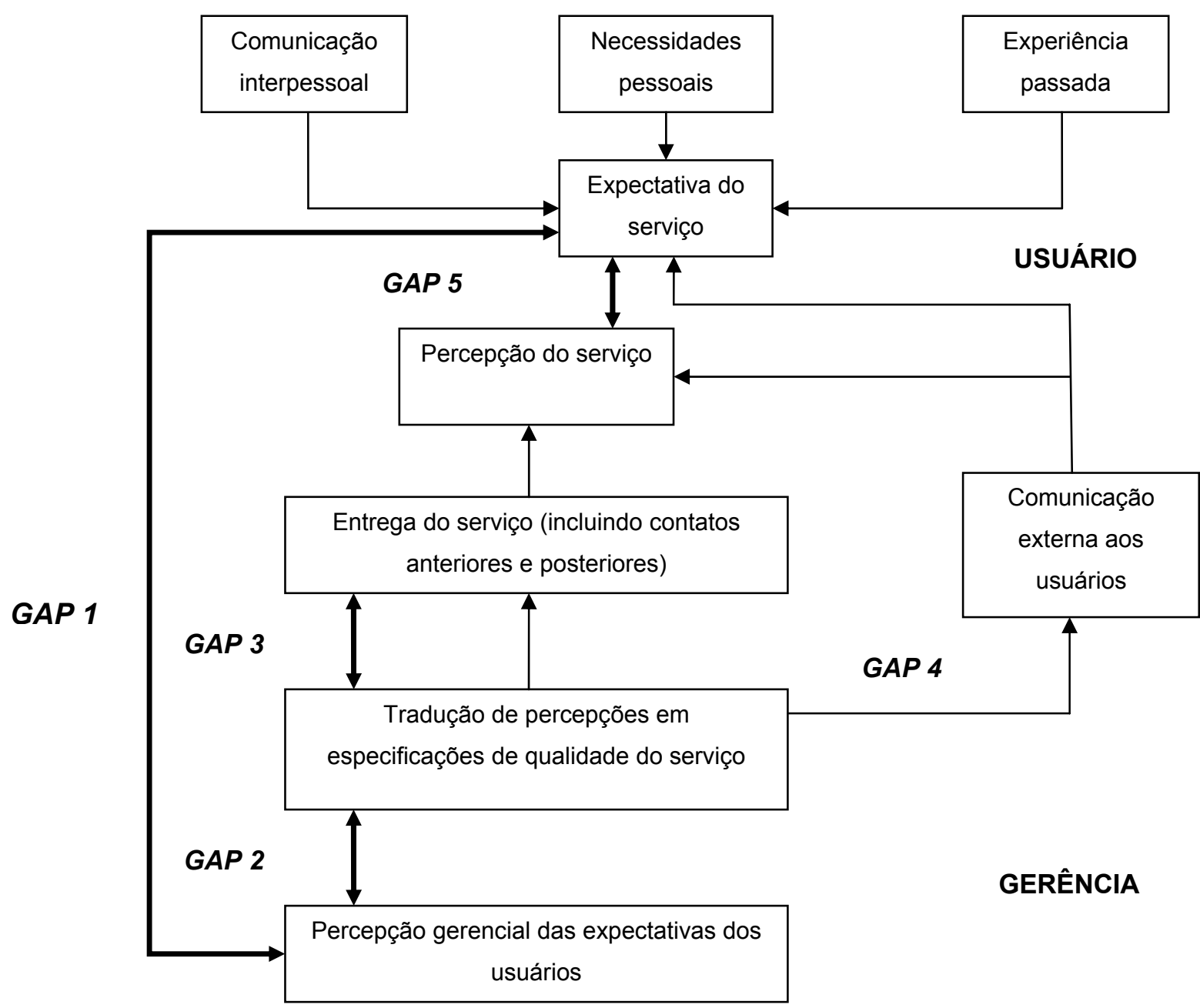

Figura 1 - Modelo GAP da Qualidade dos Serviços

Fonte: Parasuraman, Zeithaml e Berry. A conceptual model of Service Quality,1985.

Quando as percepções forem maiores que as expectativas, os gaps serão estreitos e os níveis de satisfação elevados, considerando-se o 
serviço de boa qualidade. Destacam-se cinco gaps corporativos que, usualmente, são encontrados entre as expectativas e percepções dos usuários. São eles:

Gap 1- Não conhecer o que os usuários esperam receber;

Gap 2- Não selecionar o projeto certo do serviço e padrões;

Gap 3- Não entregar o serviço padrão;

Gap 4- Não casar desempenho com promessas;

Gap 5- Estabelecido em função dos quatro gaps anteriores;

f [gap 1, gap 2, gap 3, gap 4].

Diante das considerações anteriores, Parasuraman, Zeithaml e Berry (1985, 1991) elaboraram uma escala psicométrica das dimensões de qualidade chamada Service Quality (SERVQUAL), como a primeira tentativa para operacionalização do constructo de satisfação do usuário. A escala foi desenvolvida com o auxílio do Marketing Science Institute (MSI), com a finalidade de proporcionar um instrumento para medição da qualidade funcional aplicado a inúmeros setores de serviço.

A ferramenta SERVQUAL constitui-se de 44 proposições divididas em duas seções, a primeira contendo 22 afirmações sobre as expectativas do usuário referentes ao serviço e a segunda com 22 afirmações referentes às percepções dos usuários dentro de categorias específicas do serviço.

Nessa ferramenta os usuários devem fornecer duas notas para cada atributo, uma refletindo suas expectativas do nível do serviço, que foi entregue por excelentes instituições em um setor, e outra mostrando suas percepções do serviço entregue por uma instituição específica dentro daquele setor. As pontuações variam de discordo totalmente até concordo totalmente (1-7). As diferenças obtidas entre os escores de expectativa e percepção podem ser empregadas para a melhoria da qualidade dos serviços de muitas formas.

A escala SERVQUAL, após duas décadas de emprego, tem se mostrado eficiente para mensurar as percepções e expectativas dos usuários sobre a qualidade do serviço, inclusive em serviços de saúde.

No Brasil, este instrumento foi validado por Castellanos (2002) em estudo que pesquisou a satisfação dos usuários, em um hospital 
universitário, comparando-a com a percepção que o corpo gerencial tinha dessa satisfação, tomando como base as cinco dimensões de Parasuraman, Zeithaml e Berry (1991). Nesse estudo, as variáveis pesquisadas foram agrupadas em 35 atributos do atendimento e se observou uma diferença significativa entre o que os usuários identificavam como qualidade nos serviços prestados e o que os gerentes consideravam ser qualidade, demonstrando lacunas entre as duas percepções, o que pode ser explicado pelos gaps. $O$ índice de satisfação manifestado pelos usuários foi maior do que o percebido pelos gerentes e estes, por sua vez, tinham uma expectativa superior ao real desempenho da área operacional. Quanto aos atributos do atendimento, ficou evidente que os usuários consideravam o atendimento inicial e o resultado do tratamento como os atributos de maior importância para sua satisfação, que têm como dimensões predominantes a empatia e a confiabilidade. O estudo também permitiu identificar que a qualidade da equipe de enfermagem foi um fator diferencial na instituição.

Hercos e Berezovski (2006) avaliaram a qualidade de um serviço oftalmológico ambulatorial prestado aos usuários do Sistema Único de Saúde na cidade de Belo Horizonte (MG) mediante a aplicação de dois questionários estruturados, adaptados da escala SERVQUAL modificada. Detectou-se ligeira insatisfação geral quanto à qualidade do atendimento, sendo a segurança e a confiabilidade os atributos de maior importância, concluindo a necessidade de planejamento e implementação de ações para a melhoria deste serviço.

Arroyo (2007) serviu-se do referencial de Parasuraman, Zeithaml e Berry (1985) para avaliar a qualidade dos serviços de saúde na rede pública e privada de Ribeirão Preto (SP), focada na análise do tempo de consulta médica. O estudo apontou a fragilidade no sistema de agendamento de consultas, principalmente nas instituições públicas, e a demora para espera no atendimento médico. As instituições que apresentaram o menor tempo de consulta médica também receberam um grau menor sobre a avaliação da qualidade em relação às outras instituições.

Cruz (2008) analisou os níveis de satisfação de um hospital privado do Município de São Paulo utilizando-se do instrumento validado por 
Castellanos (2002). Os atributos que alcançaram os maiores níveis de satisfação foram educação e empenho da equipe médica e de enfermagem, explicações e orientações sobre o motivo da internação, respeito à privacidade e orientação para continuidade do tratamento pós-alta hospitalar. Garantia e confiabilidade foram as dimensões que mais causaram impacto na satisfação sendo seguidas pela responsividade e empatia. Embora a equipe médica e de enfermagem tenham apresentado melhores níveis de satisfação, os demais também foram bem avaliados. Todavia, verificou-se a necessidade de adoção de estratégias no serviço de nutrição e no atendimento inicial para que os usuários fossem ainda melhor atendidos.

Frente ao exposto e considerando o sucesso obtido pelos autores supracitados ao utilizar tal referencial para mensurar a satisfação dos usuários, este estudo foi desenvolvido utilizando o instrumento validado por Castellanos (2002), tendo em vista a importância de reconhecer os aspectos que trazem satisfação aos usuários. 
2 OBJETIVOS 
$\checkmark \quad$ Conhecer o grau de satisfação dos usuários de Convênios Privados e de usuários particulares acerca do atendimento em uma Unidade de Internação de Clínica Médica e Cirúrgica de um Hospital Universitário Privado;

$\checkmark \quad$ Analisar os fatores intervenientes no grau de satisfação dos usuários, baseado no modelo avaliativo de Parasuraman, Zeithaml e Berry. 


\subsection{TIPO DE ESTUDO}

Trata-se de um estudo exploratório-descritivo de abordagem quantitativa.

Neste tipo de estudo, os fatos são observados, registrados, analisados, classificados e interpretados, sem a interferência do pesquisador. Emprega-se este desenho para buscar informações precisas sobre a frequência da ocorrência de um fenômeno (Lobiondo-Wood, Haber, 2001).

\subsection{LOCAL DO ESTUDO}

O estudo foi realizado em um Hospital Universitário Privado de grande porte, nível terciário e localizado no interior de São Paulo (SP).

Trata-se de uma instituição de ensino e pesquisa, que tem por missão "Proporcionar atendimento de qualidade na área de saúde e contribuir para a promoção do conhecimento, fundamentado no supremo valor da vida e dignidade humana".

O hospital conta com 350 leitos, sendo 240 leitos para o atendimento ao Sistema Único de Saúde (SUS) e 110 para atendimento de Convênios e Particulares, incluindo os 22 leitos de convênio nas Unidades de Terapia Intensiva (UTI). Para o atendimento da capacidade instalada a instituição conta com 2100 funcionários.

A estrutura organizacional dessa instituição é composta por uma Presidência, uma Superintendência, um Colegiado de Diretores (Clínico e Técnico), subordinados à Superintendência e responsáveis pelas áreas assistenciais; uma Controladoria, subordinada diretamente à Presidência e responsável pelas áreas técnico-administrativas e, por fim, Gestores das Unidades de Negócio (Administrativas, Apoio e Assistenciais), conforme explicitado na Figura 2. 


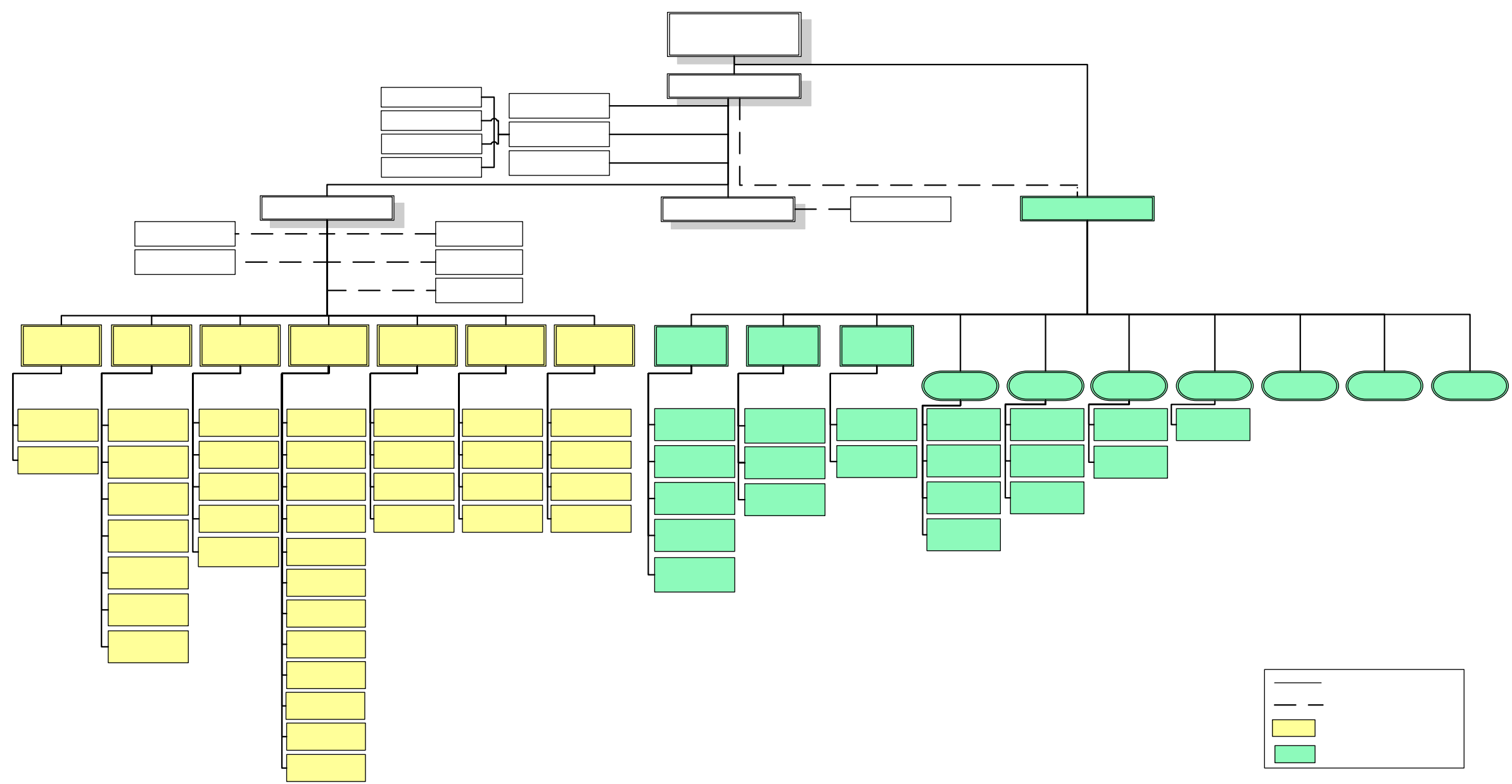

Figura 2 - Organograma de um Hospital Universitário Privado, 2010.

Fonte: Gerência de Projetos, 2010. 
O Hospital possui duas Unidades de Internação para Convênios e Particulares com 88 leitos, sendo uma delas com 44 leitos destinados à internação das especialidades de clínica médica e cirúrgica e a outra destinada às internações das especialidades materno-infantil e pediatria com número igual de leitos.

São internados, em média, 290 usuários por mês na Unidade de Clínica Médica e Cirúrgica e 260 na Unidade Materno-infantil e Pediatria, totalizando cerca de 550 internações/mês. A taxa de ocupação gira em torno de $75 \%$ e a média de permanência dos usuários é de três dias.

O local onde este estudo foi desenvolvido foi a Unidade de Clínica Médica e Cirúrgica, por atender os critérios de elegibilidade.

\subsection{POPULAÇÃO/ AMOSTRA DO ESTUDO}

A população foi constituída por usuários internados na Unidade de Internação de Clínica Médica e Cirúrgica de Convênios e Particulares. Para definir a população foram estabelecidos os seguintes critérios de elegibilidade:

$\checkmark$ Alfabetizados;

$\checkmark \quad$ Idade acima de 18 anos;

$\checkmark \quad$ Estarem em condições clínicas favoráveis para responder 0 questionário, por ocasião da alta hospitalar.

Os critérios de suspensão não foram previstos em virtude das características desta pesquisa.

Para o cálculo da amostra, tomou-se por base a hipótese de que a satisfação encontrada no serviço varia entre 70 a $80 \%$.

Assim, para obter estimativas com $95 \%$ de confiança, utilizou-se a seguinte fórmula:

$$
n=\frac{[z(\text { alfa })]^{2 *} p^{*}(1-p)}{d^{2}}
$$

onde: $\mathrm{n}=$ tamanho amostral $z(a l f a)=$ valor obtido através da distribuição Normal intervalo de confiança de $95 \%-z($ alfa $)=1,96$ 


$$
\begin{aligned}
& p=\text { proporção esperada } \\
& d=\text { precisão da estimativa }
\end{aligned}
$$

Dessa forma, a amostra foi constituída por 288 usuários internados na Unidade de Clínica Médica e Cirúrgica da instituição cenário deste estudo.

\subsection{ASPECTOS ÉTICOS}

O projeto de pesquisa foi encaminhado à apreciação do Comitê de Ética em Pesquisa - CEP (Apêndice 1), respeitando-se os trâmites legais estabelecidos por este órgão, e à Superintendência da instituição com esclarecimentos sobre o teor e os objetivos da pesquisa (Apêndice 2).

Os usuários que atendiam aos critérios de inclusão foram esclarecidos acerca dos objetivos da pesquisa e receberam o Termo de Consentimento Livre e Esclarecido (Apêndice 3), elaborado conforme as normas da Resolução 196/96, que versa sobre os aspectos éticos em pesquisas envolvendo seres humanos (Conselho Nacional de Saúde, 1996), em duas vias para sua assinatura. Garantiu-se aos participantes, o sigilo das informações, a voluntariedade na participação e a possibilidade de interromper o preenchimento do instrumento a qualquer momento, sem penalidade alguma e sem prejuízo em seu tratamento.

Cada participante recebeu uma cópia do citado termo após sua assinatura. Este estudo não incorreu em nenhum risco de caráter físico ou psicológico ao usuário, estando o mesmo livre para optar em não participar do estudo. Quanto à instituição, foi garantido o anonimato.

Os resultados serão divulgados à instituição onde foi realizado o estudo. 


\subsection{COLETA DE DADOS}

A coleta de dados ocorreu, após anuência do CEP $^{*}$ da instituição em questão, no período de abril a julho de 2009, aplicando-se o questionário intitulado: "Satisfação de Usuários de uma Unidade de Clínica Médica e Cirúrgica" (Apêndice 4).

\subsubsection{Instrumento de coleta de dados}

O instrumento de coleta de dados constituiu-se na sua primeira parte, da caracterização sócio-demográfica e na segunda parte, das proposições, contemplando os atributos do serviço mensuráveis em uma escala de 1 a 6 (Apêndice 4).

Neste estudo o instrumento utilizado foi aquele validado por Castellanos (2002), baseado na Escala SERVQUAL, que avalia o grau de satisfação do usuário considerando cinco dimensões: confiabilidade, responsividade, tangibilidade, garantia e empatia. Neste instrumento as variáveis pesquisadas foram agrupadas em 35 atributos do atendimento. As perguntas referentes ao grau de confiança e a disposição em indicar o hospital para outros usuários não se configuram como atributos do atendimento, e sim como consequência da satisfação do usuário com o atendimento recebido.

Foi realizado um pré-teste, no intuito de verificar a pertinência do instrumento, aplicado a 20 usuários, não sendo necessária a reestruturação do mesmo.

\subsubsection{Operacionalização da coleta de dados}

A pesquisadora conferia diariamente as altas previstas e abordava os usuários convidando-os a participar do estudo, sempre esclarecendo a natureza e os objetivos da pesquisa.

\footnotetext{
* O documento de aprovação da pesquisa não se encontra anexado a esta dissertação, em virtude do compromisso de anonimato. Todavia, encontra-se em poder da pesquisadora, podendo ser solicitado quando necessário.
} 
Após aceite, os usuários eram orientados quanto ao preenchimento do questionário, sendo a primeira parte preenchida pela própria pesquisadora, referente à caracterização sócio-demográfica.

O questionário era então deixado com o usuário orientado a entregar o instrumento preenchido para a própria pesquisadora ou para um membro da equipe de enfermagem da Unidade, a qual estava ciente da natureza do estudo.

\subsection{ORGANIZAÇÃO E ANÁLISE DOS DADOS}

Os dados foram organizados e armazenados em planilha Excel ${ }^{\circledR} \mathrm{e}$ analisados por meio do processamento dos recursos de computação através do software Statistic Package for Social Sciences (SPSS) for Windows 15.0.

Inicialmente todas as variáveis foram analisadas descritivamente. Para as variáveis quantitativas, esta análise foi feita através da observação dos valores mínimos e máximos e do cálculo de médias e desvios-padrão e medianas. Para as variáveis qualitativas foram calculadas as frequências absolutas e relativas.

Para a análise da hipótese de igualdade de proporções entre os dois grupos utilizou-se o teste qui-quadrado ou o teste exato de Fisher (Rosner, 1986).

Para a comparação dos tipos de internação, em relação ao tempo de internação, foi utilizado o teste não-paramétrico de Mann-Whitney (Rosner, 1986), pois a suposição de normalidade dos dados foi rejeitada.

Para o estudo univariado de correlações entre constructos e satisfação, utilizou-se o coeficiente de correlação de Pearson, e para o estudo multivariado, o modelo de regressão linear múltiplo.

Com o objetivo de selecionar os principais constructos que se associavam com satisfação, foi utilizado o processo de seleção "stepwise" (Rosner, 1986).

O nível de significância utilizado para os testes foi de $5 \%$. 


\subsection{CARACTERIZAÇÃO DOS PARTICIPANTES}

Os resultados apresentados a seguir caracterizam os participantes deste estudo quanto ao gênero, faixa etária, escolaridade, tipo de internação, especialidade em que foi internado e convênio utilizado.

$\mathrm{Na}$ variável gênero verifica-se que $147(51 \%)$ usuários eram do sexo masculino e 141 (49\%) do sexo feminino.

Em relação à faixa etária, os usuários estão entre 18 a 88 anos (média de 41,42 anos, desvio-padrão de 16,84 anos e mediana de 39 anos).

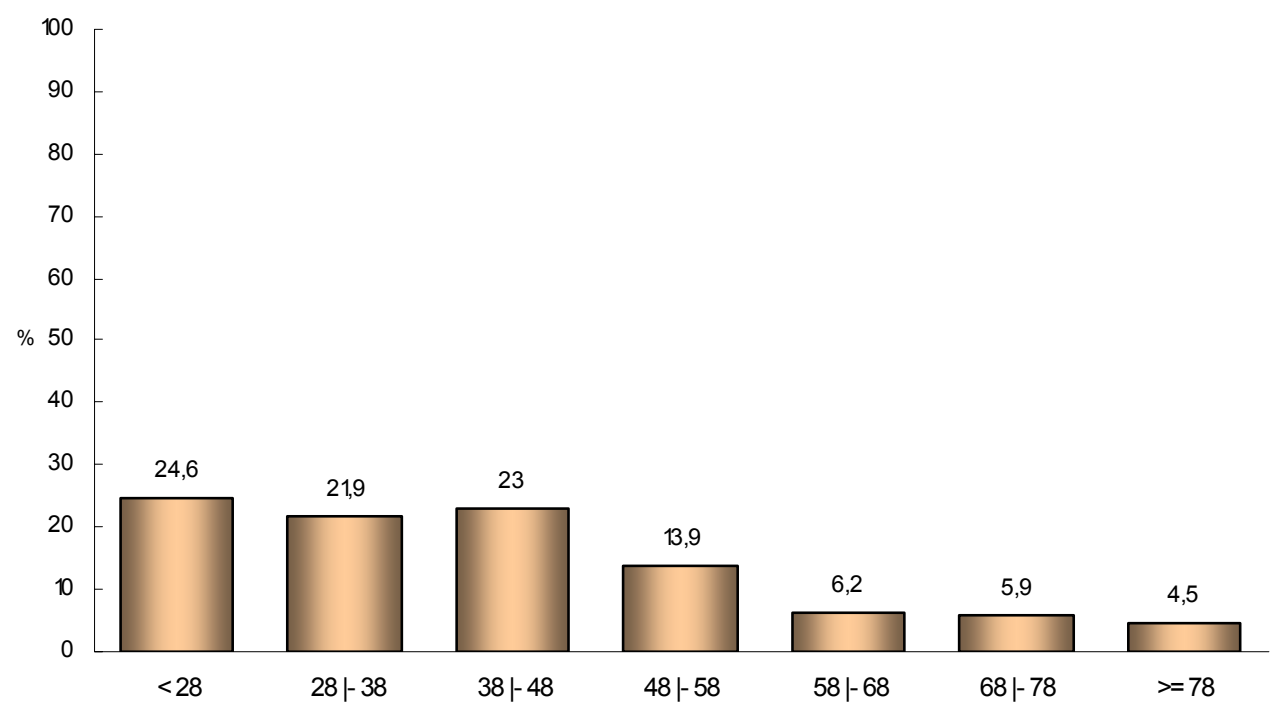

Figura 3 - Distribuição dos usuários segundo a faixa etária, São Paulo (Interior de SP) 2009

Observa-se, na Figura 3, que a idade predominante encontra-se na faixa etária abaixo de 28 anos, representada por 71 (24,6\%) usuários, seguido de $66(23 \%)$ usuários, com idade entre 38 a 48 anos e $63(21,9 \%)$ entre 28 a 38 anos, evidenciando a predominância de jovens e adultos jovens na composição da amostra.

Nas projeções realizadas pelo Instituto Brasileiro de Geografia e Estatística (IBGE) em 2008, é esperado para a população brasileira um aumento da população idosa, como consequência do declínio nas taxas de 
fecundidade e mortalidade. Em 2030, de acordo com tais projeções, o número de idosos superará o de crianças e adolescentes (IBGE, 2009).

A mudança no perfil demográfico tem sido intensamente investigada e retratada nas pesquisas realizadas pelo IBGE, bem como amplamente discutida em seminários e congressos de especialistas em estudos da população, nos quais a discussão da nova realidade demográfica brasileira é cada vez mais urgente, no sentido dessas questões serem levadas em consideração no planejamento e reformulação das políticas social, econômica e de saúde.

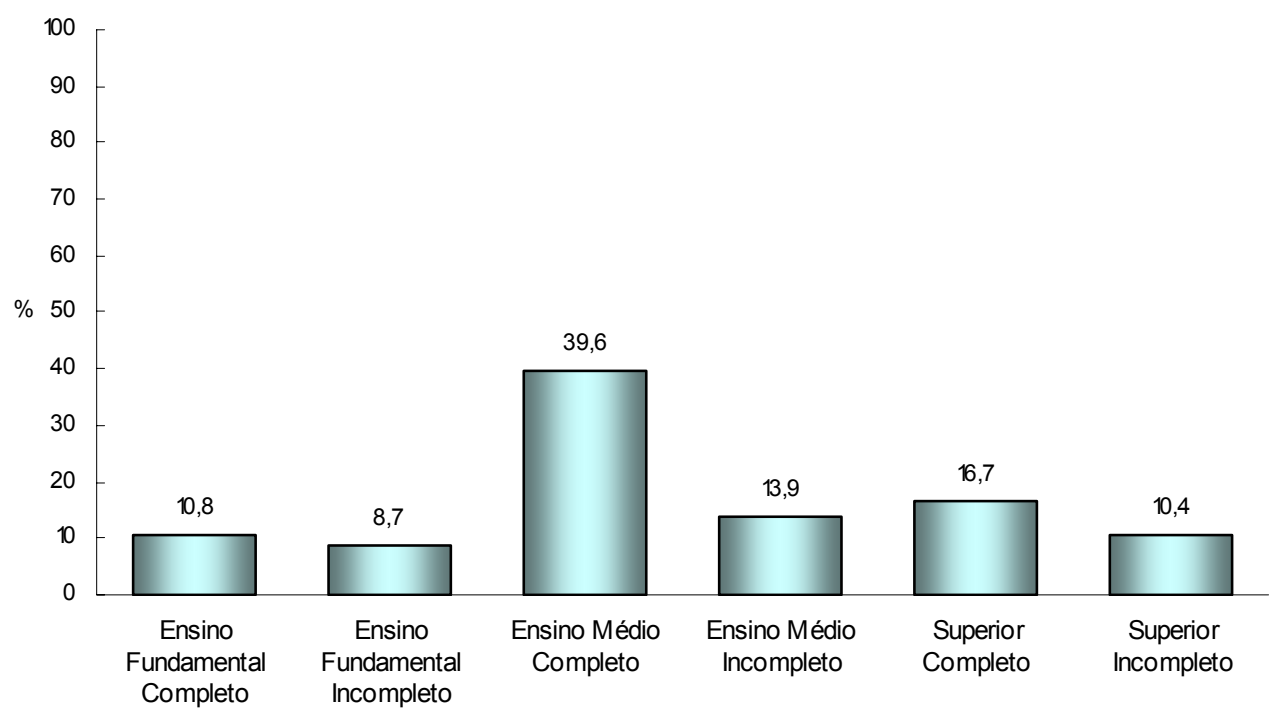

Figura 4 - Distribuição dos usuários segundo a escolaridade, São Paulo (Interior de SP) 2009

$\mathrm{Na}$ Figura 4 pode-se notar que a metade da amostra possui o ensino médio completo (incluindo ensino superior incompleto), totalizando 144 (50\%) participantes. O número de 48 (16,7\%) participantes com ensino superior completo é também bastante expressivo comparado ao cenário atual da educação no Brasil. Dados do IBGE (2009) demonstram que apenas $20 \%$ da população brasileira têm acima de 11 anos de escolaridade, o que equivale ao ensino médio completo ou mais.

No entanto, estudos apresentados pela Ernst \& Young, FGV (2006), prevêem que a escolaridade média da população brasileira em idade ativa, 
entre 15 e 64 anos, deverá passar de 7,4 anos completos para 9,3 anos de estudo, um crescimento de $1,5 \%$ ao ano até 2020 .

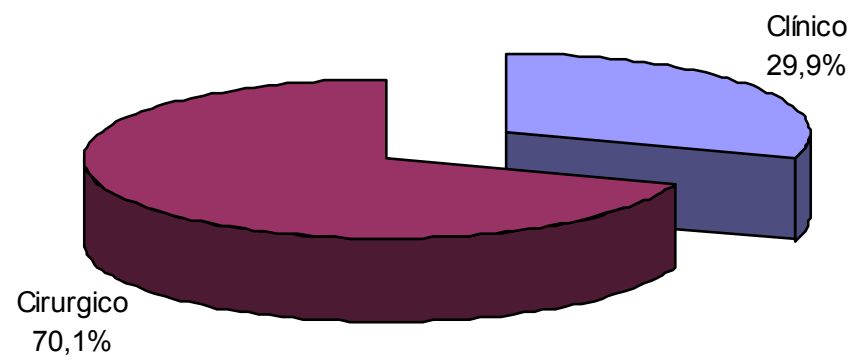

$\square$ Clínico $\square$ Cirurgico

Figura 5 - Distribuição dos usuários segundo o tipo de internação, São Paulo (Interior de SP) -2009

A Figura 5 demonstra que o perfil das internações na instituição em questão é predominantemente cirúrgico, totalizando $202 \quad(70,1 \%)$ participantes.

Tal resultado corrobora com um estudo realizado por Castro, Travassos e Carvalho (2002) que analisa os fatores associados a internações hospitalares no Brasil, onde os atendimentos cirúrgicos tiveram maior percentual de internação em estabelecimentos privados, não SUS, cobertos por planos de saúde, nos quais o usuário classificou o atendimento recebido como "muito bom".

Observa-se também a correlação entre o tipo de internação e a faixa etária dos usuários, pois a amostra pesquisada constitui-se, em sua maioria, de jovens e adultos jovens, o que justifica a predominância de procedimentos cirúrgicos. 
Tabela 1 - Distribuição dos usuários segundo a especialidade, São Paulo (Interior de SP) 2009

\begin{tabular}{lcc}
\hline \multicolumn{1}{c}{ Especialidade } & $\mathrm{n}$ & $\%$ \\
\hline Cabeça e pescoço & 3 & 1,0 \\
Cardiologia & 14 & 4,8 \\
Cirurgia cardíaca & 6 & 2,0 \\
Cirurgia geral & 19 & 6,6 \\
Cirurgia torácica & 2 & 0,7 \\
Cirurgia vascular & 17 & 6,6 \\
Clínica geral & 43 & 14,9 \\
Coloproctologia & 14 & 4,8 \\
Gastrocirurgia & 62 & 21,5 \\
Gastroclínica & 5 & 1,7 \\
Hemodinâmica & 17 & 5,9 \\
Neurocirurgia & 7 & 2,4 \\
Ortopedia & 34 & 11,8 \\
Otorrinolaringologia & 5 & 1,7 \\
Cirurgia plástica & 16 & 5,5 \\
Reumatologia & 2 & 0,7 \\
Urologia & 9 & 3,0 \\
Vascular & 6 & 2,0 \\
Outros & 7 & 2,4 \\
\hline Total & 288 & 100,0 \\
\hline
\end{tabular}

Segundo a Tabela 1, as especialidades com maior número de internações foram Gastrocirurgia com 62 (21,5\%) internações, Clínica geral com $43(14,9 \%)$, Ortopedia com $34(11,8 \%)$ internações e Cirurgia Geral com 19 (6,6\%) internações, observando-se predomínio das internações para as especialidades cirúrgicas.

No estudo de Castro, Travassos e Carvalho (2002) foram encontrados os seguintes motivos de internação referidos pelos usuários: tratamento clínico $(53,8 \%)$; parto $(20,4 \%$, sendo $41,7 \%$, relativo a esse item, por cesariana); cirurgia $(21,8 \%)$; tratamento psiquiátrico $(1,7 \%)$; exames $(2,3 \%)$. O coeficiente de internação clínica foi de $3,8 \%$ e de cirúrgica foi de $1,5 \%$. Os coeficientes de internação foram maiores para as mulheres $(8,7 \%)$ em comparação aos homens $(5,1 \%)$ e bastante semelhantes para áreas urbanas $(7 \%)$ e rurais $(6,7 \%)$. O SUS financiou $63,1 \%$ das internações e os planos de saúde $24,6 \%$. O atendimento recebido foi considerado bom ou muito bom por $87,3 \%$ dos usuários. Os usuários que se internaram referiram maior número de doenças crônicas, pior estado de saúde, pior estado funcional, maior restrição nas atividades habituais e ter estado acamado por 
motivos de saúde. Os fatores que facilitaram a internação desses usuários foram: dispor de cobertura por plano de saúde e ter um serviço de saúde do qual se faz uso regular.

Ademais, em 2007, a proporção de internações hospitalares, por especialidade, foi de 37,72\% para Cirurgia, 23,68\% para Clínica Médica, 20,86\% para Obstetrícia, 13,57\% para Pediatria, 3,26\% em Psiquiatria e $0,88 \%$ para outras especialidades, totalizando 3.314 .326 internações (DATASUS, 2009), demonstrando uma diminuição das internações clínicas em relação ao estudo apresentado anteriormente. Esses dados refletem a demanda hospitalar, que por sua vez é condicionada pela oferta de serviços no SUS, porém não expressa necessariamente o quadro nosológico da população residente. Entretanto, o Sistema de informação DATASUS não contempla as informações sobre internações de usuários com planos de saúde, dificultando a comparação dos dados.

Confirmando tal constatação, Malta et al (2004) ressaltam que trabalhar com dados epidemiológicos na avaliação dos estabelecimentos de convênios privados e de particulares não é uma prática na saúde suplementar, sendo que não existe sistematização de avaliação da qualidade do desempenho dos estabelecimentos da rede conveniada. Ainda discorrem sobre o desafio de implantar um sistema de informação baseado em: dados individuais capturados de forma contínua; avaliação de série histórica; comparação entre o desempenho dos prestadores; possíveis surgimentos de agravos inusitados que necessitam de acompanhamento; notificação obrigatória; e tudo aquilo que subsidie a tomada de decisão. Essa discussão deve ser enfrentada pelo Ministério da Saúde e Agência Nacional de Saúde Suplementar (ANS), visando à implantação das bases de dados similares ao SUS com registros individualizados de todos os usuários ou o Sistema de Informação da Saúde Suplementar.

Assim, percebe-se que a concentração de internações em determinados grupos de causas sugere correlações com os contextos econômicos e sociais. A redução das desigualdades sociais, através da elaboração de políticas públicas, poderia melhorar o acesso aos serviços 
hospitalares, contribuindo de forma positiva na equidade do consumo desses serviços no Brasil.

Tabela 2 - Distribuição dos usuários segundo convênio utilizado, São Paulo (Interior de SP) $-2009$

\begin{tabular}{lcc}
\hline Convênios & $\mathrm{n}$ & $\%$ \\
\hline $\mathrm{A}$ & 20 & 6,9 \\
$\mathrm{~B}$ & 12 & 4,0 \\
$\mathrm{C}$ & 3 & 1,0 \\
$\mathrm{D}$ & 1 & 0,3 \\
$\mathrm{E}$ & 13 & 4,5 \\
$\mathrm{~F}$ & 2 & 0,7 \\
$\mathrm{G}$ & 2 & 0,7 \\
$\mathrm{H}$ & 8 & 2,7 \\
$\mathrm{I}$ & 2 & 0,7 \\
$\mathrm{~J}$ & 4 & 1,4 \\
$\mathrm{~K}$ & 4 & 1,4 \\
$\mathrm{~L}$ & 2 & 0,7 \\
$\mathrm{M}$ & 1 & 0,3 \\
$\mathrm{~N}$ & 210 & 73,4 \\
$\mathrm{O}$ & 1 & 0,3 \\
$\mathrm{P}$ & 1 & 0,3 \\
Particular & 2 & 0,7 \\
\hline Total & 288 & 100,0 \\
\hline & &
\end{tabular}

Conforme Tabela 2, $286(99,3 \%)$ usuários são atendidos pelos convênios e $2(0,7 \%)$ são particulares, sendo o convênio "N" o mais expressivo, representado por $210(73,4 \%)$ usuários.

Gerschman et al (2007) apontam que a dificuldade de acesso ao atendimento do serviço público de saúde leva uma grande parcela dos cidadãos a procurar os planos de saúde, muitas vezes sem dispor de recursos financeiros para o pagamento da saúde privada. Esses indivíduos ficam preocupados com as deficiências do sistema de saúde público e temem ficar vulneráveis às mesmas.

Cabe ressaltar que a maioria da população brasileira ainda é atendida pelo SUS, que é o responsável pela maior parte dos procedimentos de alta complexidade realizados no país. Enquanto a população brasileira gira em torno de 191,5 milhões de habitantes (IBGE, 2009) estima-se que no Brasil haja mais de 40 milhões de usuários, vinculados a algum tipo de Plano Privado de Assistência à Saúde (ANS, 2008), ou seja, 21\% do total da população brasileira. 
A Tabela 3 apresenta o tipo de internação e a média de tempo para cada uma delas. Pode se observar que os grupos diferem em relação ao tempo de permanência na referida unidade, sendo que o grupo cirúrgico apresenta valores significativamente maiores que o do grupo clínico. A média das internações clínicas foi de 6,29 dias, com mediana de cinco dias e das internações cirúrgicas foi de 12,85 dias, com mediana de 6,27.

Tabela 3 - Valores de média, desvio-padrão, mediana, mínimo e máximo do tempo de internação (em dias) segundo a unidade de internação, São Paulo (Interior de SP) - 2009

\begin{tabular}{cccccccc}
\hline Tipo de internação & $\mathrm{n}$ & Média & $\mathrm{dp}$ & Mediana & Mínimo & Máximo & $\mathrm{p}^{*}$ \\
\hline Clínica & 86 & 6,29 & 5 & 5 & 1 & 20 & $<0,001$ \\
Cirúrgica & 202 & 12,85 & 6,27 & 15 & 1 & 20 & \\
\hline
\end{tabular}

${ }^{*}$ ) nível descritivo de probabilidade do teste não-paramétrico de Mann-Whitney

Castro, Travassos e Carvalho (2002) encontraram em seu estudo, tempo médio de permanência de 6,5 dias para internações clínicas e de 6,8 dias para cirúrgicas. Comparados a este estudo, a média para as internações clínicas mostra-se equivalente, porém o tempo para as internações cirúrgicas é evidentemente maior, chegando quase ao dobro do número de dias.

Esse resultado opõe-se ao esperado, que seria menor tempo de permanência para procedimentos cirúrgicos, em relação às internações clínicas, principalmente pela lógica de trabalho dos convênios. Porém, analisando tais dados, pode se supor que essas médias sejam explicadas pela complexidade dos procedimentos cirúrgicos realizados, pelas internações clínicas que se transformam em cirúrgicas após resolução do caso, ou, até mesmo, as complicações decorrentes de tais procedimentos. 


\subsection{CLASSIFICAÇÃO DOS ATRIBUTOS DO ATENDIMENTO DE ACORDO COM O MODELO AVALIATIVO DE PARASURAMAN, ZEITHAML E BERRY}

Para a obtenção dos níveis de satisfação dos participantes, foram pesquisados 36 atributos do atendimento, classificados de acordo com o modelo avaliativo proposto por Parasuraman, Zeithaml e Berry (1985). Dentre esses atributos quatro correspondiam à equipe médica, oito à equipe de enfermagem, oito ao serviço de nutrição, oito a atributos gerais, um ao serviço social e sete ao atendimento inicial.

As questões referentes ao grau de confiança, intenção em indicar o hospital e satisfação geral foram avaliadas separadamente dos atributos do atendimento.

Os atributos de atendimento foram agrupados de acordo com as dimensões da qualidade, sendo onze atributos pertencentes à dimensão tangibilidade, cinco à dimensão confiabilidade, oito à dimensão responsividade, cinco à dimensão garantia e sete à empatia.

Segundo Parente (2000), o grau de satisfação depende da diferença entre o serviço real e o serviço esperado. O grau "satisfeito" é definido quando o serviço real é mais que o esperado. "Insatisfeito" ocorre quando o serviço real é menor que o esperado, ou seja, quando o usuário encontra situações que causam desapontamento ou frustração. "Nem satisfeito nem insatisfeito" ocorre quando o serviço real equivale ao esperado.

Em relação à apresentação dos resultados optou-se por definir como "nível de satisfação" a somatória das respostas "muito" e "totalmente satisfeito". Dessa maneira, a somatória do restante das respostas representa o "nível de insatisfação".

Assim, o nível de satisfação resultou das respostas "muito satisfeito" adicionado às respostas "totalmente satisfeito" e o nível de insatisfação resultou da soma das respostas "pouco satisfeito", "muito insatisfeito" e "totalmente insatisfeito". 
O Quadro 2, a seguir, apresenta os 36 atributos do atendimentos e os respectivos percentuais de satisfação, bem como a dimensão da qualidade correspondente:

Quadro 2 - Atributos de atendimento segundo dimensão, São Paulo (Interior de SP) 2009

\begin{tabular}{|c|c|c|}
\hline Atributos do Atendimento & $\%$ & Dimensão \\
\hline 1 Atenção-interesse da equipe médica & 92 & Empatia \\
\hline 2 Educação da equipe médica & 95,8 & Garantia \\
\hline 3 Empenho da equipe médica & 94,1 & Responsividade \\
\hline 4 Explicações-orientações da equipe médica & 90,3 & Responsividade \\
\hline 5 Atenção-interesse da equipe de enfermagem & 94,4 & Empatia \\
\hline \begin{tabular}{|ll}
6 & Educação da equipe de enfermagem \\
\end{tabular} & 96,2 & Garantia \\
\hline 7 Empenho da equipe de enfermagem & 92,7 & Responsividade \\
\hline \begin{tabular}{|ll}
8 & Explicações-orientações da equipe de enfermagem \\
\end{tabular} & 91,7 & Responsividade \\
\hline 9 Cuidados prestados pela equipe de enfermagem & 96,2 & Confiabilidade \\
\hline 10 Tempo de espera para atender o usuário quando este toca a campainha & 80,2 & Responsividade \\
\hline 11 Qualidade geral da enfermagem que atende durante o dia & 94,8 & Confiabilidade \\
\hline 12 Qualidade geral da enfermagem que atende durante a noite & 95,8 & Confiabilidade \\
\hline 13 Atendimento da nutricionista (se houve contato) & 76,2 & Empatia \\
\hline 14 Qualidade-sabor da comida & 83 & Tangibilidade \\
\hline 15 Aparência-apresentação da comida & 85,6 & Tangibilidade \\
\hline 16 Temperatura da comida & 81,7 & Tangibilidade \\
\hline 17 Quantidade da comida & 87,7 & Tangibilidade \\
\hline 18 Variedade na comida & 82,7 & Tangibilidade \\
\hline 19 Regularidade nos horários em que a comida é servida & 92,7 & Responsividade \\
\hline 20 Atenção da copeira que serve a comida & 94 & Empatia \\
\hline 21 Conforto do quarto & 89,6 & Tangibilidade \\
\hline 22 Limpeza do quarto & 92,4 & Tangibilidade \\
\hline 23 Instalações do banheiro do quarto & 87,2 & Tangibilidade \\
\hline 24 Nível de barulho à noite para dormir & 81,6 & Tangibilidade \\
\hline 25 Respeito à privacidade do usuário durante a internação & 95,1 & Empatia \\
\hline 26 Resultado do tratamento-cirurgia a que o usuário se submete & 95,8 & Confiabilidade \\
\hline 27 Orientação para continuidade do tratamento em casa, pós-alta & 96,2 & Garantia \\
\hline 28 Orientação para alimentação em casa, pós-alta & 92,3 & Garantia \\
\hline $\begin{array}{l}29 \text { Atendimento do serviço social durante o período em que esteve internado (a) se teve } \\
\text { contato. }\end{array}$ & 89,5 & Empatia \\
\hline $\begin{array}{l}30 \text { Facilidade de localização do balcão ou pessoa a qual se dirigir logo que entra no } \\
\text { hospital }\end{array}$ & 89,6 & Tangibilidade \\
\hline 31 Tempo de espera para conseguir atendimento inicial & 75,3 & Responsividade \\
\hline $\begin{array}{l}32 \text { Cortesia ou educação da pessoa que recebe o usuário para preencher os dados da } \\
\text { internação }\end{array}$ & 94,4 & Garantia \\
\hline 33 Rapidez do preenchimento dos dados iniciais & 89,2 & Responsividade \\
\hline 34 Clareza das informações que o usuário recebe no atendimento inicial & 89,2 & Empatia \\
\hline 35 Organização geral desse atendimento inicial & 86,5 & Confiabilidade \\
\hline $\begin{array}{l}6 \text { Conforto (instalações, poltronas, água, banheiros, etc) que o hospital oferece ao usuário } \\
\text { enquanto este espera pela internação }\end{array}$ & 85,8 & Tangibilidade \\
\hline
\end{tabular}


A Figura 6, assim como o Quadro 2, demonstra os níveis de satisfação dos usuários, referentes aos 36 atributos do atendimento. Os atributos dividem-se da seguinte forma: de 1 a 4 referem-se à equipe médica; 5 a 12 à equipe de enfermagem; 13 a 20 ao serviço de nutrição; 21 a 28 atributos gerais; 29 ao serviço social e 30 a 36 ao atendimento inicial.

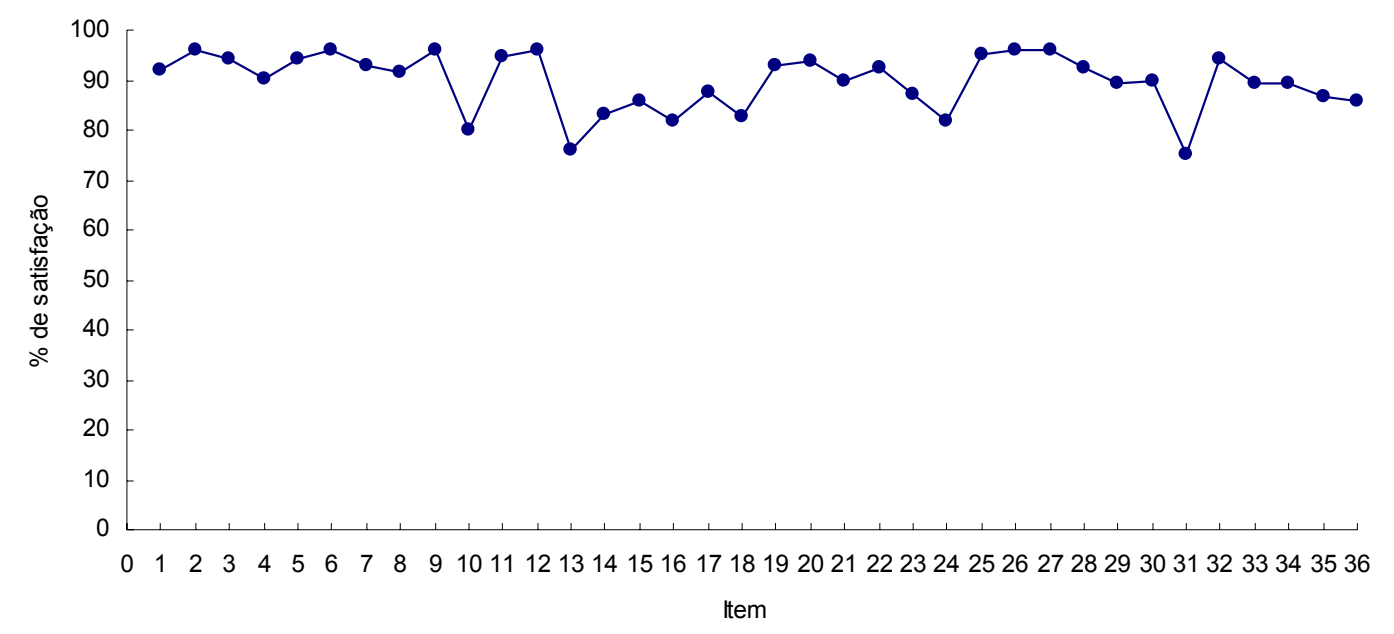

Figura 6 - Distribuição dos níveis de satisfação dos usuários por atributos, São Paulo (Interior de SP) - 2009

Os atributos com maior índice de satisfação foram: educação da equipe de enfermagem com 277 (96,2\%), cuidados prestados pela equipe de enfermagem com 277 (96,2\%), qualidade geral da enfermagem que atende durante a noite com 276 (95,8\%), orientação para continuidade do tratamento 277(96,2\%), educação da equipe médica com 276 (95,8\%) usuários, resultado do tratamento ou cirurgia com 276 (95,8\%).

Os atributos que tiveram impacto negativo foram: atendimento da nutricionista com $112(76,2 \%)$ usuários e tempo de espera para conseguir atendimento inicial com $217(75,3 \%)$ usuários, ambos com os menores índices de satisfação.

Dentre os atributos que causaram maior satisfação estão aqueles pertencentes às dimensões garantia e confiabilidade. Já os atributos que causaram insatisfação se enquadram nas dimensões empatia e responsividade. A dimensão tangibilidade não se destacou dentre os atributos com maior ou menor satisfação. 
No estudo de Castellanos (2002), os maiores índices de satisfação, tanto para gerentes como para usuários, encontram-se naqueles referentes à equipe de enfermagem, que tem como dimensão predominante a confiabilidade. Os menores índices de satisfação referem-se a atributos do atendimento inicial tais como rapidez, organização do atendimento e conforto das instalações, atributos estes que estão inseridos na dimensão tangibilidade.

Cruz (2008) constatou que a dimensão de maior relevância para sua amostra foi a garantia $(95,9 \%)$, seguida da confiabilidade $(95,7 \%)$ e a menos relevante foi a tangibilidade $(88 \%)$.

Observa-se convergência dos três estudos no que diz respeito à importância dada pelos usuários para as dimensões garantia e confiabilidade, para o alto padrão de qualidade dos serviços em questão.

Esses resultados confirmam os achados prévios de Parasuraman, Zeithaml e Berry (1991) de que a confiabilidade é a dimensão mais importante e a tangibilidade, a menos relevante para a elevada qualidade do serviço.

Na seqüência, o Quadro 3 permite a visualização dos níveis de satisfação dos usuários segundo o tipo de internação. Pode-se notar que o maior índice de satisfação nas internações clínicas foi referente à atenção da copeira com $83(96,4 \%)$ usuários e o menor índice, o tempo de espera para atender a campainha com 61 (70,9\%), enquanto que nas internações cirúrgicas observou-se maior índice de satisfação no item educação da equipe de enfermagem, representado por 197 (97,5\%) usuários e menor índice de satisfação em relação ao atendimento da nutricionista com 77 (77\%) usuários. 
Quadro 3 - Atributos de atendimento segundo tipo de internação e dimensão, São Paulo (Interior de SP) - 2009

\begin{tabular}{|c|c|c|c|}
\hline Atributos do Atendimento & $\begin{array}{c}\text { Clínica } \\
\%\end{array}$ & $\begin{array}{c}\text { Cirúrgica } \\
\%\end{array}$ & Dimensão \\
\hline 1 Atenção-interesse da equipe médica & 89,5 & 93,1 & Empatia \\
\hline 2 Educação da equipe médica & 94,2 & 96,5 & Garantia \\
\hline 3 Empenho da equipe médica & 93 & 94,6 & Responsividade \\
\hline 4 Explicações-orientações da equipe médica & 91,9 & 89,6 & Responsividade \\
\hline 5 Atenção-interesse da equipe de enfermagem & 93 & 95,1 & Empatia \\
\hline \begin{tabular}{|ll}
6 & Educação da equipe de enfermagem
\end{tabular} & 93 & 97,5 & Garantia \\
\hline \begin{tabular}{|ll}
7 & Empenho da equipe de enfermagem
\end{tabular} & 91,9 & 93,1 & Responsividade \\
\hline 8 Explicações-orientações da equipe de enfermagem & 88,4 & 93,1 & Responsividade \\
\hline 9 Cuidados prestados pela equipe de enfermagem & 94,2 & 97 & Confiabilidade \\
\hline 10 Tempo de espera para atender o usuário quando este toca a campainha & 70,9 & 84,2 & Responsividade \\
\hline 11 Qualidade geral da enfermagem que atende durante o dia & 94,2 & 95,1 & Confiabilidade \\
\hline 12 Qualidade geral da enfermagem que atende durante a noite & 94,2 & 96,5 & Confiabilidade \\
\hline 13 Atendimento da nutricionista (se houve contato) & 74,5 & 77 & Empatia \\
\hline 14 Qualidade-sabor da comida & 78,6 & 84,9 & Tangibilidade \\
\hline 15 Aparência-apresentação da comida & 81 & 87,6 & Tangibilidade \\
\hline 16 Temperatura da comida & 79,8 & 82,5 & Tangibilidade \\
\hline 17 Quantidade da comida & 88,1 & 87,5 & Tangibilidade \\
\hline 18 Variedade na comida & 83,3 & 82,5 & Tangibilidade \\
\hline 19 Regularidade nos horários em que a comida é servida & 94 & 92,3 & Responsividade \\
\hline 20 Atenção da copeira que serve a comida & 96,4 & 93 & Empatia \\
\hline 21 Conforto do quarto & 93 & 88,1 & Tangibilidade \\
\hline 22 Limpeza do quarto & 93 & 92,1 & Tangibilidade \\
\hline 23 Instalações do banheiro do quarto & 90,7 & 85,6 & Tangibilidade \\
\hline 24 Nível de barulho à noite para dormir & 82,6 & 81,2 & Tangibilidade \\
\hline 25 Respeito à privacidade do usuário durante a internação & 95,4 & 95,1 & Empatia \\
\hline 26 Resultado do tratamento-cirurgia a que o usuário se submete & 92,9 & 97 & Confiabilidade \\
\hline 27 Orientação para continuidade do tratamento em casa, pós-alta & 97,7 & 95,5 & Garantia \\
\hline 28 Orientação para alimentação em casa, pós-alta & 91,6 & 92,5 & Garantia \\
\hline $\begin{array}{l}29 \text { Atendimento do serviço social durante o período em que esteve } \\
\text { internado (a) se teve contato. }\end{array}$ & 86,4 & 90,8 & Empatia \\
\hline $\begin{array}{l}30 \text { Facilidade de localização do balcão ou pessoa a qual se dirigir logo } \\
\text { que entra no hospital }\end{array}$ & 83,7 & 92,1 & Tangibilidade \\
\hline 31 Tempo de espera para conseguir atendimento inicial & 73,3 & 76,2 & Responsividade \\
\hline $\begin{array}{l}32 \text { Cortesia ou educação da pessoa que recebe o usuário para preencher } \\
\text { os dados da internação }\end{array}$ & 94,2 & 94,6 & Garantia \\
\hline 33 Rapidez do preenchimento dos dados iniciais & 89,5 & 89,1 & Responsividade \\
\hline 34 Clareza das informações que o usuário recebe no atendimento inicial & 89,5 & 89,1 & Empatia \\
\hline 35 Organização geral desse atendimento inicial & 87,2 & 86,1 & Confiabilidade \\
\hline $\begin{array}{l}36 \text { Conforto (instalações, poltronas, água, banheiros, etc) que o hospital } \\
\text { oferece ao usuário enquanto este espera pela internação }\end{array}$ & 84,9 & 86,1 & Tangibilidade \\
\hline
\end{tabular}


A Figura 7 exibe os níveis de satisfação por atributos segundo o tipo de internação e destaca os atributos onde foi encontrada diferença estatística significante entre os usuários internados para tratamento clínico e cirúrgico.

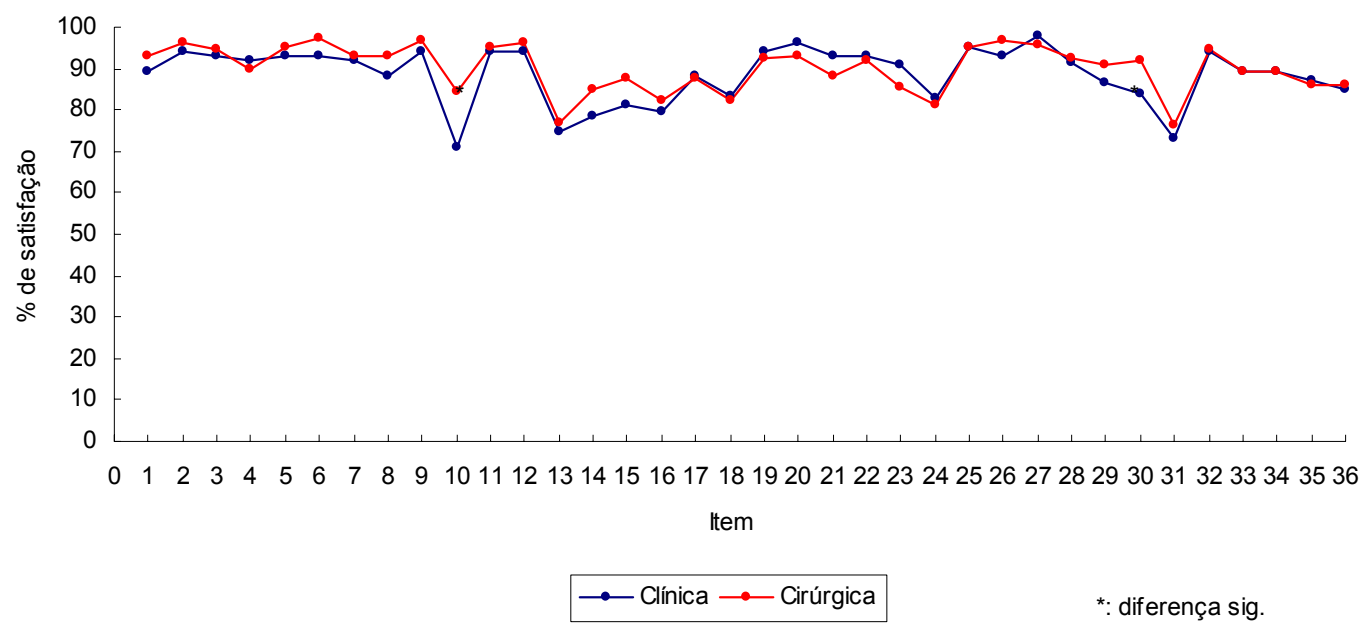

Figura 7 - Distribuição dos níveis de satisfação dos usuários por atributos segundo tipo de internação, São Paulo (Interior de SP) - 2009

No atributo "tempo de espera para atender a campainha" $61(70,9 \%)$ usuários internados para tratamento clínico demonstram-se satisfeitos com este item, enquanto que dentre os usuários internados para tratamento cirúrgico o número cresce para 170 (84,2\%) usuários satisfeitos. Evidenciase que os usuários clínicos demonstram-se mais insatisfeitos do que os cirúrgicos. Supõe-se que usuários internados para tratamento clínico tendem a ter idade mais avançada e ser mais dependentes, enquanto que os cirúrgicos são mais jovens e requerem menos auxílio para suas atividades. Portanto, para os usuários do primeiro grupo esse atributo pode ter peso maior e consequentemente menor faixa de tolerância.

O segundo caso de divergência refere-se ao atributo "facilidade de localização do balcão ou pessoa a qual se dirigir logo que entra no hospital", pois, enquanto $72(83,7 \%)$ usuários internados para tratamento clínico mostram-se satisfeitos, $186(92,1 \%)$ usuários cirúrgicos referem sua satisfação. Novamente os usuários clínicos ratificam-se menos satisfeitos com o serviço do que os cirúrgicos, provavelmente pelos mesmos motivos descritos acima. 


\subsubsection{Análise da satisfação dos usuários relacionados aos atributos dos cinco constructos avaliados}

\section{Equipe médica}

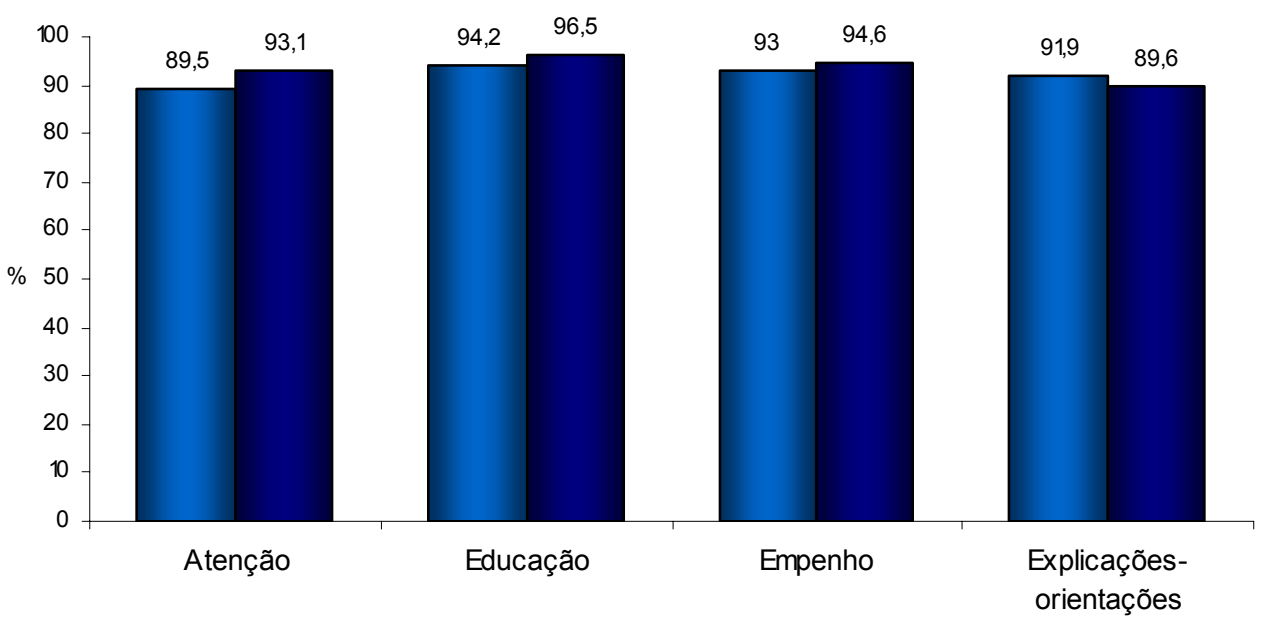

口 Internação clínica $\mathbf{Q}$ Internação cirúrgica

Figura 8 - Distribuição do grau de satisfação dos usuários em relação aos itens da equipe médica segundo o tipo de internação, São Paulo (Interior de SP) - 2009

Na Figura 8 pode-se observar que o constructo "equipe médica" é um dos que apresenta os maiores níveis de satisfação obtidos nesta pesquisa. Nos seguintes atributos a equipe cirúrgica apresenta maior índice de satisfação: atenção com 188 (93,1\%) usuários, educação com 195 (96,5\%) e empenho com 191 (94,6\%) usuários satisfeitos. No atributo explicaçõesorientações, a clínica médica apresenta 79 (91,9\%) usuários satisfeitos, porcentagem discretamente maior que a da equipe cirúrgica com 181 $(89,6 \%)$ de usuários satisfeitos.

Quando se comparam os níveis de satisfação entre os tipos de internação clínica e cirúrgica, denotam-se maiores níveis de satisfação entre os usuários submetidos a procedimentos cirúrgicos. Neste estudo, tais usuários apresentaram maior tempo de internação em relação aos usuários clínicos e, portanto, maior tempo de convívio com o médico, podendo formar suas opiniões baseados nesse tempo de convívio. 
No entanto, através da análise estatística, observamos que não há diferença significativa entre os tipos de internação em relação à satisfação dos itens da equipe médica.

Para alguns autores, os modelos de avaliação não refletem a relação médico-usuário, pois os usuários apresentam-se sempre numa atitude passiva frente ao serviço. Tais modelos são pautados no seguinte esquema: "Os usuários chegam ao serviço com os objetivos, os médicos fazem algo pelos objetivos (ou não); um satissímetro (satisometer) registra o resultado". Não é problematizado se os usuários participam de forma ativa no processo de avaliação para influenciar sua própria satisfação (Carr-Hill, 1992; Aspinal et al, 2003).

Todavia, é sabido que a relação médico-usuário está entre os principais determinantes da satisfação, assim como as características dos usuários (incluindo as sócio-demográficas; as expectativas desses sobre a consulta médica e seu estado de saúde); as características dos profissionais que prestam o atendimento (incluindo traços da personalidade, qualidade técnica e a arte do cuidado) e os fatores estruturais e ambientais, incluindo o acesso, forma de pagamento, tempo de tratamento, marcação de consulta e outros (Espiridião, Trad, 2006).

Em pesquisa realizada numa operadora de planos de saúde do Rio Grande do Sul (RS), observou-se que a equipe médica foi, em ordem de importância, o terceiro atributo citado pelos usuários como relevante para sua satisfação. Evidenciaram-se aspectos intimamente relacionados aos profissionais médicos, confirmando a noção empírica de que os usuários, quando necessitam escolher ou manter a preferência por um determinado médico, avaliam questões como segurança e confiança, as quais estão fundamentadas na percepção de competência profissional e/ou resolubilidade de tratamentos anteriores, mesmo que em outras especialidades (Milan, Trez, 2005).

Em outro estudo sobre a qualidade de cuidados de saúde, realizado com médicos da Austrália, Estados Unidos, Grã-Bretanha e Nova Zelândia foi constatado que a maioria dos médicos pesquisados relataram que, para o aprimoramento da qualidade, são necessárias reformas para que eles 
tenham mais tempo com os usuários, porém apenas $33 \%$ a $44 \%$ dos inquiridos concordavam que as avaliações feitas pelos usuários poderiam contribuir para melhorar a qualidade. Isso mostra a dificuldade da equipe médica em acolher o feedback dos usuários, apesar do interesse em dedicar-lhes mais tempo (Blendon et al, 2001).

Percebe-se que a relação médico-usuário está intimamente ligada a satisfação e a qualidade dos serviços de saúde, influenciando também, de forma positiva, no estado de saúde dos usuários, o que confirma a necessidade de uma comunicação mais estreita e aberta entre ambos. Pode-se afirmar que o desempenho da equipe médica é um dos principais fatores que contribuem para a fidelização do usuário.

Cruz (2008) encontrou resultados semelhantes em sua pesquisa, tendo a equipe cirúrgica atingido maior nível de satisfação nos atributos educação (93\%) e empenho (93\%) e discreto predomínio sobre a clínica médica no atributo explicações-orientações (97\%).

\section{Equipe de enfermagem}

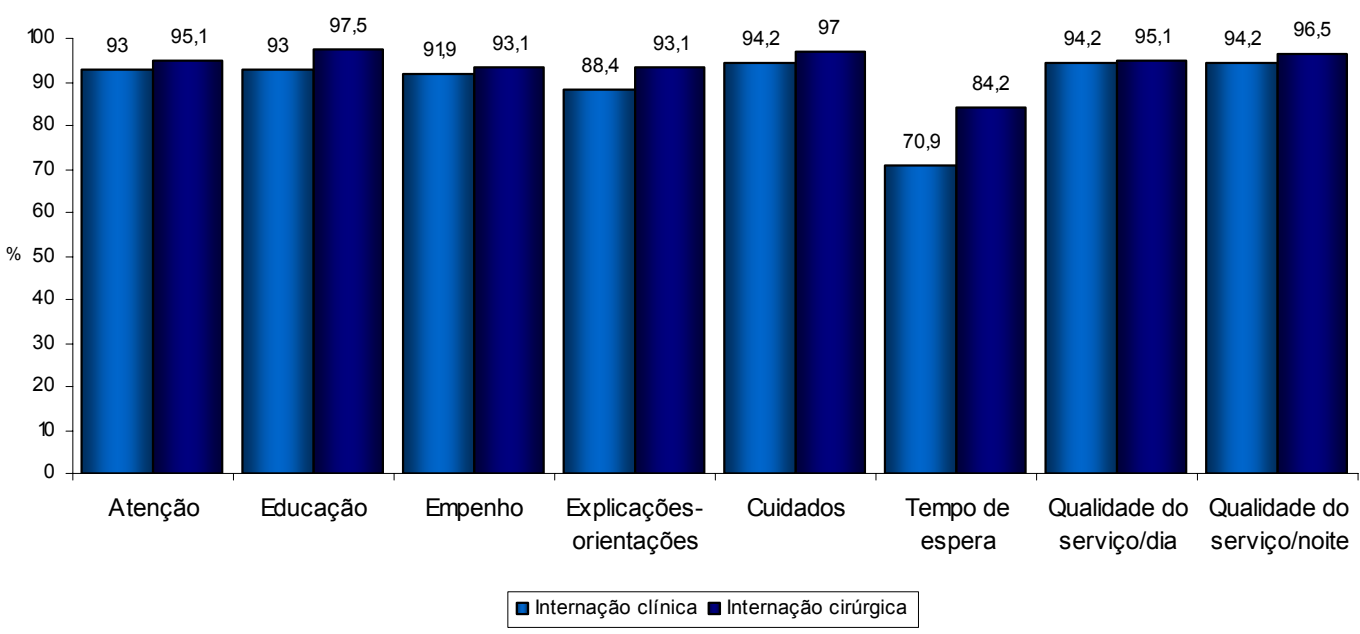

Figura 9 - Distribuição do grau de satisfação dos usuários em relação aos itens da equipe de enfermagem segundo o tipo de internação, São Paulo (Interior de SP) - 2009

Na Figura 9, evidencia-se o elevado grau de satisfação dos usuários em relação à equipe de enfermagem, segundo o tipo de internação. No atributo "educação da equipe de enfermagem" observou-se 197 (97,5\%) usuários satisfeitos, em "cuidados prestados pela enfermagem" houve 196 
(97\%) usuários e a "qualidade do serviço de enfermagem da noite" atingiu $195(96,5 \%)$ usuários cirúrgicos satisfeitos. No entanto, vale destacar o item "tempo de espera para atender a campainha", que apresenta 61 (70,9\%) usuários clínicos satisfeitos e 170 (84,2\%) usuários cirúrgicos, sendo esse o menor índice de satisfação dentre todos os itens. Observa-se também uma diferença estatística significativa entre os tipos de internação em relação à satisfação. Os usuários das internações clínicas apresentam satisfação significativamente menor que os da unidade cirúrgica.

Segundo a hipótese formulada por Parasuraman, Zeithaml e Berry (1991), em qualidade de serviços, deve existir uma associação inversa entre importância e tolerância, no sentido de que quanto maior a importância atribuída pelo usuário à determinada dimensão da qualidade, mais estreita deve ser a faixa de tolerância correspondente.

Frente a isso, pode-se afirmar que o atributo "tempo de espera para atender a campainha", pautado na dimensão responsividade, é de extrema importância para os usuários. Tal atributo merece uma análise diferenciada por parte dos responsáveis pelo serviço, instigando reflexões e análises das causas de tal descontentamento. Cabem aqui várias discussões: o dimensionamento do pessoal de enfermagem está adequado à realidade assistencial dessa Unidade? Existe monitoramento da taxa de absenteísmo? Qual é o tempo mínimo de espera considerado aceitável para atender a campainha?

$\mathrm{Na}$ avaliação dos Serviços de Enfermagem, os aspectos pontuados pelos manuais dos programas de Acreditação Hospitalar, habitualmente, partem de dados sobre satisfação do usuário, dados de mortalidade, restauração da saúde, informações dadas antes da alta ou cuidados no retorno aos hábitos diários, como se esses critérios de resultado fossem suficientes para a avaliação da qualidade assistencial.

Referindo-se ao contexto hospitalar, Zeithaml e Bitner (2000) afirmam que os encontros com a equipe de enfermagem são mais importantes para predizer satisfação do que aqueles com o pessoal de outros serviços.

Parece oportuno lembrar que a maioria das interações do usuário hospitalizado ocorre com a equipe de enfermagem, uma vez que essa 
equipe permanece continuamente ao seu lado, ao longo de todo o período da internação, enquanto que as demais categorias desenvolvem atividades parcelares devido às características de seu trabalho.

Feldman e Cunha (2006) verificaram escassez de estudos sobre avaliação dos serviços de saúde, especificamente sobre resultados da assistência ou indicadores de resultado para avaliação da qualidade, sobretudo dos serviços de enfermagem.

A qualidade da assistência de enfermagem é um conceito amplo e difícil de mensurar, pois sobre esse atributo incidem uma ampla gama de fatores. Considera-se que a satisfação do usuário com o cuidado recebido é somente uma medida da qualidade funcional do cuidado, porque a qualidade técnica do que está sendo fornecido seria difícil de ser avaliada pelo usuário (Waltz, Strickland, Lenz, 2004).

Contudo, estudos internacionais como os de Hiidenhovi, Nojonem, Laippala (2002); Staniszewska, Henderson (2004) e Currie et al (2005) e nacionais como os de Castellanos (2002) e Cruz (2008) apontam altos índices de satisfação do usuário com o cuidado recebido da equipe de enfermagem.

Tal fato pode ser explicado por Ayres (2004) que se fundamenta nas proposições de que o cuidado transcende o âmbito técnico do atendimento ou do nível de atenção em saúde, embora represente a materialidade das relações interpessoais, que se estabelecem nesse campo e, portanto, as impressões desse cuidado derivam das percepções e expectativas dos usuários.

Visualiza-se, ainda, uma clara interface com o pressuposto da humanização, que se refere ao plano das relações intersubjetivas processadas nas práticas sociais referidas ao campo da saúde; nesse caso a relação cuidador-usuário, tendo como fundamento a capacidade de simbolização e construção de sentidos em relação.

Discorrer sobre humanização e integralidade no cuidado em saúde e refletir sobre a incorporação desses princípios ao campo da avaliação, implica reconhecer e considerar a centralidade dos processos simbólicos e práticas discursivas dos atores envolvidos, em especial dos usuários, 
compreendendo, sobretudo, o que para eles significa qualidade, um objeto ontologicamente distinto para aqueles que se submetem à quantificação. (Bosi, Uchimura, 2007).

\section{Serviço de Nutrição}

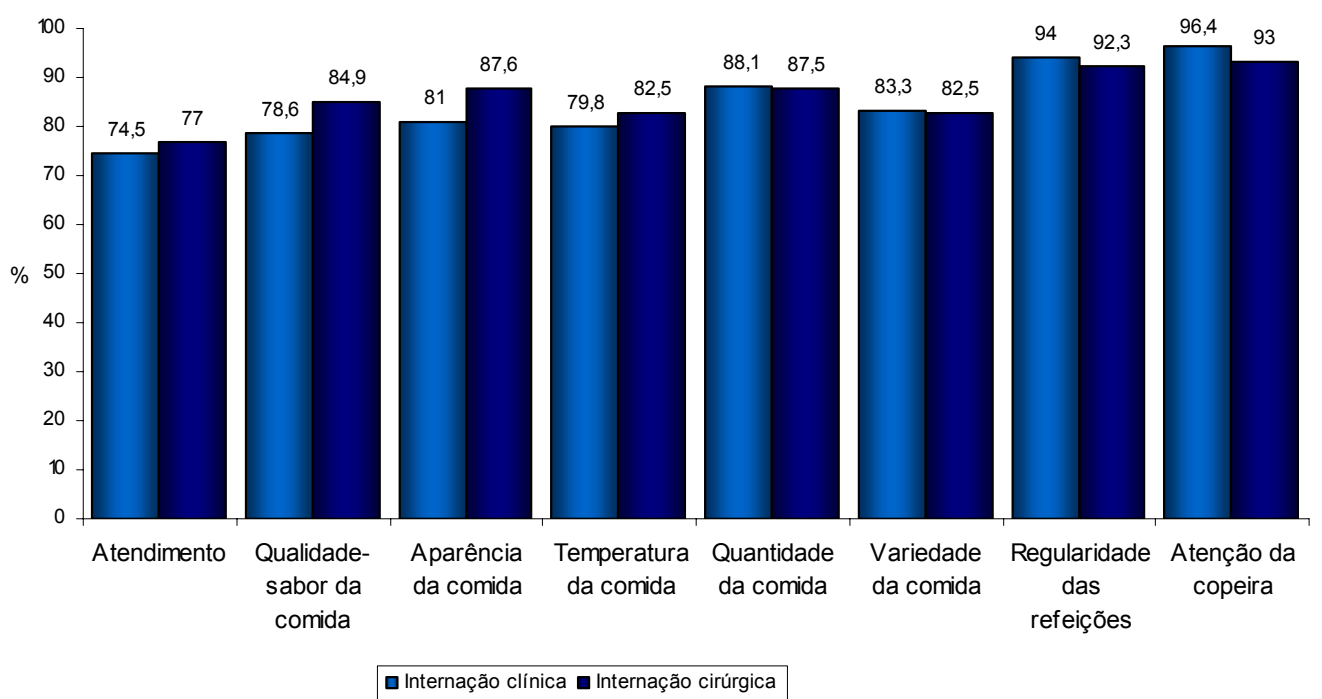

Figura 10 - Distribuição do grau de satisfação dos usuários em relação aos itens da equipe de nutrição segundo o tipo de internação, São Paulo (Interior de SP) - 2009

A Figura 10 apresenta os resultados referentes à satisfação dos usuários em relação aos atributos da equipe de nutrição, sendo que o item com menor nível de satisfação refere-se ao "atendimento da nutricionista" com 35 (74,5\%) usuários clínicos e 77 (77\%) usuários cirúrgicos, seguido por "temperatura da comida", respectivamente com índices de satisfação de 69 (79,8\%) e 166 (82,5\%). Vale lembrar que 141 (49\%) usuários não tiveram contato com a nutricionista durante sua internação, provavelmente por se tratar de internações com tempo de permanência reduzido.

Esses resultados corroboram com estudo de Cruz (2008), que identificou os menores níveis de satisfação nos atributos do serviço de nutrição, sendo que o atendimento da nutricionista apresentou nível de satisfação de $76 \%$, semelhante ao deste estudo. Além disso, a qualidade e o sabor da dieta e a sua variedade alcançaram $77 \%$ e $84,5 \%$ de níveis de satisfação, respectivamente. 
Ressalta-se que a alimentação é extremamente importante e, muitas vezes, vital para o restabelecimento dos usuários. A dieta hospitalar tem como objetivos garantir o aporte de nutrientes ao usuário internado, para preservar ou recuperar seu estado nutricional, e também apresenta papel co-terapêutico, por auxiliar na adaptação ao período de internação (Garcia, 2006).

Segundo Nonino-Borges et al (2006), apesar da disponibilidade de alimentos, uma boa parte dos usuários pode ingerir uma quantidade insuficiente para o suprimento de suas necessidades, devido aos aspectos clínicos, oferta insuficiente de alimentos, rejeição de alimentos por falta de sabor, falta de porções menores e energicamente mais densas para grupos especiais e a prescrição de dietas muito restritas.

Nesse cenário, cabe ressaltar a importância da relação nutricionistausuário, para o conhecimento das preferências e expectativas do usuário frente ao serviço de nutrição, contribuindo para a escolha de um cardápio mais adequado às suas necessidades.

Nonino-Borges et al (2006) apontam, ainda, para a relevância da interdisciplinaridade, pois entendem que a equipe de atendimento ao usuário deve ser estimulada a trabalhar efetivamente e em conjunto. Isso significa a tomada da consciência, por parte dos gestores, da importância do trabalho de cada categoria, em prol do melhor tratamento do usuário. É obvio que esse objetivo só pode ser atingido com um número adequado de profissionais em cada unidade, possibilitando a prescrição da dieta e a revisão do cuidado nutricional.

Ademais, o contexto nacional é desfavorável ao desenvolvimento da assistência nutricional a partir da abordagem interdisciplinar, visto que o número de nutricionistas, na maioria dos hospitais, ainda é inferior às suas necessidades.

Cabe ressaltar que na referida instituição existem sete nutricionistas para atendimentos dos 350 leitos, sendo uma delas responsável pela chefia do Serviço de Nutrição e Dietética.

A Lei 8234 que regulamenta a profissão de nutricionista não trata da proporção de profissionais versus número de leitos hospitalares (Brasil, 
1991), no entanto, tramita no Senado um Projeto de Lei que visa preencher tais lacunas.

O Projeto de Lei $6819^{*}$ estabelece que a jornada de trabalho do nutricionista não poderá exceder trinta horas semanais. Quanto ao número de profissionais, os hospitais, clínicas, ambulatórios gerais e congêneres devem ter em seu quadro de funcionários um nutricionista por até trinta leitos ou usuários, com tolerância de até sete leitos ou usuários acima desse limite. Para hospitais, clínicas e ambulatórios especializados esse número passa a ser de um nutricionista para cada quinze leitos ou usuários, com tolerância de até três leitos ou usuários acima do limite.

De acordo com tal projeto, o número adequado de nutricionistas para o referido hospital seria de doze nutricionistas, no mínimo, considerando a proporção de um nutricionista para cada 30 leitos. Portanto, o número de profissionais é inferior ao preconizado refletindo de forma negativa na satisfação do usuário, podendo causar prejuízos à assistência.

\section{Atributos gerais}
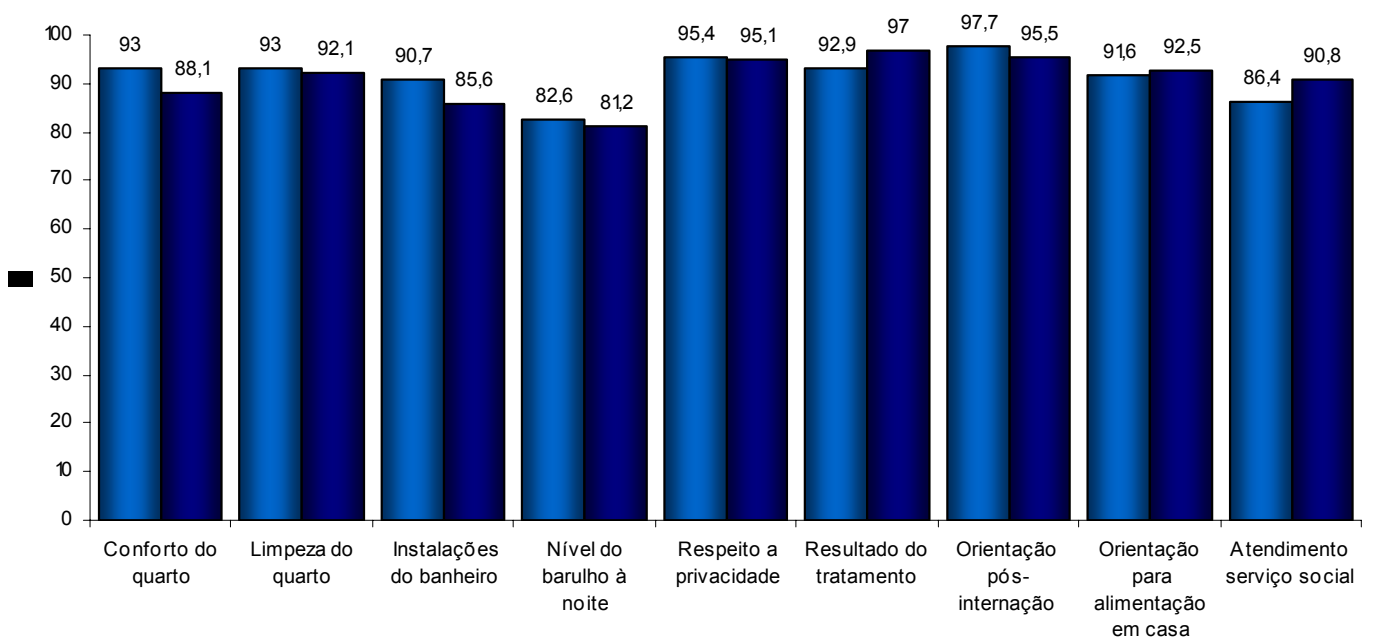

- Internação clínica Internação cirúrgica

Figura 11 - Distribuição do grau de satisfação dos usuários em relação aos atributos gerais segundo o tipo de internação, São Paulo (Interior de SP) - 2009

\footnotetext{
* Projeto de Lei 6819, de 10 de fevereiro de 2010, altera a Lei 8234 de 17 de setembro de 1991 para dispor sobre a jornada e condições de Trabalho dos Nutricionistas.
} 
Observa-se, na Figura 11, altos índices de satisfação com relação aos atributos gerais, tanto para os usuários clínicos como os cirúrgicos.

Os itens "conforto do quarto", "limpeza do quarto", "instalações do banheiro" e "nível do barulho à noite" referem-se, basicamente, aos aspectos de estrutura física do serviço, pertencentes à dimensão tangibilidade, sendo melhor pontuados pelos usuários de internação clínica.

O atributo "nível de barulho à noite" é o que possui menor pontuação na categoria com $71(82,6 \%)$ usuários clínicos e 164 (81,2\%) usuários cirúrgicos.

Os itens "resultado do tratamento", "orientação para alimentação em casa" e "atendimento do serviço social", pertencentes respectivamente, às dimensões confiabilidade, garantia e empatia apresentaram maiores índices de satisfação nos usuários cirúrgicos.

Melleiro et al (2009) analisaram a qualidade da assistência de enfermagem em unidades pediátricas na percepção do usuário e com enfoque especial para os aspectos referentes à estrutura, como os recursos humanos, as acomodações e o conforto dos acompanhantes. As dimensões de processo e resultado também foram avaliadas, porém a dimensão com escore menos favorável foi a de estrutura, evidenciada pelo índice de insatisfação de $84,4 \%$ dos acompanhantes. Os autores ressaltam que tal resultado pode ser decorrente das dificuldades enfrentadas pelos gerentes de instituições públicas no que tange à alocação de recursos financeiros, humanos, materiais e físicos.

Segundo Azevedo (1991); Moreno Júnior e Zucchi (2005), a análise de estrutura que se constitui na ênfase dos sistemas brasileiros de classificação e análise de hospitais, foi sempre tratada com relativa superficialidade pelos autores americanos, desde os critérios da Joint Commission on Accreditation of Healthcare Organizations (JCAHO) até os trabalhos de Donabedian e outros autores que tratam do problema da avaliação dos serviços. Prova disso é que nos estudos de Donabedian $(1980,1985)$ existe pouco mais do que um parágrafo dedicado ao tema estrutura. 
Infere-se que, na avaliação de serviços em países industrializados, a pouca consideração da estrutura deve-se ao fato de seus estabelecimentos de saúde apresentarem níveis de qualidade de planta física e de equipamentos bastante razoáveis, situação distinta da que ocorre no Brasil, até mesmo nas instituições privadas.

No entanto, estudos recentes apontam para o interesse de organizações norte-americanas quanto aos aspectos estruturais e seu impacto para a qualidade do cuidado (Coile Jr, 2001; Varni et at, 2004).

O atributo "orientação pós-internação" alcançou os maiores níveis de satisfação com 84 (97,7\%) usuários clínicos e 193 (95,5\%) cirúrgicos. Este atributo refere-se à dimensão confiabilidade, que é considerada a mais importante nos estudos de Parasuraman, Zeithaml e Berry (1991).

As orientações dadas ao usuário, pós-alta, garantem o sucesso de seu tratamento e recuperação, o que consequentemente diminui as reinternações. Tal princípio é observado no cenário atual da assistência hospitalar, onde há uma tendência de reduzir o número de leitos e de hospitais, exceto em casos específicos.

De acordo com Vecina Neto e Malik (2007), a tendência é criar escalas econômicas mais adequadas para serviços com maior complexidade, com concentração de tecnologia, tanto em equipamentos quanto em processos. Isso aponta para o fim dos pequenos hospitais, salvo em especialidades e condições especiais (centros de excelência com sua própria demanda). Também se observa a necessidade pela busca de mais resultados. A integralidade está incorporada aos discursos de serviços públicos e privados, de prestadores e operadoras. A busca por novas formas de financiamento tem sido incessante, pois o modelo atual tem deixado os usuários insatisfeitos. Não é simples padronizar medicamentos, equipamentos, materiais de consumo, órteses e próteses, quando se está discutindo ganhos de empresas, profissionais e até operadoras de saúde. Ter todos os membros de um setor satisfeitos com os resultados faz parte de uma das grandes utopias da economia e do cenário atual. 


\section{Atendimento inicial}

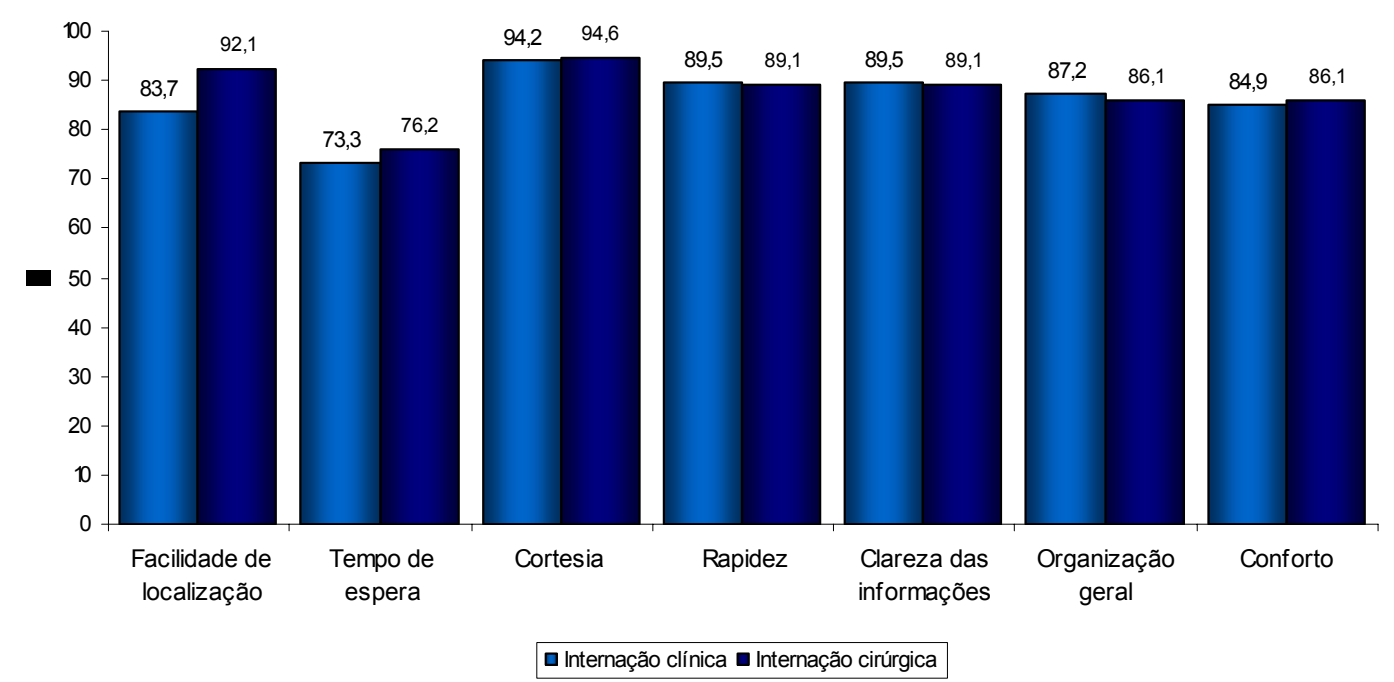

Figura 12 - Distribuição do grau de satisfação dos usuários em relação ao atendimento inicial segundo o tipo de internação, São Paulo (Interior de SP) - 2009

Pela Figura 12 observam-se níveis de satisfação elevados quanto ao item "cortesia", tanto para internações clínicas 81 (94,2\%) como cirúrgicas 191 (94,6\%). Os menores níveis de satisfação foram encontrados no item "tempo de espera para conseguir o atendimento inicial", sendo 63 (73,3\%) usuários clínicos e 154 (76,2\%) cirúrgicos. Nota-se, ainda, que há diferença significativa entre as internações em relação à satisfação, quanto à "facilidade de localização", pois $72(83,7 \%)$ usuários com internação clínica apresentam satisfação significativamente menor que 186 (92,1\%) usuários cirúrgicos.

Acesso e acolhimento são elementos essenciais para avaliação da qualidade dos serviços de saúde, pois contribuem para o retorno do usuário e para a visibilidade do serviço. A conjugação de fatores facilitadores do acesso e/ou acolhimento propicia a satisfação do usuário com o atendimento, determinando a escolha do serviço e estabelecendo, frequentemente, um bom vínculo expresso através de um longo tempo de uso (Ramos, Lima, 2003).

Quanto ao tempo de espera, averigua-se que é um atributo bastante importante na percepção dos usuários, podendo levar à insatisfação dos mesmos. 
A constatação do tempo perdido provoca sentimentos como frustração, angústias, irritação, dentre outros, que podem interferir na avaliação do serviço por parte do usuário. Assim como a qualidade, a passagem do tempo também sofre impacto pela percepção do usuário, obtendo-se duas dimensões: uma dimensão real, que se refere ao tempo de espera efetivo e uma dimensão percebida, que está relacionada à forma como o usuário sentiu a passagem do tempo (Mrtvi, 2003).

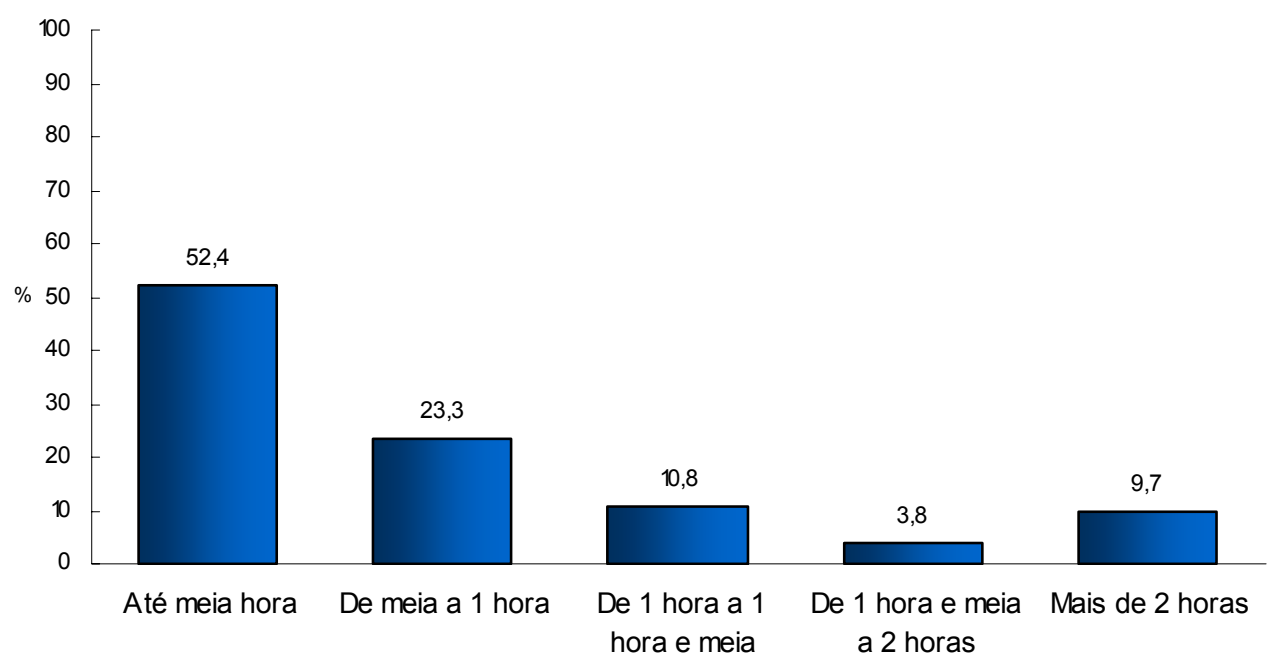

Figura 13 - Distribuição dos usuários em relação ao tempo de espera para internação, São Paulo (Interior de SP) - 2009

$\mathrm{Na}$ figura 13, observa-se que mais da metade dos usuários 151 $(52,4 \%)$ revelou tempo de espera para internação em torno de meia hora, embora esse item tenha sido um dos atributos com o menor nível de satisfação entre os dois grupos de usuários. Concomitantemente, 67 (23,3\%) usuários relataram tempo de espera entre meia e uma hora e $70(24,3 \%)$ usuários apresentaram tempo de espera maior que uma hora.

Em trabalho realizado por Mrtvi (2003), sobre o tempo de espera para consulta médica, foram entrevistados usuários, médicos e equipes de apoio de duas clínicas médicas particulares, da cidade de Londrina (PR), constatando que a percepção do tempo de espera diferiu significativamente entre os grupos pesquisados, pois enquanto $71,4 \%$ dos médicos informaram que a espera para atendimento estava entre 11 a 20 minutos, $90 \%$ dos 
funcionários da equipe de apoio e $57 \%$ dos usuários relataram que o tempo médio de espera seria de 21 a 40 minutos. Uma das explicações para as diferenças de percepção entre os médicos, as equipes de apoio e os usuários poderia estar relacionada ao fluxo de trabalho, pois os primeiros se concentram em um usuário por vez, de forma que, mesmo sendo informados dos atrasos, suas atenções estão prioritariamente voltadas para cada consulta. Os membros da equipe de apoio, no entanto, sofrem a pressão direta de usuários que questionam, dentre outros procedimentos, o cumprimento do horário. A maioria dos médicos entrevistados $(71,4 \%)$ considerou que uma espera de até 30 minutos deve ser tolerável, dada à imprevisibilidade inerente de cada consulta médica. Quanto aos profissionais de apoio, houve divergências, pois $50 \%$ deles entenderam uma espera de até 20 minutos como aceitável e $50 \%$, de até 30 minutos, sendo que $50 \%$ deles ressalvaram que o correto seria atender no horário marcado. Os usuários, porém, não se mostraram tão complacentes, pois apenas $32,8 \%$ consideraram aceitável um atraso de até 30 minutos. A maior parte deles $(57,4 \%)$ gostaria de ser atendida em até 20 minutos.

O estudo mostrou, também, que a demora no atendimento não comprometeu a avaliação da qualidade com relação ao trabalho do médico ou dos demais processos referente à prestação do serviço, embora o tempo de espera seja uma das causas mais comuns de insatisfação dos usuários revelada em alguns estudos como os de De Brun et al (2002) e Tsai et al (2007).

A sensação de que o tempo do usuário não é importante está presente na maioria dos processos de consumo. As filas e os tempos de espera são sintomáticos dessa realidade. Rotondaro e Muto (2008) destacam a pré-internação como uma das medidas adotadas na implantação de um Programa de Gestão do Atendimento a Pacientes, em um hospital da rede privada do município de São Paulo. Houve também o controle dos tempos de chamada que possibilitou ações para redistribuir a demanda, redirecionar postos e pessoas para atendimento. Tais medidas resultaram na diminuição do tempo total do processo admissional, fazendo com que o usuário despendesse menos tempo com os processos burocráticos. No 
período de 12 meses, a instituição passou de 79\% de usuários, com tempo de espera até 30 minutos e $26 \%$ com tempo de espera entre 30 minutos e 1 hora, para $97 \%$ do total dos atendimentos com espera de 30 minutos.

Assim, fica explícito que medidas simples, porém efetivas e que envolvem pouco ou nenhum custo para os gestores, podem gerar resultados extremamente positivos, contribuindo para a satisfação do usuário. 


\subsubsection{Análise das dimensões de qualidade segundo os atributos do atendimento}

\section{TANGIBILIDADE}

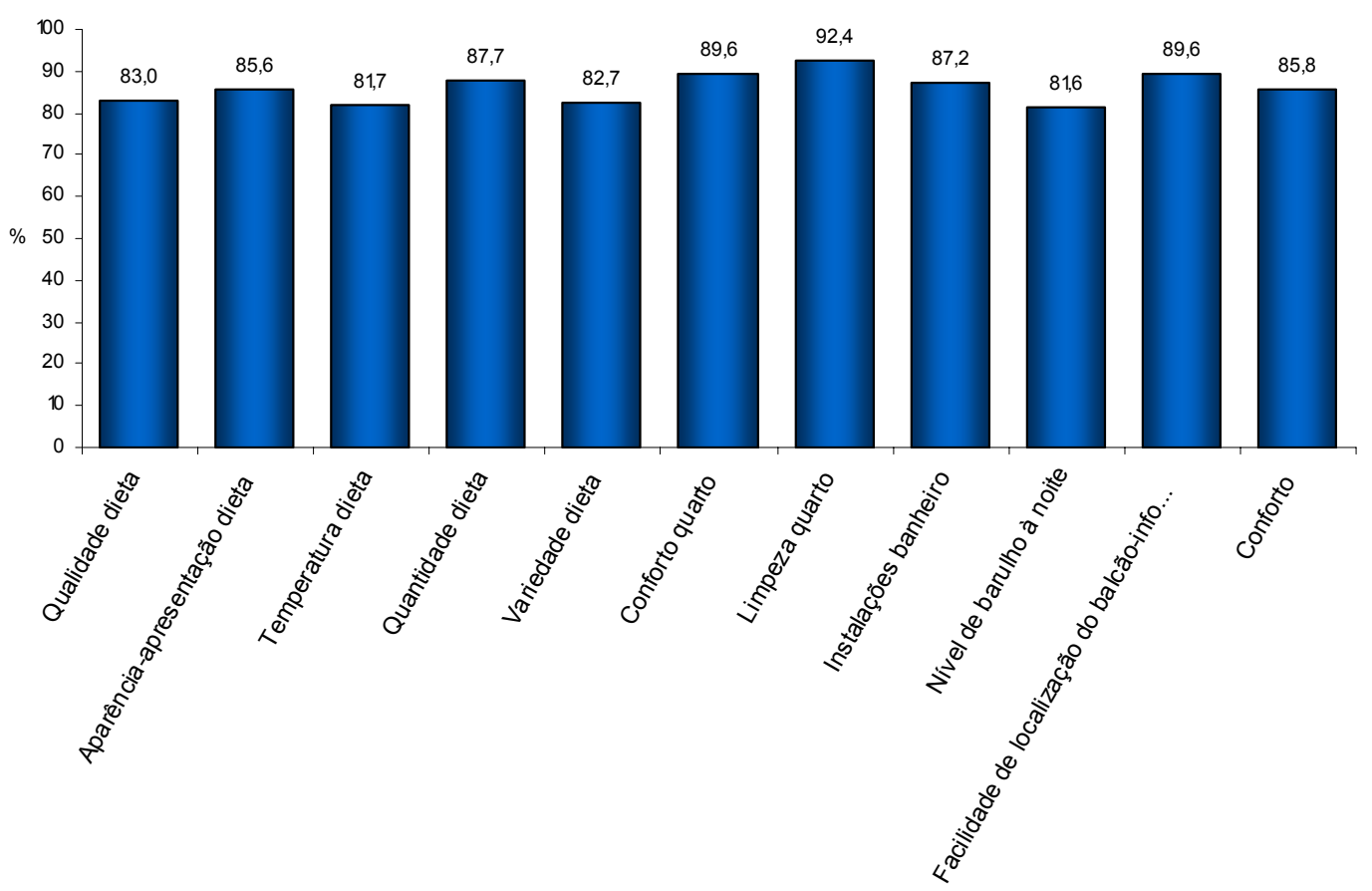

Figura 14 - Distribuição dos atributos do atendimento segundo a dimensão de qualidade Tangibilidade, São Paulo (Interior de SP) - 2009

$\mathrm{Na}$ Figura 14 evidencia-se que a dimensão tangibilidade é aquela que apresenta maior variação de satisfação entre os seus atributos. O item com avaliação mais positiva foi "limpeza do quarto" com 266 (92,4\%) usuários satisfeitos e o item com menor pontuação foi "nível de barulho à noite para dormir" com $235(81,6 \%)$ usuários.

Nessa dimensão estão incluídos os aspectos referentes à estrutura física que são comprovadamente intervenientes na recuperação dos usuários, podendo influenciar a assistência através dos aspectos ergonômicos, o nível de saúde e a própria causa da doença, ao proteger ou expor o usuário à infecção (Guelli, Zucchi, 2005).

O ambiente exerce forte influência sobre os indivíduos e pode estimular ou inibir a interação entre os envolvidos. Engloba não só o espaço físico utilizado pelas pessoas, como também as pessoas que interagem 
nesse contexto, a sua cultura, o mobiliário, o arejamento, a temperatura, os ruídos e as condições de espaço (Stefanelli, 2005).

A qualidade no processo de atenção, quando inclui a percepção do espaço pelos diferentes usuários, requer um ambiente construído "saudável" que é preconizado pelo chamado "Healing Environment", uma forma de cuidado à saúde que envolve a influência do espaço físico na recuperação do usuário (Varni et al, 2004).

O objetivo do "Healing Environment" é a criação de espaços que reduzam as fontes externas causadoras de stress proporcionando paz, esperança, motivação, alegria, reflexão e consolo para o cuidado do usuário. Este conceito propõe a otimização do entorno do cuidado com o mesmo, não só com um ambiente que lhe proporcione satisfação e possibilidade de controle, como também disponha de um sistema de suporte social, apoio aos familiares, informação ao e sobre o usuário a até a opção de medicina alternativa (Coile Jr, 2001).

Observa-se que organizações norte-americanas, como o "Center for Health Design", uma organização norte americana sem fins lucrativos focada na pesquisa e promoção do "Healthcare Design", tem desenvolvido estudos sobre a influência positiva do espaço na recuperação e satisfação dos usuários, enfatizando a importância da estrutura física no processo de qualidade das instituições, atributo até então pouco enfatizado pelos países desenvolvidos (The Center for Health Design, 2010).

No Brasil, a Resolução RDC n 50 da Agência Nacional de Vigilância Sanitária (ANVISA), em vigor desde 21 de fevereiro de 2002, dispõe sobre o regulamento técnico para planejamento, programação, elaboração e avaliação de projetos físicos de estabelecimentos assistenciais de saúde, enfatizando a preocupação com o aspecto físico e estrutural de tais instituições (Brasil, 2002).

Segundo Castellanos (2002), a dimensão tangibilidade permite avaliações mais objetivas, levando o usuário a expressar exatamente suas expectativas e percepções em relação ao serviço oferecido, o que pode explicar as variações entre os níveis de satisfação e as menores pontuações. 
Além disso, quanto maior o grau de escolaridade do usuário, menos sensível ele será para com as dimensões tangíveis. A dimensão tangível não convence o usuário, mas fatores como limpeza, areação e iluminação, quando presentes e adequados, auxiliam na decisão de escolha ou compra. Neste estudo, a escolaridade dos participantes evidenciou-se acima da média nacional, porém a avaliação feita quanto aos aspectos tangíveis revelou-se bastante criteriosa.

\section{CONFIABILIDADE}

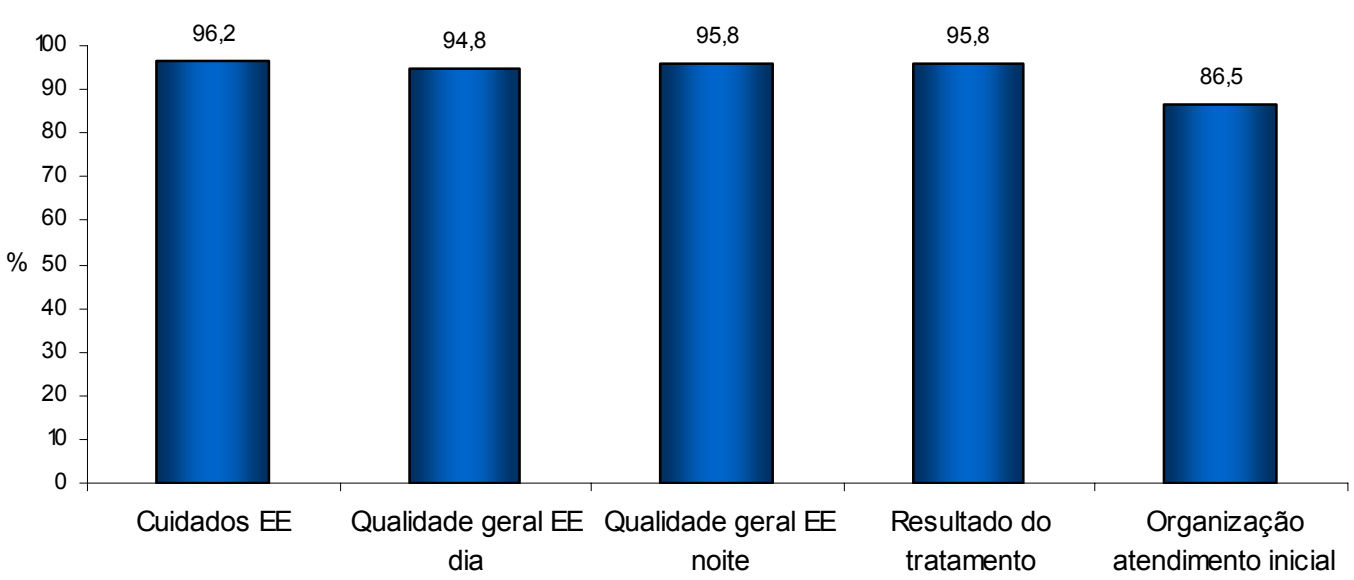

Figura 15 - Distribuição dos atributos do atendimento segundo a dimensão de qualidade Confiabilidade, São Paulo (Interior de SP) - 2009

Conforme se observa na Figura 15, os níveis de satisfação para a dimensão confiabilidade são os mais elevados entre as cinco dimensões, apresentando variação entre $277(96,2 \%)$ no item "cuidados da equipe de enfermagem" e 249 (86,5\%) no item "organização do atendimento inicial".

O consumo de ações de saúde difere do consumo de serviços em geral, pois não se operam escolhas livres no ato da decisão do consumo. $O$ usuário não se porta como um consumidor comum diante da mercadoria por ser desprovido de conhecimentos técnicos e por não deter as informações necessárias para a tomada de decisão sobre o que irá consumir. Não cabem as premissas comuns ao mercado, como a livre escolha e a concorrência. Muitas vezes, o consumo em saúde é imposto por situações de emergência, quando até a escolha do serviço e do profissional torna-se muitas vezes 
imposta por outros determinantes, como, por exemplo, a proximidade e a disponibilidade (Malta et al, 2004).

\section{RESPONSIVIDADE}

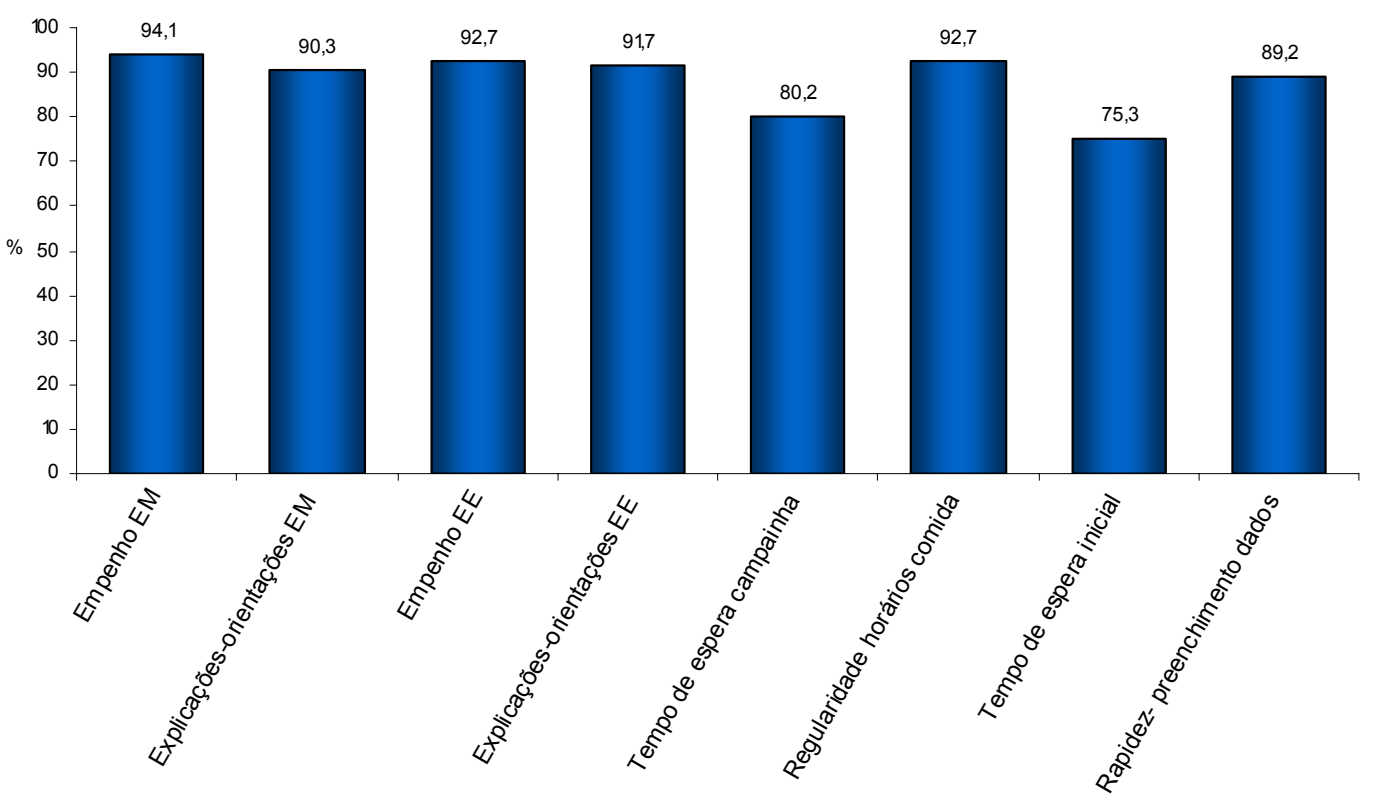

Figura 16 - Distribuição dos atributos do atendimento segundo a dimensão de qualidade Responsividade, São Paulo (Interior de SP) - 2009

Na Figura 16 nota-se que os maiores níveis de satisfação estão entre os atributos: empenho da equipe médica com 271 (94,1\%) usuários satisfeitos, empenho da equipe de enfermagem com 267 (92,7\%) usuários e regularidade nos horários da comida com 267 (92,7\%) usuários. Os atributos com menor nível de satisfação foram: tempo de espera para o atendimento inicial com $217(75,3 \%)$ usuários e tempo de espera para atender a campainha com 231 (80,2\%) usuários, evidenciando a importância do tempo para os entrevistados.

Para Vaitsman e Andrade (2005), responsividade diz respeito ao modo como o desenho do sistema de saúde reconhece e consegue responder às expectativas, universalmente legitimadas dos indivíduos, em relação aos aspectos não-médicos do cuidado. Segundo esses autores, pesquisas sobre responsividade consideram dois elementos: o primeiro é medir o que acontece quando as pessoas interagem com o sistema de 
saúde, o que implica coletar dados sobre o comportamento, evento ou ação do sistema de saúde; o segundo é medir como as pessoas atendidas pelo sistema de saúde percebem e avaliam o que acontece. Trata-se, portanto, de dois procedimentos distintos quanto ao desempenho do sistema de saúde. Uma coisa é medir o que acontece e a outra é medir a percepção das pessoas sobre o que acontece, uma vez que as pessoas podem ter uma percepção negativa ou positiva sobre o sistema de saúde, mesmo que os indicadores sobre "o que acontece" apontem o contrário.

Alguns autores, ainda, definem responsividade como uma combinação de satisfação do usuário com o modo como o sistema age (Blendon, Kim, Benson, 2001).

Tal definição alia-se ao conceito do gap 4, considerado no estudo de Parasuraman, Zeithaml e Berry $(1985,1991)$, no qual ocorre a falha quando o prestador não oferece o serviço que foi prometido ou em casos que o usuário constate que o serviço oferecido não foi tal como o anunciado.

Em pesquisa realizada com usuários de uma operadora de planos de saúde do Rio Grande do Sul (RS), onde se buscava identificar os atributos que influenciavam na sua satisfação, Millan e Trez (2005) verificaram que o constructo atendimento alcançou o maior nível de importância para os usuários, enfatizando agilidade e tempo de espera como itens requerentes de melhoria, assim como a capacitação e aperfeiçoamento dos colaboradores nos aspectos comportamentais, por exemplo, respeito e atenção aos usuários. Tais dados corroboram com as informações verificadas nessa dimensão no que diz respeito aos tempos de espera, que atingiram os menores níveis de satisfação.

Assim, quando o profissional não puder atender o usuário no momento, ele deverá esclarecê-lo e, se for urgente, solicitar, obviamente, que outro profissional $\mathrm{o}$ atenda. Quando o profissional demonstra desatenção, o usuário poderá sentir-se inferiorizado, rejeitado, assim como apresentar sentimentos de raiva, o que pode levá-lo à participação passiva no seu processo de cura. 


\section{GARANTIA}

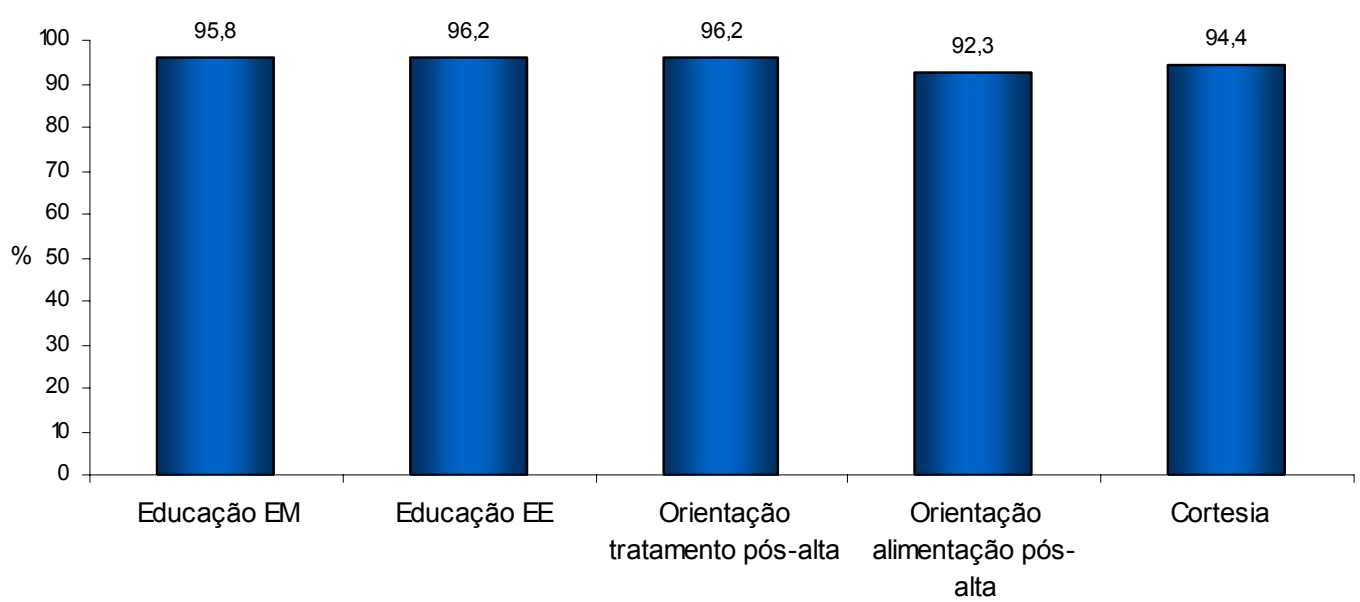

Figura 17 - Distribuição dos atributos do atendimento segundo a dimensão de qualidade Garantia, São Paulo (Interior de SP) - 2009

$\mathrm{Na}$ dimensão garantia obtêm-se níveis de satisfação elevados em relação aos itens "educação da equipe de enfermagem" com 277 (96,2\%) participantes satisfeitos e "orientação sobre tratamento pós-alta" com 277 $(96,2 \%)$ ambos com mesmo índice de satisfação, e educação da equipe médica com 276 (95,8\%) usuários satisfeitos.

A dimensão garantia é identificada como a cortesia, o conhecimento dos colaboradores e suas habilidades de transmitir confiança (Zeithaml e Parasuraman, 1990).

Em relação à equipe de enfermagem, Marquis e Huston (2005), discorrendo sobre a satisfação do usuário com os serviços de saúde, declaram que os usuários desejam cortesia, atmosfera de alegria e atitudes dos funcionários que demonstrem sua sensibilidade diante do inconveniente da hospitalização. A responsabilidade pelo atendimento dessas expectativas recai, em grande parte, sobre os cuidadores diretos que atuam no setor onde o usuário encontra-se internado, ou seja, a equipe de enfermagem.

Schaack (2003) investiga a satisfação de usuários de convênios privados internados em um Complexo Hospitalar de Porto Alegre (RS). O estudo revela que as maiores médias de satisfação estão relacionadas a aspectos do tratamento humano dos funcionários para com os usuários, sendo que os três aspectos que mais se destacam são a educação e 
cortesia da equipe médica, a cordialidade e a presteza das enfermeiras e a cordialidade dos prestadores de exames.

Assim, em relação à dimensão garantia, os estudos supracitados revelam o valor dos aspectos interpessoais como determinantes da satisfação dos usuários.

\section{EMPATIA}

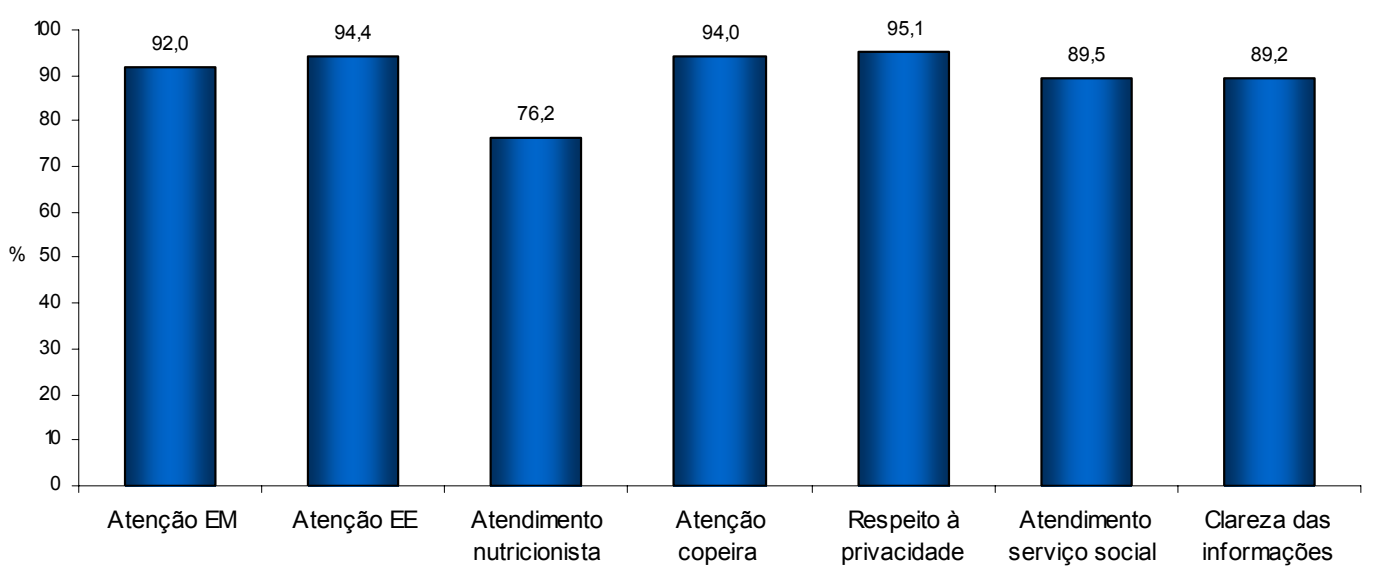

Figura 18 - Distribuição dos atributos do atendimento segundo a dimensão de qualidade Empatia, São Paulo (Interior de SP) - 2009

Na dimensão empatia os atributos melhor avaliados foram: "respeito à privacidade" com 274 (95,1\%) usuários, "atenção da equipe de enfermagem" com 272 (94,4\%) usuários e "atenção da copeira" com 271 (94\%) usuários. O atributo com menor nível de satisfação foi o "atendimento da nutricionista" com $112(76,2 \%)$ usuários satisfeitos.

Tanto do ponto de vista normativo quanto empírico, os direitos dos usuários variam de acordo com contextos culturais e sócio-políticos. São resultado do modo como se estruturam, implementam e distribuem os direitos individuais, sociais e políticos em cada contexto nacional e também do modo como se instituíram as formas de relação médico-usuário. Mesmo assim, vem se construindo crescente consenso internacional em relação aos princípios de que todo usuário deve ter direito fundamental à privacidade, confidencialidade de sua informação médica, em consentir ou recusar tratamento e ser informado sobre os riscos relevantes dos procedimentos 
médicos. Estes princípios, difundidos também pelo papel político-institucional dos organismos internacionais na construção do vocabulário e das políticas, são hoje parte das instituições de governança global (Vaitsman, Andrade, 2005) e, por isso, tão valorizados pelos usuários nesta pesquisa.

Os atributos relacionados à atenção dispensada ao usuário remetem ao conceito de humanização, objeto de distintas interpretações. Todavia, é sabido que o conceito de humanização está ligado ao paradigma dos direitos e que a cada dia surgem novas reivindicações, que se remetem à singularidade dos sujeitos. Tal paradigma vem se tornando complexo e tem se expandido, alcançando novas esferas sociais e discursivas. Visualiza-se, neste contexto, que os usuários em questão exigem maior atenção das equipes inseridas no processo de cuidado, valorizando os aspectos de atenção e atendimento ao usuário. 


\subsection{ANÁliSE DO QUESITO CONFIANÇA EM RELAÇÃO À INSTITUIÇÃO}

A confiança adquirida pelo usuário na instituição está intimamente ligada aos níveis de satisfação obtidos com relação a esse serviço.

Neste estudo, observaram-se níveis elevados de satisfação do usuário em relação à instituição pesquisada, refletindo na confiança expressa pelo usuário em utilizar e indicar o serviço em questão.

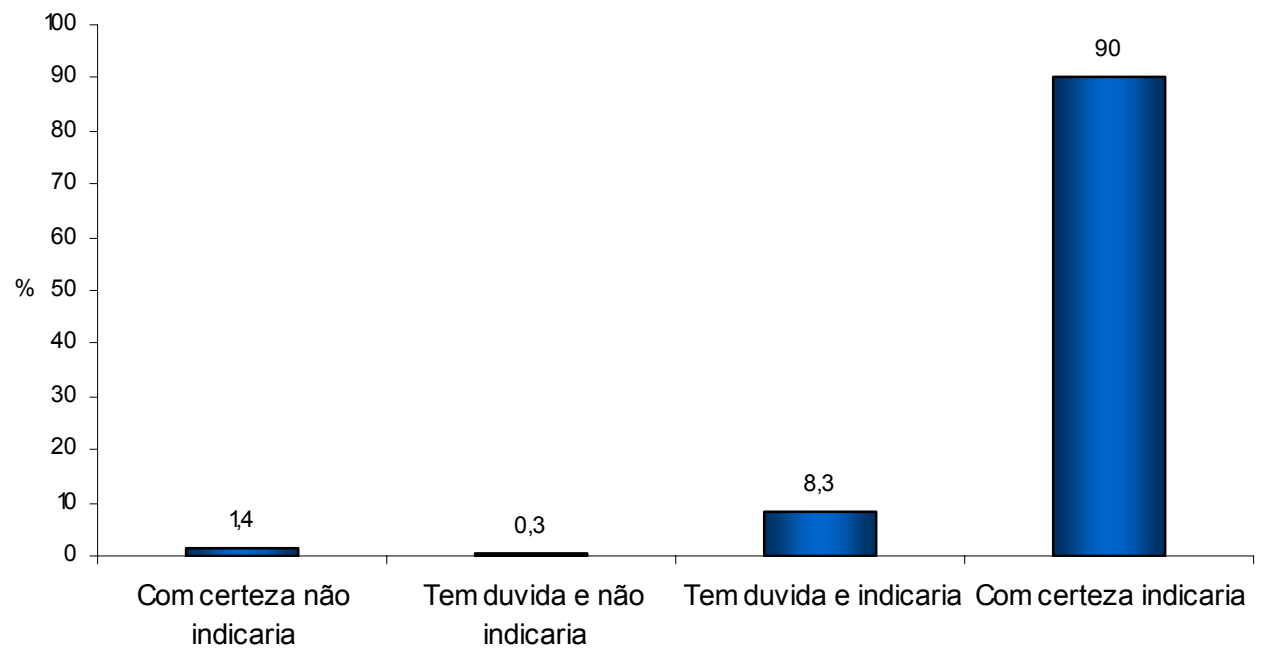

Figura 19 - Distribuição dos usuários segundo a intenção de indicar o hospital a parentes e amigos, São Paulo (Interior de SP) - 2009

Na Figura 19 observa-se que 259 (90\%) usuários entrevistados demonstraram intenção em indicar o hospital para parentes ou amigos, explicitando sua satisfação e lealdade a essa instituição.

$\mathrm{Na}$ pesquisa realizada por Castellanos (2002), 96,7\% dos usuários relataram predisposição em indicar o hospital a parentes e amigos, enquanto no estudo de Cruz (2008) este índice atingiu 91,5\% dos entrevistados.

A satisfação do usuário com a qualidade do serviço traz inúmeras vantagens para a instituição, especialmente no que diz respeito a sua fidelidade. Usuários satisfeitos, além de retornarem para novos atendimentos, disseminam informações positivas sobre o estabelecimento de saúde, tornando-se verdadeiros anunciantes ambulantes. Esses usuários 
também são mais condescendentes, pois uma experiência ruim ocasional é compensada pelas experiências prévias positivas (Lovelock, Wright, 2001).

Millan e Trez (2005) apontam para o crescente nível de competitividade do mercado, inferindo que a retenção dos usuários é fundamental e que o grande desafio passa a ser o de reconhecê-los, mostrando-Ihes o quanto a instituição os estima por ter sido eleita como preferida. Ademais, usuários satisfeitos e leais tendem a se engajar em propaganda "boca a boca", favorável à empresa.

Segundo Schiffman e Kanuk (2000), os grupos mais comuns e importantes para o usuário são: família, amigos, grupos sociais formais e grupos de trabalho. Tais grupos concentram os chamados "formadores de opinião", fontes de alta credibilidade para informações relacionadas aos serviços. Esses indivíduos são comumente percebidos como objetivos em relação à informação ou conselho que fornecem. Além disso, seus conselhos reduzem o risco percebido ou a ansiedade referente a um novo serviço para os receptores de opinião pelo fato de frequentemente basearem seus comentários sobre um serviço em suas próprias experiências.

$\mathrm{Na}$ maioria dos casos, os grupos de referência não dizem aos usuários o que fazer; na verdade, os usuários é que se deixam influenciar pela opinião do grupo ou por se preocupar com os sentimentos dos membros desse grupo (Churchill, Peter, 2003).

Convergindo com esses aspectos, deve-se considerar as evidências de que uma postura mais direcionada ao desenvolvimento de relacionamentos, por parte de uma organização, é valorizada pelos usuários, proporcionando a criação de confiança e comprometimento desses em relação à empresa (Mückenberger, 2000).

Ratifica-se que usuários satisfeitos, além de estabelecer vínculos com o serviço, também recrutam novos usuários através das informações positivas que fornecem sobre o atendimento recebido. 


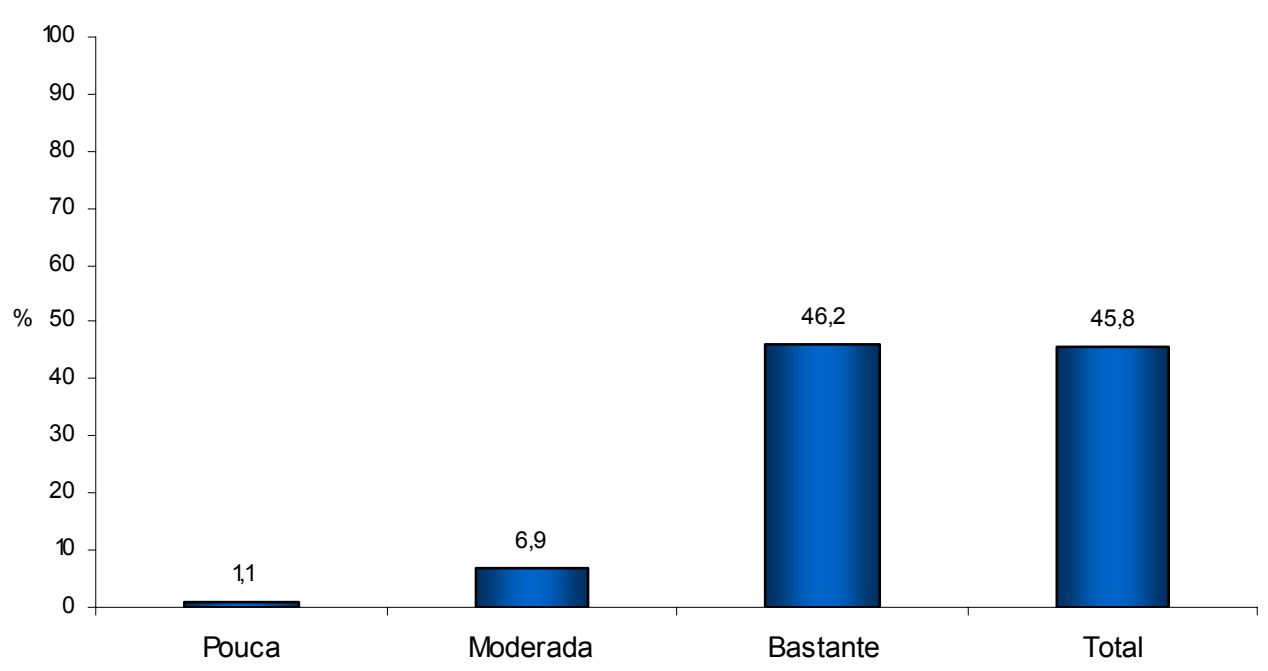

Figura 20 - Distribuição dos usuários segundo a confiança no hospital, São Paulo (Interior de SP) -2009

$\mathrm{Na}$ figura 20 nota-se os elevados índices de confiança no hospital expressados pelos participantes do estudo, sendo que $132(45,8 \%)$ usuários relatam sentir total confiança no referido hospital, $133(46,2 \%)$ referem bastante confiança, $20(6,9 \%)$ usuários, moderada confiança e apenas três $(1,1 \%)$ usuários apresentam pouca confiança no hospital.

Tais achados ratificam os elevados níveis de satisfação encontrados neste estudo, referentes aos atributos equipe médica, equipe de enfermagem, serviço de nutrição, atributos gerais e atendimento inicial.

No estudo de Castellanos (2002), o grau de confiança foi considerado como a soma dos itens: "sinto bastante confiança" e "sinto total confiança", resultando num índice de $76 \%$ de confiança na instituição.

Cruz (2008) encontrou índices ainda maiores de confiança comparados A este estudo, sendo que $71,8 \%$ dos participantes manifestaram total confiança na instituição, $22,5 \%$ bastante confiança e $5,6 \%$ confiança moderada.

O conjunto satisfação/ desempenho/ lealdade guarda relação com a confiança, atributo muito valorizado pelo usuário no momento da escolha de um serviço ou produto. Por sua vez, confiança é um sentimento baseado no conceito que se tem em relação a uma pessoa, instituição ou produto. Um bom conceito geralmente está associado a uma imagem de integridade, 
competência, segurança e decência, dentre outros. Assim sendo, a ausência de uma dessas características pode influenciar negativamente no grau de confiança na instituição ( Schiffman, Kanuk, 2000; Castellanos, 2002).

Segundo Valentim e Kruel (2007), a decisão de confiar ou não em alguém é influenciada por um componente constituído pelo julgamento racional do indivíduo. Porém, para que essa avaliação seja realizada é importante que o indivíduo disponha de uma base de informações. Tal base, tratada com familiaridade, é formada pelo conhecimento prévio do observado, englobando as experiências anteriores e as informações a respeito do mesmo, constituindo elementos de uma dimensão cognitiva do constructo. Essas informações a respeito do observado podem incluir a identificação de valores, os quais o observador considera como característicos de uma pessoa confiável, como o respeito ou a honestidade.

Transpondo-se tal conceito para a confiança que se dá nos serviços de saúde, conclui-se que o usuário adquire confiança na instituição quando conhece e experimenta seus serviços e os relacionam com seus valores e experiências anteriores, atribuindo-Ihes afinidades e aceitação. 
O estudo da análise da satisfação dos usuários de um hospital universitário privado do interior de São Paulo, pautado nas dimensões de qualidade do modelo avaliativo de Parasuraman, Zeithaml e Berry, permitiu constatar que:

\section{Quanto à caracterização dos participantes:}

$\checkmark \quad$ Os participantes eram jovens e adultos jovens em sua maioria, a média de idade foi de 41,42 anos e a mediana 39 anos;

$\checkmark \quad$ O número de participantes do sexo masculino 147 (51\%) foi semelhante aos do sexo feminino $141(49 \%)$;

$\checkmark \quad$ A escolaridade da amostra demonstrou-se elevada para os padrões nacionais: $144(50 \%)$ usuários com ensino médio completo e $48(16,7 \%)$ usuários com ensino superior completo;

$\checkmark \quad$ O maior quantitativo de usuários foi submetido a procedimentos cirúrgicos, totalizando $202(70,1 \%)$ participantes. As especialidades cirúrgicas com maior número de internações foram: Gastrocirurgia com 62 $(21,5 \%)$ internações, Ortopedia com $34(11,8 \%)$ e Cirurgia Geral com 19 $(6,6 \%)$ internações;

$\checkmark \quad$ Apenas dois $(0,7 \%)$ usuários passaram por atendimento particular e o restante da amostra, $286(99,3 \%)$ usuários, possuíam algum tipo de convênio;

$\checkmark$ A média de permanência das internações clínicas foi de 6,29 dias, mediana de 5 dias e nas internações cirúrgicas média de 12,85 dias e mediana de 6,27 dias. 


\section{Quanto aos atributos do atendimento:}

$\checkmark \quad$ O instrumento utilizado permitiu avaliar os 36 atributos e conhecer os níveis de satisfação dos usuários de internações clínicas e cirúrgicas e os atributos impactantes na satisfação geral;

$\checkmark \quad$ Observou-se que o predomínio de usuários com maior escolaridade esteve associado a elevados níveis de satisfação;

$\checkmark \quad$ Os atributos com maior índice de satisfação foram: educação da equipe de enfermagem com 277 (96,2\%), cuidados prestados pela equipe de enfermagem com 277 (96,2\%), qualidade geral da enfermagem que atende durante a noite com 276 (95,8\%), orientação para continuidade do tratamento 277 (96,2\%), educação da equipe médica com 276 (95,8\%) usuários e resultado do tratamento ou cirurgia com 276 (95,8\%).

$\checkmark \quad$ A maioria da amostra mostrou percepção favorável em relação ao serviço, sendo que os usuários cirúrgicos demonstraram maior satisfação nos atributos relativos à equipe médica e de enfermagem, enquanto os usuários clínicos atingiram maiores níveis de satisfação nos atributos relacionados ao atendimento inicial e aspectos gerais;

$\checkmark \quad$ Observaram-se diferenças estatísticas significativas nos índices de satisfação, entre usuários de internação clínica e cirúrgica, em relação aos itens: tempo de espera para atender a campainha, no qual 61 (70,9\%) usuários clínicos e 170 (84,2\%) usuários cirúrgicos estavam satisfeitos e facilidade de localização do balcão ou pessoa a qual se dirigir logo que entra no hospital com $72(83,7 \%)$ usuários clínicos e $186(92,1 \%)$ usuários cirúrgicos satisfeitos.

$\checkmark \quad$ Nas internações clínicas, o maior índice de satisfação foi referente à orientação pós-alta com $84(97,7 \%)$ usuários, seguido por atenção da copeira $83(96,4 \%)$ e respeito à privacidade $82(95,4 \%)$ e apresentando o 
menor índice tem-se tempo de espera para atender a campainha com 61 $(70,9 \%)$.

$\checkmark \quad$ Nas internações cirúrgicas observou-se maior índice de satisfação no item educação da equipe de enfermagem, representado por 197 (97,5\%) usuários, seguido por resultado do tratamento 196 (97\%), qualidade da enfermagem que atende a noite 195 (96,5\%), educação da equipe médica com $195(96,5 \%)$ e o menor índice de satisfação obtido foi em relação ao atendimento da nutricionista com 77 (77\%) usuários;

$\checkmark \quad$ Usuários clínicos e cirúrgicos apresentaram altos níveis de satisfação em relação à equipe médica. Os resultados sugerem maior satisfação entre a equipe cirúrgica nos atributos atenção 188 (93,1\%), educação 195 (96,5\%) e empenho 191 (94,6\%);

$\checkmark \quad$ Quanto à equipe de enfermagem também se evidencia maior índice de satisfação para as internações cirúrgicas, destacando-se os itens: educação da equipe de enfermagem 197 (97,5\%), cuidados prestados pela enfermagem 196 (97\%) e qualidade do serviço de enfermagem da noite 195 $(96,5 \%)$. O item tempo de espera para atender a campainha, apresentou menor índice de satisfação: 170 (84,2\%) para usuários cirúrgicos e 61 (70,9\%) para usuários clínicos;

$\checkmark \quad$ Os atributos da equipe de nutrição receberam os menores níveis de satisfação: atendimento da nutricionista 35 (74,5\%) para usuários clínicos e $77(77 \%)$ para os cirúrgicos, seguido pelo item temperatura da comida com respectivos índices de satisfação de 69 (79,8\%) e 166 (82,5\%). Novamente os usuários cirúrgicos demonstraram-se mais satisfeitos que os clínicos;

$\checkmark \quad$ Quanto aos atributos gerais, os níveis de satisfação oscilaram entre $71(82,6 \%)$ e $84(97,7 \%)$ para os usuários clínicos e $196(97 \%)$ a 173 $(85,6 \%)$ para os cirúrgicos. Os itens melhor pontuados pelos usuários de internação clínica referem-se, basicamente, aos aspectos de estrutura física 
do serviço, pertencentes à dimensão tangibilidade. Os itens pertencentes às dimensões confiabilidade, garantia e empatia, apresentaram maiores índices de satisfação nos usuários cirúrgicos;

$\checkmark \quad$ Constatou-se que o tempo de espera é um dos atributos considerados como gerador de insatisfação no serviço, tanto para os usuários clínicos quanto para os cirúrgicos;

$\checkmark$ Observou-se 151 (52,4\%) usuários aguardaram meia hora para internação, 67 (23,3\%) usuários relataram tempo de espera entre meia e uma hora e $70(24,3 \%)$ usuários esperaram mais de uma hora, embora este item tenha sido um dos atributos com o menor nível de satisfação entre os dois grupos de usuários.

$\checkmark \quad$ Foi possível detectar atributos do serviço que requerem maior atenção dos gestores e a implementação de medidas para melhoria dos níveis de satisfação, inclusive a readequação dos recursos humanos em algumas áreas.

\section{Quanto às dimensões do serviço:}

$\checkmark \quad$ A dimensão tangibilidade foi a que apresentou maior variação nos níveis de satisfação: maior índice no item limpeza do quarto com 266 $(92,4 \%)$ usuários e menor índice no item nível de barulho à noite com 235 $(81,6 \%)$ usuários.

$\checkmark \quad$ As dimensões confiabilidade e garantia representam os atributos que causaram maior satisfação.

$\checkmark \quad$ Nas dimensões responsividade e empatia estão inseridos os atributos com menores níveis de satisfação: tempo de espera para atendimento inicial $217(75,3 \%)$ e tempo de espera para atender a campainha $231(80,2 \%)$; atendimento da nutricionista $112(76,2 \%)$. 


\section{Quanto ao quesito confiança na instituição:}

$\checkmark \quad$ Evidenciou-se que elevados níveis de satisfação estão relacionados com a confiança depositada pelo usuário na instituição;

$\checkmark \quad$ Observou-se que 259 (90\%) usuários entrevistados demonstraram intenção em indicar o hospital para parentes ou amigos;

$\checkmark \quad$ Com relação à confiança, $132(45,8 \%)$ usuários relataram sentir total confiança no referido hospital, $133(46,2 \%)$ referiram bastante confiança, 20 $(6,9 \%)$ moderada confiança e apenas três $(1,1 \%)$ usuários apresentaram pouca confiança no hospital. 
O presente estudo permitiu conhecer o grau de satisfação dos usuários de um hospital universitário, bem como os fatores intervenientes em sua satisfação. Assim, algumas considerações são necessárias, a fim de contribuir com a instituição pesquisada e com novos estudos acerca do tema.

Referente aos atributos pesquisados, constatou-se de forma geral que todos foram bem avaliados pelos usuários, principalmente os referentes à equipe de enfermagem e médica. Todavia, não se deve excluir a necessidade de intervenção nos serviços de nutrição e no atendimento inicial no intuito de elevar ainda mais os padrões de qualidade de tal serviço.

A identificação de jovens e adultos jovens como faixa etária predominante na amostra, além de nível de escolaridade acima da média nacional, sugere a adoção de medidas para fidelização de tal grupo, principalmente àquelas referentes às dimensões tangibilidade $\mathrm{e}$ responsividade, que apresentaram as maiores variações nos níveis de satisfação, indicando a necessidade de intervenções.

A predominância de usuários cirúrgicos recomenda a adequação do serviço para o atendimento de tal demanda, investindo em processos de melhoria como avaliação de área física do Centro Cirúrgico, revisão e capacitação dos recursos humanos do referido setor, fidelização das equipes operatórias e gerenciamento de leitos.

Ressalta-se a importância do serviço de enfermagem dentro da instituição pesquisada, haja vista a relevância do papel que desempenha e sua presença constante em todas as etapas do tratamento, influenciando diretamente na satisfação dos usuários.

Apesar dos altos níveis de satisfação em relação à equipe médica, cabe mencionar a necessidade da inserção desse profissional como membro de uma equipe de trabalho integrada que participa da solução de problemas e do desenho de novos processos hospitalares com resultados e metas a alcançar e regido por um conjunto de práticas gerenciais. Essa é uma questão bastante complexa da gestão hospitalar atual e que deve ser trabalhada em prol da excelência da assistência aos usuários. 
Outro aspecto abordado no estudo diz respeito ao número de nutricionistas para o atendimento da demanda hospitalar, visto que foi evidenciado que o atendimento da nutricionista é um dos fatores mencionados nos níveis de satisfação dos usuários.

Assim, acredita-se que informações relevantes para a tomada de decisão dos gestores foram explicitadas nesta pesquisa, fornecendo subsídios para intervenções específicas e eficientes na melhoria da instituição como um todo.

Por fim, reconhece-se a satisfação do usuário como importante instrumento para a medida da qualidade dos serviços de saúde, bem como norteadora para o planejamento das ações, tomada de decisão e monitoramento dos resultados dos serviços de saúde. 


\section{REFERÊNCIAS}


Adami NP. Melhoria da qualidade nos serviços de enfermagem. Acta Paul Enferm. 2000;13(n. esp, Pt 1):190-6.

Adami NP, Yoshitome AY. Métodos de avaliação de resultados da assistência de enfermagem. Rev Bras Enferm. 2003;56(1):52-6.

Brasil. Ministério da Saúde. Agência Nacional de Saúde Suplementar (ANS). [homepage na Internet]. Brasília. [citado 2008 nov.1]. Disponível em: http://www.ans.gov.br/data/files/8A958865266CAFE20126962E49AB6727/ca derno informaca 09 2008.pdf.

Allen DR. Customer satisfaction research management. A comprehensive guide to integrating customer loyalty and satisfaction metrics in the management of complex organizations. Milwaukee: ASQ Quality; 2004. Customer satisfaction retention and profitability; p. 1-17.

Arroyo CS. Qualidade de serviços de assistência à saúde: o tempo de atendimento da consulta médica [tese]. São Paulo: Faculdade de Economia, Administração e Contabilidade, Universidade de São Paulo; 2007.

Aspinal F, Addington-Hall, Hughes R, Higginson U. Using satisfaction to measure the quality of palliative care: a review of the literature. J Adv Nurs. 2003;42(4):324-39.

Ayres JRCM. O cuidado, os modos de ser (do) humano e as práticas em saúde. Saúde Soc. 2004;13:16-29.

Azevedo AC. Avaliação de desempenho de serviços de saúde. Rev Saúde Pública. 1991;25(1):64-71.

Baron-Epel O, Dushenat M, Friedman N. Evaluation of the consumer model: relationship between patient's expectations, perception and satisfaction with care. Int J Qual Health Care. 2001;13(4):317-23. 
Blendon RJ, Schoen C, Donelan K, Osborn R, DesRoches CM, Scoles K et al. Physician's view on quality of care: a five country comparison. Health Aff (Millwood). 2001;20(3):233-43.

Blendon RJ, Kim M, Benson JM. The public versus the world health organization on health system performance. Health Aff (Millwood). 2001;20(3):10-20.

Bolton LB, Goodenough A. A magnet nursing service approach to nursing's role in quality improvement. Nurs Adm Q. 2003;27(4):344-54.

Bosi MLM, Uchimura KY. Avaliação da qualidade ou avaliação qualitativa do cuidado em saúde? Rev Saúde Pública. 2007;41(1):150-3.

Brasil. Lei n. 8234, de 17 de setembro de 1991. Regulamenta a profissão de nutricionista e determina outras providências. Diário Oficial da União, Brasília, 18 set. 1991. Seção 1:1.

Brasil. Resolução n. 50, de 21 de fevereiro de 2002. Dispõe sobre o regulamento técnico para planejamento, programação e avaliação de projetos físicos de estabelecimentos assistenciais de saúde. Diário Oficial da União. Brasília; 21 fev. 2002. Seção 1:39-75.

Brasil. Ministério da Saúde. Secretaria de Assistência a Saúde. Manual brasileiro de acreditação hospitalar. 4ª ed. Brasília; 2003.

Carr-Hill RA. The measurement of patient satisfaction. J Public Health Med. 1992;14(3):236-49.

Castellanos PL. Comparação entre a satisfação do usuário com os serviços oferecidos num hospital geral e a percepção gerencial dessa satisfação [dissertação]. São Paulo: Escola de Administração de Empresas de São Paulo, Fundação Getúlio Vargas; 2002.

Castro MSM. Travassos C. Carvalho MS. Fatores associados às internações hospitalares no Brasil. Ciênc Saúde Coletiva. 2002;7(4):795-811. 
Churchill GA. Peter JP. Marketing: criando valor para os clientes. $2^{a}$ ed. São Paulo: Saraiva; 2003.

Conselho Nacional de Saúde (CNS). Resolução n. 196, de 10 de outubro de 1996. Dispõe sobre diretrizes e normas regulamentadoras de pesquisa envolvendo seres humanos. Diário Oficial da União, Brasília. 16 out. 1996; Seção 1:51-3.

Coile RC Jr. Competing by design: hospitals of the future offer healing environments. Russ Coiles Health Triends. 2001;13(11):1,4-8.

Cronin JJ Jr, Taylor SA. Modeling patient satisfaction and service quality. J Health Care Mark. 1994;14(1):34-44.

Cruz WBS. Análise dos níveis de satisfação dos usuários de um hospital privado [dissertação]. São Paulo: Escola de Enfermagem, Universidade de São Paulo; 2008.

Currie V, Harvey G, West E, Mckenna H, Keeney S. Relationship between quality of care, staffing levels, skill mix and nurse autonomy: literature review. J Adv Nurs. 2005;51(1):73-82.

De Brun C, Howell F, Bedford D, Corcoran R, Kelly A. Outpatient experiences in acute hospitals.Ir J Med Sci. 2002;171(2):89-93.

Brasil. Ministério da Saúde. DATASUS [homepage na internet]. Brasília; c2008. [citado 2009 nov. 20]. Disponível em:

http://www.datasus.gov.br/datasus/index.php?area=0201/.

Deming WE. Qualidade: a revolução da administração. Rio de Janeiro: Marques-Saraiva; 1990.

Donabedian A. Explorations in quality assessment and monitoring: the definition of quality and approaches to its assessment. Chicago: Health Administration Press; 1980. v.1. 
Donabedian A. La calidad de la atención médica: definición y métodos de evaluación. México, DF: La Prensa Mexicana; 1984.

Donabedian A. The methods and findings of quality assessment and monitoring: an illustrated analysis. Michigan: Health Administration Press; 1985.

Donabedian A. The quality of care: how can it be assessed? JAMA. 1988;260(12):1743-8.

Donabedian A. The seven pillars of quality. Arch Pathol Lab Med. 1990;114(11):1115-8.

Donabedian A. Evaluación de la calidad de la atención médica. In: White KL, Frank J, organizadores. Investigaciones sobre serviços de salud: una antologia. Washington, (DC): OPAS; 1992. p. 382-404.

Ernst \& Young, FGV. Brasil 2020: os desafios da economia global [homepage na Internet]. Reino Unido; c2009. [citado 2009 out. 20]. Disponível em:

http://www.ey.com/BR/pt/SearchResults?query=RELATORIO+ANUAL+2006 \&search options=country name.

Espiridião AM, Trad LAB. Avaliação de satisfação de usuários: considerações teórico-conceituais. Cad Saúde Pública. 2006;6:1267-76.

Feldman LB. Como alcançar a qualidade nas instituições de saúde. Critérios de avaliações, procedimentos de controle, gerenciamento de riscos hospitalares até a certificação. São Paulo: Martinari; 2004.

Feldman LB, Cunha ICKO. Identificação dos critérios de avaliação de resultados do serviço de enfermagem nos programas de acreditação hospitalar. Rev Lat-Am Enferm. 2006;14(4):540-5.

Garcia RWD. A dieta hospitalar na perspectiva dos sujeitos envolvidos em sua produção e em seu planejamento. Rev Nutr. 2006;19(2):129-44. 
Gerschman S, Veiga L, Guimarães C, Ugá MAD, Portela MC, Vasconcellos MM, et al. Estudo de satisfação dos beneficiários de planos de saúde de hospitais filantrópicos. Ciênc Saúde Coletiva. 2007; 12(2):487-500.

Guelli A, Zucchi P. A influência do espaço físico na recuperação do paciente e os sistemas e instrumentos de avaliação. Rev Adm Saude. 2005;7(27):4350.

Hercos BVS, Berezoysky A. Qualidade do serviço oftalmológico prestado aos pacientes ambulatoriais do Sistema Único de Saúde - SUS. Arq Bras Oftalmol. 2006;69(2):213-9.

Hiidenhovi H, Nojonen K, Laippala P. Measurement of outpatients: views of service quality in a Finish university hospital. J Adv Nurs. 2002;38(1):59-67.

Instituto Brasileiro de Geografia e Estatística (IBGE) [homepage na Internet]. Brasília; 2009 [citado 2009 out. 20]. Disponível em:

http://www.ibge.gov.br/home/estatistica/populacao/indic sociosaude/2009/co $\underline{\mathrm{m} \text { din.pdf }}$

Kotaka F, Pacheco MLR, Higaki Y. Avaliação pelos usuários dos hospitais participantes do programa de qualidade hospitalar no Estado de São Paulo, Brasil. Rev Saúde Pública. 1997;31(2):171-7.

Linder-Pelz S. Toward a theory of patient satisfaction. Soc Sci Med.1982; 16(5):577-82.

Lovelock C, Wright L. Serviços de marketing e gestão. São Paulo: Saraiva; 2001.

Lobiondo-Wood G, Haber J. Pesquisa em enfermagem: métodos, avaliação crítica e utilização. 4ª ed. Rio de Janeiro: Guanabara Koogan; 2001.

Malik AM, Schiesari LMC. Qualidade na gestão local de serviços e ações de saúde. São Paulo: Fundação Editora Peirópolis; 1998. 
Malta DC, Cecílio LCO, Merhy EE, Franco TB, Jorge AO, Costa MA. Perspectivas da regulação na saúde suplementar diante dos modelos assistenciais. Cienc Saúde Coletiva. 2004;9(2):433-44.

Marley KA, Collieri DA, Goldstein SM. The role of clinical and process quality in achieving patient satisfaction hospitals. Decis Sci. 2004;35(3):432-37.

Marquis BL, Huston CJ. Administração e liderança em enfermagem. $2^{\mathrm{a}}$ ed. Porto Alegre: Artmed; 2005.

Marshall G, Murdoch L. Service quality in consulting marketing engineers. Oxford: Oxford Brookes University; 2001.

Melleiro MM, Coleto VA, Passos JA, Sais LC. Análise da qualidade da assistência de enfermagem em unidades pediátricas: a percepção dos usuários. Enferm Atual. 2009; 54:30-6.

Miguel PAC. Qualidade: enfoque e ferramentas. São Paulo: Artiliber; 2001.

Milan GS, Trez G. Pesquisa de satisfação: um modelo para planos de saúde. RAE-eletrônica [periódico na Internet]. 2005 [citado 2009 nov 18];4(2):[cerca de 21 p]. Disponível em:

http://www.rae.com.br/eletrônica/index.cfm?FuseAction+Artigo\&ID2165\&Sec $\underline{\mathrm{ao}=\mathrm{ARTIGOS} \& \text { Volume}=4 \& \text { Numero }=2 \& A n o=2005}$.

Morais AS, Braga AT, Nicole AG, Tronchin DMR, Melleiro MM. Qualidade e avaliação em saúde: publicações em periódicos de enfermagem nas últimas duas décadas. Rev Enferm UERJ. 2008;16(3):404-9.

Moreno Júnior JMP, Zucchi P. Avaliação de qualidade em serviços de saúde: acreditação, certificação e programas de melhoria da qualidade em hospitais públicos e privados do município de São Paulo. Rev Adm Pública. 2005:39(1):7-16.

Mrtvi VO. O impacto da percepção do tempo de espera para atendimento em clínicas médicas na avaliação da qualidade do serviço pelo consumidor. In: 
Anais do $6^{\circ}$ SEMEAD; 2003 mar. 25-26; São Paulo, BR [evento na Internet]. São Paulo: FEA-USP; 2003. [citado 2009 dez. 3]. Disponível em: http://www.ead.fea.usp.br/semead/6semead/

Mückenberger E. O papel da satisfação, confiança e comprometimento na formação de intenções futuras de compra entre clientes com níveis de experiência diferenciados [dissertação]. Porto Alegre: Escola de Administração, Universidade Federal do Rio Grande do Sul; 2000.

Nonino-Borges CB, Rabito El, Silva K, Ferraz CA, Chiarello PG, Santos JS, et al. Desperdício de alimentos intra-hospitalar. Rev Nutr [periódico na Internet]. 2006 mai-jun. [citado 2009 nov 18];19(3);346-56. Disponível em: http://www.scielo.br/scielo.php?script=sci arttext\&pid=S1415$\underline{52732006000300006 .}$

Novaes HMD. Avaliação de programas, serviços e tecnologias em saúde. Rev Saúde Pública. 2000;34(5):547-9.

Oliveira CG. Análise do conceito de satisfação do usuário na obra de Donabedian. Rio de Janeiro: Ed. UERJ; 1992.

Parasuraman A, Zeithaml VA, Berry LL. A conceptual model of service quality and its implications for future research. J Mark. 1985;49(4):41-50.

Parasuraman A, Zeithaml VA, Berry LL. SERVQUAL: a multiple-scale for measuring consumer perceptions of service quality. J Retailing. 1988;64(1):12-40.

Parasuraman A, Zeithaml VA, Berry LL. Refinement and reassessment of the SERVQUAL dimensions. J Retailing. 1991;67(4):420-50.

Parente J. Varejo no Brasil: gestão e estratégia. São Paulo: Atlas; 2000.

Ramos DD, Lima MADS. Acesso e acolhimento aos usuários em uma unidade de saúde em Porto Alegre, Rio Grande do Sul, Brasil. Cad Saúde Pública. 2003;19(1):27-34. 
Rosner B. Fundamentals of biostatistics. $2^{\text {nd }}$ ed. Boston: PWS; 1986.

Rotondaro RG, Muto M. Melhoria no atendimento em um hospital privado da cidade de São Paulo. In: Anais do $27^{\circ}$ Encontro Nacional da Engenharia de Produção; 2008 out.13-16; Rio de Janeiro, BR. Rio de Janeiro: ABEPRO; 2008. p. 102.

Schaack AC. A satisfação dos pacientes diferenciados internados em unidades hospitalares do Complexo Hospitalar Santa Casa de Porto Alegre. [dissertação]. Porto Alegre: Escola de Administração, Universidade Federal do Rio Grande do Sul; 2003.

Schiffman LG; Kanuk LA. Comportamento do consumidor. Trad. de Vicente Ambrósio. $6^{\text {a }}$ ed. Rio de Janeiro: LTC; 2000.

Sitzia J. Wood N. Patient satisfaction: a review of issues e concepts. Soc Sci Med.1997;45(12):1829-43.

Staniszewska S, Henderson L. Patients' evaluations of their health care: the expression of negative evaluation and the role of adaptive strategies. Patient Educ Couns. 2004;55(2):185-92.

Starfield B. Atenção primária: equilíbrio entre necessidades de saúde, serviços e tecnologias. Brasília: UNESCO/Ministério da Saúde; 2002.

Stefanelli MC. Conceitos teóricos sobre comunicação. Barueri: Manole; 2005. A comunicação nos diferentes contextos da enfermagem; p. 28-46.

The Center for Health Design (CHD) [homepage in the Internet]. United States of America; c2010. [cited 2010 jan. 30]. Available from: http://www.healthdesign.org.

Tronchin DMR, Melleiro MM, Takahashi RT. A qualidade e a avaliação dos serviços de saúde e de enfermagem. In Kurcgant $P$, coordenadora. Gerenciamento em enfermagem. Rio de Janeiro: Guanabara Koogan; 2005. p. 75-88. 
Tsai CY, Wang MC, Liao WT, Lu JH, Sun PH, Lin BY, et al. Hospital outpatient perceptions environment of waiting areas: the role of patient characteristics on atmospherics in one academic medical center. BMC Health Serv Res. 2007;5;7:198.

Vaitsman J, Andrade GRB. Satisfação e responsividade: formas de medir a qualidade e a humanização da assistência à saúde. Cienc Saúde Coletiva. 2005;10(3);599-613.

Valentim IVL, Kruel AJ. A importância da confiança interpessoal para a consolidação do Programa de Saúde da Família. Cienc Saúde Coletiva. 2007;12(3);777-88.

Varni JW, Burwinkle TM, Dickinson P, Sherman AS, Dixon P, et al. Evaluation of the built environment at a children's convalescent hospital: development of the pediatric quality of life inventory parent and staff satisfaction measures for pediatric health care facilities. J Dev Behav Pediatr. 2004;25(1):10-20.

Vasconcellos PP. Desenvolvimento de um modelo de avaliação da qualidade do serviço odontológico [dissertação]. Florianópolis: Centro tecnológico, Universidade Federal de Santa Catarina; 2002.

Vecina Neto G, Malik AM. Tendências na assistência hospitalar. Cienc Saúde Coletiva. 2007;12(4):825-39.

Waltz CF, Strickland OL, Lenz ER. Measurement in nursing and health research. $3^{\text {rd }}$ ed. Philadelphia: Springer Publishing; 2004.

Williams B. Patients satisfaction: a valid concept. Soc Sci Med. 1994;38(4):509-16.

Zaicaner R. Satisfação da clientela: um objetivo a ser alcançado pelo serviço público de saúde [dissertação]. São Paulo: Faculdade de Saúde Pública, Universidade de São Paulo; 2001. 
Zanon U. Qualidade da assistência médico-hospitalar: conceito, avaliação e discussão dos indicadores de qualidade. Rio de Janeiro: Medsi; 2001.

Zeithaml VA, Bitner MJ. Services marketing: integrating customer focus across the firm. $2^{\text {nd }}$ ed. Boston: Irvwin McGraw-Hill; 2000.

Zeithaml V, Parasuraman A. Service quality. Cambridge: Marketing Science Institute; 1990.

Zeithaml V, Parasuraman A, Berry LL.Delivering Service Quality: balancing customers perceptions and expectations:New York:The Free Press; 1990. 


\section{APÊNDICES}




\section{APÊNDICE 1}

\section{ENCAMINHAMENTO AO COMITÊ DE ÉTICA EM PESQUISA}

de de 2009.

IImo(a) $\operatorname{Sr}(a)$.

Presidente do Comitê de Ética em Pesquisa

Venho solicitar a análise e a autorização para realização da pesquisa intitulada: "Análise do Grau de Satisfação de Usuários de um Hospital Universitário Privado do Interior do Estado de São Paulo: uma abordagem multissetorial" que tem por objetivos: conhecer o grau de satisfação dos usuários de Convênios Privados e Particulares acerca do atendimento em uma Unidade de Internação de Clinica Médica e Cirúrgica e analisar os fatores intervenientes no grau de satisfação desses usuários, utilizando o modelo avaliativo de Parasuraman, Zeithaml e Berry.

Aproveito o ensejo para esclarecer tratar-se de uma dissertação para obtenção do título de mestre, na área de concentração de Administração de Serviços de Saúde e Enfermagem da Escola de Enfermagem da Universidade de São Paulo, sob orientação da Prof ${ }^{\mathrm{a}} \mathrm{Dr}^{\mathrm{a}}$ Marta Maria Melleiro.

Outrossim, esclareço que serão respeitadas as exigências da Resolução nº. 196/96 do Conselho Nacional de Saúde.

Atenciosamente, 


\section{APÊNDICE 2}

\section{SOLICITAÇÃO DE AUTORIZAÇÃO PARA COLETA DE DADOS}

de de 2009.

IImo(a) $\operatorname{Sr}(a)$.

Superintendente

Prezada Sr (a)

Venho por meio desta, solicitar autorização para realizar a coleta de dados nesta instituição para o trabalho de pesquisa, intitulado "Análise do Grau de Satisfação de Usuários de um Hospital Universitário Privado do Interior do Estado de São Paulo: uma abordagem multissetorial" que tem por objetivos: conhecer o grau de satisfação dos usuários de Convênios Privados e Particulares acerca do atendimento em uma Unidade de Internação de Clínica Médica e Cirúrgica e analisar os fatores intervenientes no grau de satisfação desses usuários, utilizando o modelo avaliativo de Parasuraman, Zeithaml e Berry.

Aproveito o ensejo para esclarecer que estudo trata-se de uma dissertação para obtenção do título de mestre na área de concentração de Administração de Serviços de Saúde e Enfermagem da Escola de Enfermagem da Universidade de São Paulo, sob a orientação da Prof ${ }^{\mathrm{a}} \mathrm{Dr}^{\mathrm{a}}$ Marta Maria Melleiro.

Outrossim, informo que não coloco em evidência a identificação de qualquer usuário participante, bem como esta instituição.

Certa de poder contar com sua colaboração, coloco-me à disposição para outros esclarecimentos.

No aguardo de sua resposta, aproveito a oportunidade para renovar meu protesto de estima e consideração.

Atenciosamente, 


\section{APÊNDICE 3}

\section{TERMO DE CONSENTIMENTO LIVRE E ESCLARECIDO}

PESQUISA: "Análise do Grau de Satisfação de Usuários de um Hospital Universitário Privado do Interior do Estado de São Paulo: uma abordagem multissetorial"

PESQUISADOR: Mileide Morais Pena

\section{I - Registro dos esclarecimentos e responsabilidades do pesquisador}

Eu, Mileide Morais Pena, mestranda da Escola de Enfermagem da USP-SP, venho convidá-lo a participar do estudo acima, que tem por objetivos conhecer o grau de satisfação dos usuários de Convênios Privados e Particulares acerca do atendimento em uma Unidade de Internação de Clínica Médica e Cirúrgica e analisar os fatores intervenientes no grau de satisfação desses usuários, utilizando o modelo avaliativo de Parasuraman, Zeithaml e Berry.

O conteúdo do questionário será confidencial, sigiloso e as suas respostas estarão sob minha responsabilidade, sendo que será utilizado apenas para a realização do estudo, podendo o resultado ser apresentado em eventos e/ou publicados em revistas científicas.

A sua participação no estudo será totalmente voluntária, podendo deixá-lo a qualquer momento em que desejar, sem que isto prejudique o seu tratamento. Caso aceite participar desta pesquisa, solicito a sua assinatura no item II deste documento.

Desde já agradeço a sua atenção e coloco-me à disposição para quaisquer esclarecimentos sobre a pesquisa. O meu telefone para contato é (19) 3343-8455 e meu email é mileide@usp.br.

de

Mileide Morais Pena (Pesquisadora)

\section{TERMO DE CONSENTIMENTO LIVRE E ESCLARECIDO}

Compreendo o objetivo desta pesquisa e concordo em participar de forma voluntária da mesma, entendendo que as informações serão confidenciais, que não haverá identificação nominal e que não sofrerei qualquer tipo de sanção ou prejuízo, caso desista de participar deste estudo.

Declaro, ainda, que ao ser convidado a participar desta pesquisa, todos os esclarecimentos foram prestados pelo pesquisador. de de 2009. 
APÊNDICE 4

INSTRUMENTO DE COLETA DE DADOS

"Satisfação de Usuários de uma Unidade de Clínica Médica e Cirúrgica"

Data:

No

PARTE I - Dados sócio-demográficos

Tempo de internação: dias

Idade:

Sexo: ( ) masculino ( ) feminino

Escolaridade: ( ) ensino fundamental ( ) completo ( ) incompleto
( ) ensino médio
( ) completo ( ) incompleto
( ) ensino superior
( ) completo ( ) incompleto

Tipo de vínculo com a instituição ( ) Convênio Qual?
( ) Particular
( ) Outros Qual?

Diagnóstico: 


\section{PARTE II - Avaliação do Período de Internação}

1. Favor responder, assinalando com um "X" qual seu grau de satisfação em relação ao atendimento recebido durante o período de internação.

2. Primeiramente pense se o (a) $\mathrm{Sr}$ (a) ficou insatisfeito (a) ou satisfeito (a) com o atendimento e a seguir, pense na intensidade da sua discordância ou concordância (totalmente, muito ou pouco).

\begin{tabular}{|c|c|c|c|c|c|c|}
\hline \multirow{3}{*}{ Atributos do atendimento } & \multicolumn{6}{|c|}{ GRAU DE SATISFAÇÃO } \\
\hline & \multicolumn{3}{|c|}{ INSATISFEITO (A) } & \multicolumn{3}{|c|}{ SATISFEITO (A) } \\
\hline & Totalmente & Muito & Pouco & Pouco & Muito & Totalmente \\
\hline \multicolumn{7}{|l|}{ Equipe médica } \\
\hline $\begin{array}{l}\text { Atenção/ interesse da equipe médica } \\
\text { para com o usuário durante a } \\
\text { internação. }\end{array}$ & 1 & 2 & 3 & 4 & 5 & 6 \\
\hline $\begin{array}{l}\text { Educação da equipe médica para } \\
\text { com o usuário durante a sua } \\
\text { internação. }\end{array}$ & 1 & 2 & 3 & 4 & 5 & 6 \\
\hline $\begin{array}{l}\text { Empenho da equipe médica em } \\
\text { resolver os problemas do usuário } \\
\text { durante a internação. }\end{array}$ & 1 & 2 & 3 & 4 & 5 & 6 \\
\hline \multirow[t]{4}{*}{$\begin{array}{l}\text { Explicações/ orientações sobre o } \\
\text { problema, dadas pela equipe médica } \\
\text { ao usuário. }\end{array}$} & 1 & 2 & 3 & 4 & 5 & 6 \\
\hline & \multicolumn{6}{|c|}{ GRAU DE SATISFAÇÃO } \\
\hline & \multicolumn{3}{|c|}{ INSATISFEITO (A) } & \multicolumn{3}{|c|}{ SATISFEITO (A) } \\
\hline & Totalmente & Muito & Pouco & Pouco & Muito & Totalmente \\
\hline \multicolumn{7}{|l|}{ Equipe de enfermagem } \\
\hline $\begin{array}{l}\text { Atenção/ interesse da equipe de } \\
\text { enfermagem para com o usuário } \\
\text { durante a internação. }\end{array}$ & 1 & 2 & 3 & 4 & 5 & 6 \\
\hline $\begin{array}{l}\text { Educação da equipe de enfermagem } \\
\text { para com o usuário durante a sua } \\
\text { internação. }\end{array}$ & 1 & 2 & 3 & 4 & 5 & 6 \\
\hline $\begin{array}{l}\text { Empenho da equipe de enfermagem } \\
\text { em resolver os problemas do usuário } \\
\text { durante a internação. }\end{array}$ & 1 & 2 & 3 & 4 & 5 & 6 \\
\hline $\begin{array}{l}\text { Explicações/ orientações sobre o } \\
\text { problema dadas pela equipe de } \\
\text { enfermagem ao usuário. }\end{array}$ & 1 & 2 & 3 & 4 & 5 & 6 \\
\hline $\begin{array}{l}\text { Cuidados prestados pela equipe de } \\
\text { enfermagem ao usuário tais como: } \\
\text { medir pressão, realizar curativos, dar } \\
\text { os remédios, higienização, etc. }\end{array}$ & 1 & 2 & 3 & 4 & 5 & 6 \\
\hline $\begin{array}{l}\text { Tempo de espera para atender o } \\
\text { usuário quando este toca a } \\
\text { campainha. }\end{array}$ & 1 & 2 & 3 & 4 & 5 & 6 \\
\hline $\begin{array}{l}\text { Qualidade geral da equipe de } \\
\text { enfermagem que atende durante o } \\
\text { dia. }\end{array}$ & 1 & 2 & 3 & 4 & 5 & 6 \\
\hline $\begin{array}{l}\text { Qualidade geral da equipe de } \\
\text { enfermagem que atende durante a } \\
\text { noite. }\end{array}$ & 1 & 2 & 3 & 4 & 5 & 6 \\
\hline
\end{tabular}




\begin{tabular}{|c|c|c|c|c|c|c|}
\hline \multirow{3}{*}{ Atributos de atendimento } & \multicolumn{6}{|c|}{ GRAU DE SATISFAÇÃO } \\
\hline & \multicolumn{3}{|c|}{ INSATISFEITO (A) } & \multicolumn{3}{|c|}{ SATISFEITO (A) } \\
\hline & Totalmente & Muito & Pouco & Pouco & Muito & Totalmente \\
\hline \multicolumn{7}{|l|}{ Nutrição } \\
\hline $\begin{array}{l}\text { Atendimento da nutricionista (se teve } \\
\text { contato). }\end{array}$ & 1 & 2 & 3 & 4 & 5 & 6 \\
\hline Qualidade/ sabor da comida. & 1 & 2 & 3 & 4 & 5 & 6 \\
\hline Aparência/ apresentação da comida. & 1 & 2 & 3 & 4 & 5 & 6 \\
\hline Temperatura da comida. & 1 & 2 & 3 & 4 & 5 & 6 \\
\hline Quantidade de comida. & 1 & 2 & 3 & 4 & 5 & 6 \\
\hline Variedade da comida. & 1 & 2 & 3 & 4 & 5 & 6 \\
\hline $\begin{array}{l}\text { Regularidade nos horários que a } \\
\text { comida foi servida. }\end{array}$ & 1 & 2 & 3 & 4 & 5 & 6 \\
\hline \multirow[t]{4}{*}{$\begin{array}{l}\text { Atenção da copeira que servia a } \\
\text { comida. }\end{array}$} & 1 & 2 & 3 & 4 & 5 & 6 \\
\hline & \multicolumn{6}{|c|}{ GRAU DE SATISFAÇÃO } \\
\hline & \multicolumn{3}{|c|}{ INSATISFEITO (A) } & \multicolumn{3}{|c|}{ SATISFEITO (A) } \\
\hline & Totalmente & Muito & Pouco & Pouco & Muito & Totalmente \\
\hline \multicolumn{7}{|l|}{ Atributos gerais } \\
\hline Conforto do quarto. & 1 & 2 & 3 & 4 & 5 & 6 \\
\hline Limpeza do quarto. & 1 & 2 & 3 & 4 & 5 & 6 \\
\hline Instalações do banheiro do quarto. & 1 & 2 & 3 & 4 & 5 & 6 \\
\hline Nível de barulho à noite para dormir. & 1 & 2 & 3 & 4 & 5 & 6 \\
\hline $\begin{array}{l}\text { Respeito à privacidade do usuário } \\
\text { enquanto esteve internado. }\end{array}$ & 1 & 2 & 3 & 4 & 5 & 6 \\
\hline $\begin{array}{l}\text { Resultado do tratamento / cirurgia a } \\
\text { que o usuário se submeteu enquanto } \\
\text { esteve internado. }\end{array}$ & 1 & 2 & 3 & 4 & 5 & 6 \\
\hline $\begin{array}{l}\text { Orientação para continuidade do } \\
\text { tratamento após saída do hospital. }\end{array}$ & 1 & 2 & 3 & 4 & 5 & 6 \\
\hline $\begin{array}{l}\text { Orientação para sua alimentação em } \\
\text { casa, após saída do hospital. }\end{array}$ & 1 & 2 & 3 & 4 & 5 & 6 \\
\hline $\begin{array}{l}\text { Atendimento do serviço social durante } \\
\text { o período em que esteve internado } \\
\text { (a) se teve contato. }\end{array}$ & 1 & 2 & 3 & 4 & 5 & 6 \\
\hline
\end{tabular}




\section{PARTE III - Avaliação do atendimento inicial para pacientes internados}

1. As frases apresentadas a seguir referem-se a vários fatores do atendimento inicial prestados aos pacientes no momento da internação. Com base nas alternativas das respostas, assinale um " $X$ " naquela que melhor representa sua opinião em relação ao grau de satisfação dos pacientes com esses serviços.

- $\quad$ Primeiramente, pense se o $\mathrm{Sr}$ (a) discorda ou concorda com cada frase.

- A seguir pense na intensidade da sua concordância ou discordância (totalmente, muito ou pouco).

Assinale apenas um "X" em cada frase, como resposta.

\begin{tabular}{|l|c|c|c|c|c|c|}
\hline \multirow{2}{*}{ Atributos do atendimento } & \multicolumn{5}{c|}{ GRAU DE SATISFAÇÃO } \\
\cline { 2 - 7 } & \multicolumn{2}{|c|}{ INSATISFEITO (A) } & \multicolumn{3}{c|}{ SATISFEITO (A) } \\
\cline { 2 - 7 } & Totalmente & Muito & Pouco & Pouco & Muito & Totalmente \\
\hline $\begin{array}{l}\text { Facilidade de localização do balcão } \\
\text { ou pessoa a qual se dirigir logo que } \\
\text { entra no hospital. }\end{array}$ & 1 & 2 & 3 & 4 & 5 & 6 \\
\hline $\begin{array}{l}\text { Tempo de espera para conseguir } \\
\text { atendimento inicial. }\end{array}$ & 1 & 2 & 3 & 4 & 5 & 6 \\
\hline $\begin{array}{l}\text { Cortesia ou educação da pessoa que } \\
\text { recebe os usuários para preencher os } \\
\text { dados da internação. }\end{array}$ & 1 & 2 & 3 & 4 & 5 & \\
\hline $\begin{array}{l}\text { Rapidez de preenchimento desses } \\
\text { dados iniciais. }\end{array}$ & 1 & 2 & 3 & 4 & 5 & \\
\hline $\begin{array}{l}\text { Clareza das informações que o } \\
\text { usuário recebe esse atendimento } \\
\text { inicial. }\end{array}$ & 1 & 2 & 3 & 4 & 5 & 6 \\
\hline $\begin{array}{l}\text { Organização geral desse atendimento } \\
\text { inicial. }\end{array}$ & 1 & 2 & 3 & 4 & 5 & 6 \\
\hline $\begin{array}{l}\text { Conforto (instalações, poltronas, } \\
\text { água, banheiros, etc) que o hospital } \\
\text { oferece ao usuário enquanto este } \\
\text { espera pela internação. }\end{array}$ & & & & & & \\
\hline
\end{tabular}

2. Entre o preenchimento dos dados iniciais e a internação, quanto tempo, em média, o (a) $\mathrm{Sr}$ (a) considera que o usuário espera?

( ) Até meia hora

( ) De meia a uma hora

( ) De uma hora a uma hora e meia

( ) De uma hora e meia a duas horas

( ) Mais de duas horas 


\section{PARTE IV - Avaliação do quesito confiança em relação à instituição}

1. O (a) $\mathrm{Sr}(a)$ sente confiança neste hospital? Eu gostaria que o(a) $\mathrm{Sr}(a)$ me respondesse, levando em consideração as seguintes alternativas para resposta:
( ) Sinto nenhuma confiança
( ) Sinto pouca confiança
( ) Sinto moderada confiança
( ) Sinto bastante confiança
( ) Sinto total confiança

2. $\mathrm{O}(\mathrm{a}) \mathrm{Sr}(\mathrm{a})$ indicaria este hospital para algum parente/ amigo que precisasse de uma internação?

( ) Com certeza eu não indicaria.

( ) Tenho duvida, mas penso que eu não indicaria.

( ) Tenho duvida, mas penso que eu indicaria.

( ) Com certeza eu indicaria.

3. $\mathrm{O}$ (a) $\operatorname{Sr}(a)$ sentiu e avaliou uma série de fatores deste hospital: atendimento médico, de enfermagem, qualidade nas instalações. Pensando agora no geral, neste hospital como um todo, o(a) Sr(a) poderia me dizer se ficou satisfeito (a) ou insatisfeito (a) com o hospital, após seu atendimento?

INSATISFEITO (A)

( ) Totalmente

() Muito

( ) Pouco

SATISFEITO (A)

( ) Totalmente

( ) Muito

( ) Pouco 


\section{APÊNDICE 5}

\section{Correlação univariada entre a satisfação e os construtos}

Pearson Correlation Coeficients / Prob > |R| under Ho: Rho=0/ Number of Observations

$\begin{array}{cccc}X 1 & X 2 & X 3 & X \\ 0.43503=r & 0.45385 & 0.45200 & 0.57237 \\ 0.0001=\mathrm{p} & 0.0001 & 0.0001 & 0.0001 \\ 288=\mathrm{n} & 288 & 285 & 145 \\ \mathrm{X} 5 & & & X 8 \\ 0.47840 & 0.38123 & X 7 & 0.39447 \\ 0.0001 & 0.0001 & 0.30646 & 0.0001 \\ 288 & 288 & 0.0001 & 153\end{array}$

Análise multivariada - regressão linear multivariada

Dependent Variable: SAST

\begin{tabular}{|c|c|c|c|c|c|}
\hline & & Paramete & Estimates & & \\
\hline Parameter & & Standard & $\mathrm{T}$ for $\mathrm{HO}$ : & & \\
\hline Variable & $\mathrm{DF}$ & Estimate & Error & Parameter $=0$ & Prob $>|\mathrm{T}|$ \\
\hline INTERCEP & 1 & 2,172408 & 0,43167557 & 5,033 & 0,0001 \\
\hline $\mathrm{X} 1$ & 1 & 0,108534 & 0,09983674 & 1,087 & 0,2795 \\
\hline $\mathrm{x} 2$ & 1 & 0,108383 & 0,06924429 & 1,565 & 0,1206 \\
\hline x3 & 1 & $-0,129814$ & 0,17674491 & $-0,734$ & 0,4643 \\
\hline X4 & 1 & 0,119237 & 0,08754627 & 1,362 & 0,1762 \\
\hline$\times 5$ & 1 & 0,262497 & 0,11916621 & 2,203 & 0,0299 \\
\hline x6 & 1 & $-0,017106$ & 0,11001377 & $-0,155$ & 0,8767 \\
\hline X7 & 1 & 0,118813 & 0,15617970 & 0,761 & 0,4486 \\
\hline x8 & 1 & 0,042007 & 0,04007378 & 1,048 & 0,2970 \\
\hline
\end{tabular}

Stepwise Procedure for Dependent Variable SAST

Step 1 Variable X5 Entered R-square $=0.38336422$

$C(p)=10.02601100$

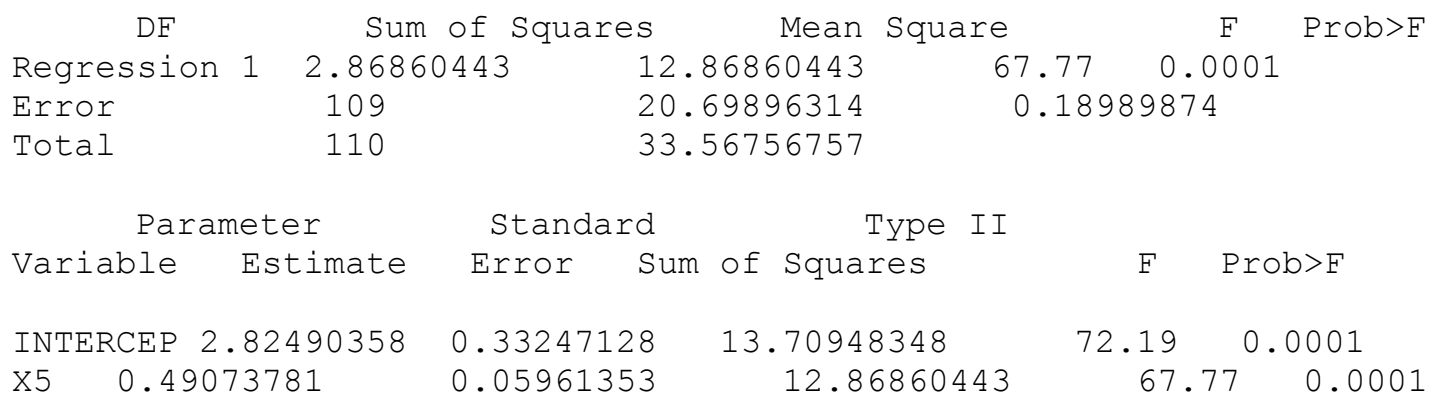




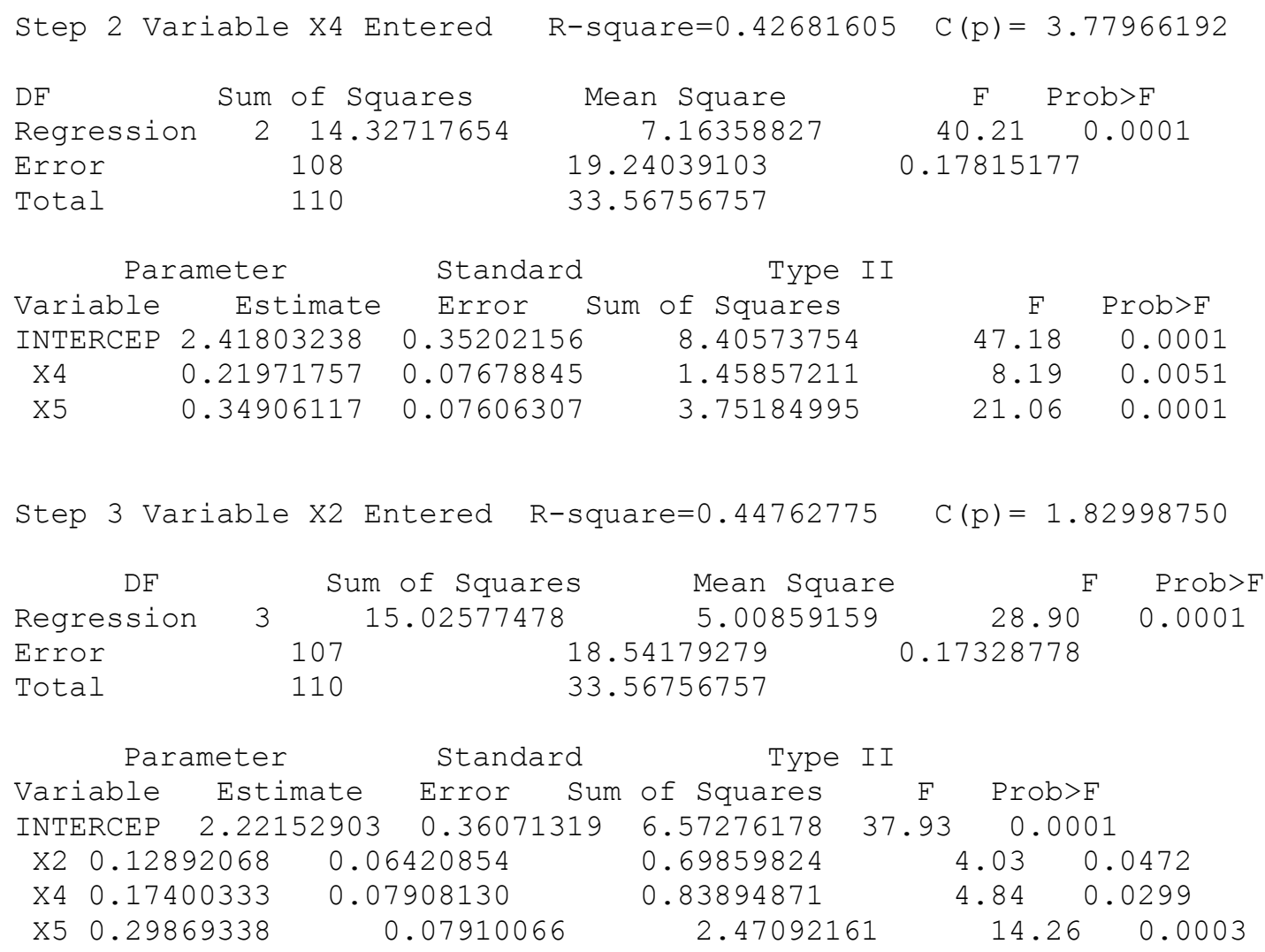

All variables left in the model are significant at the 0.1500 level. No other variable met the 0.1500 significance level for entry into the model.

\section{The SAS System}

\section{Summary of Stepwise Procedure for Dependent Variable SAST}

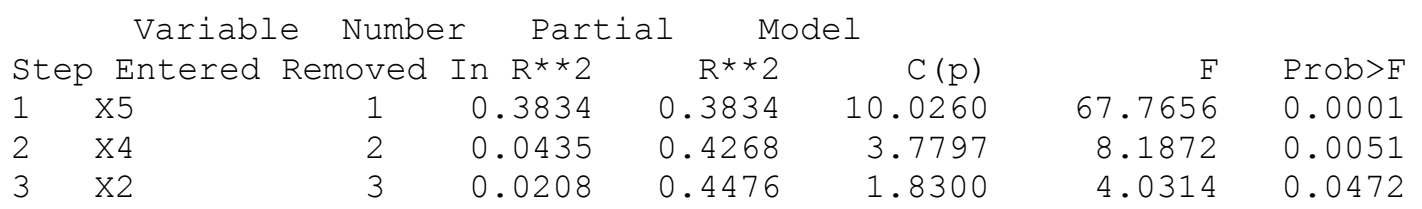

\section{Modelo final}

Dependent Variable: SAST

\section{Parameter Estimates}

\begin{tabular}{lccrrr}
\multicolumn{2}{c}{ Parameter } & Standard & T for H0: \\
Variable & DF & Estimate & Error & Parameter=0 & Prob > |T \\
INTERCEP & 1 & 1,316841 & 0,37236464 & 3,536 & 0,0005 \\
X2 & 1 & 0,212567 & 0,06826212 & 3,114 & 0,0022 \\
X4 & 1 & 0,182829 & 0,07511699 & 2,434 & 0,0162 \\
X5 & 1 & 0,361484 & 0,08783903 & 4,115 & 0,0001
\end{tabular}


Modelo de regressão linear multivariada

Tabela: Valores dos parâmetros estimados para o modelo de regressão linear multivariada

\begin{tabular}{llll}
\hline Construto & Parâmetro Estimado & Erro-padrão & $\mathrm{p}$ \\
\hline Intercepto & 2,172 & 0,432 & $<0,001$ \\
Atendimento & 0,109 & 0,100 & 0,280 \\
Equipe Médica & 0,108 & 0,069 & 0,121 \\
Equipe de Enfermagem & $-0,130$ & 0,177 & 0,464 \\
Equipe de Nutrição & 0,119 & 0,088 & 0,176 \\
Privacidade & 0,262 & 0,119 & 0,030 \\
Instalações & $-0,017$ & 0,110 & 0,877 \\
Resultados & 0,119 & 0,156 & 0,449 \\
Assistência social & 0,042 & 0,040 & 0,297 \\
\hline
\end{tabular}

Tabela: Valores dos parâmetros estimados para o modelo de regressão linear multivariada, após processo de seleção de variáveis

\begin{tabular}{llll}
\hline Construto & Parâmetro Estimado & Erro-padrão & $\mathrm{p}$ \\
\hline Intercepto & 1,317 & 0,372 & 0,001 \\
Equipe Médica & 0,213 & 0,068 & 0,002 \\
Equipe de Nutrição & 0,183 & 0,075 & 0,016 \\
Privacidade & 0,361 & 0,088 & 0,000
\end{tabular}

